\title{
Oxygen and ROS in Photosynthesis
}

\author{
Sergey Khorobrykh, Vesa Havurinne, Heta Mattila and Esa Tyystjärvi * \\ Department of Biochemistry/Molecular Plant Biology, University of Turku, FI-20014 Turku, Finland; \\ serkho@utu.fi or khorobrykh@rambler.ru (S.K.); vetahav@utu.fi (V.H.); hkmatt@utu.fi (H.M.) \\ * Correspondence: esatyy@utu.fi
}

Received: 27 November 2019; Accepted: 2 January 2020; Published: 10 January 2020

\begin{abstract}
Oxygen is a natural acceptor of electrons in the respiratory pathway of aerobic organisms and in many other biochemical reactions. Aerobic metabolism is always associated with the formation of reactive oxygen species (ROS). ROS may damage biomolecules but are also involved in regulatory functions of photosynthetic organisms. This review presents the main properties of ROS, the formation of ROS in the photosynthetic electron transport chain and in the stroma of chloroplasts, and ROS scavenging systems of thylakoid membrane and stroma. Effects of ROS on the photosynthetic apparatus and their roles in redox signaling are discussed.
\end{abstract}

Keywords: reactive oxygen species; chloroplasts; photosynthetic electron transport chain; photodamage; redox signaling

\section{Introduction}

Molecular oxygen $\left(\mathrm{O}_{2}\right)$ is a natural acceptor of electrons in the respiratory pathway of aerobic organisms and in many other biochemical reactions. In its ground state, $\mathrm{O}_{2}$ has two unpaired electrons with parallel spins in two separate $\pi$ antibonding orbitals. Thus, ground-state $\mathrm{O}_{2}$ is a triplet diradical. According to Pauli's principle, $\mathrm{O}_{2}$ reacts slowly with many biomolecules because spin restriction causes a kinetic barrier, as almost all biomolecules are in the singlet state, having paired electrons with opposite spins. The kinetic barrier of $\mathrm{O}_{2}$ is removed either by spin inversion of one unpaired electron or by a partial reduction in $\mathrm{O}_{2}$. Spin inversion requires the absorption of energy and converts the triplet state of $\mathrm{O}_{2}$ to the singlet state of molecular oxygen $\left({ }^{1} \mathrm{O}_{2}\right)$. All other forms of active oxygen are produced via an electron transfer mechanism. ${ }^{1} \mathrm{O}_{2}$ and partially reduced forms of oxygen have a higher reactivity towards many organic molecules than the ground state of oxygen and they are collectively called reactive oxygen species (ROS).

ROS can be classified as radical and non-radical species. In addition, ROS can be roughly divided into free ROS, small molecules composed of oxygen and hydrogen only, and incorporated ROS, in which oxygen is bound to other molecules to form reactive oxygen derivatives. Furthermore, a family of reactive species containing nitrogen moieties associated with oxygen are classified as reactive nitrogen species, and reactive oxygen derivatives like lipid peroxyl radicals $\left(\mathrm{LOO}^{\bullet}\right)$ can be classified as both ROS and reactive lipid species. The free $\operatorname{ROS}$ are ${ }^{1} \mathrm{O}_{2}$, superoxide anion radical $\left(\mathrm{O}_{2}{ }^{\bullet-}\right)$, hydroperoxyl radical $\left(\mathrm{HO}_{2}{ }^{\bullet}\right)$, hydrogen peroxide $\left(\mathrm{H}_{2} \mathrm{O}_{2}\right)$, hydroxyl radical $\left(\mathrm{HO}^{\bullet}\right)$ and ozone $\left(\mathrm{O}_{3}\right)$. Other molecules containing active oxygen are ROS derivatives. Table 1 presents the most important reactive species containing active oxygen according to this classification. 
Table 1. Most significant reactive oxygen species (ROS) and ROS derivatives. $\mathrm{R}$ is a residual of an organic molecule.

\begin{tabular}{cc}
\hline Radicals & Non-Radicals \\
\hline \multicolumn{2}{c}{ Reactive oxygen species } \\
\hline $\begin{array}{c}\text { Superoxide anion radical, } \mathrm{O}_{2}{ }^{\bullet} \\
\text { Hydroperoxyl radical, } \mathrm{HO}_{2} \\
\text { Hydroxyl radical, } \mathrm{HO}^{\bullet}\end{array}$ & $\begin{array}{c}\text { Singlet oxygen, }{ }^{1} \mathrm{O}_{2} \\
\text { Hydrogen peroxide, } \mathrm{H}_{2} \mathrm{O}_{2} \\
\text { Ozone, } \mathrm{O}_{3}\end{array}$ \\
\hline ROS derivatives and reactive nitrogen species \\
\hline Peroxyl radical, $\mathrm{ROO}^{\bullet}$ & Organic peroxides, $\mathrm{ROOH}$ \\
Alkoxyl radical, $\mathrm{RO}^{\bullet}$ & Peroxynitrite ion, $\mathrm{ONOO}{ }^{-}$ \\
Nitric Oxide, $\mathrm{NO}^{\bullet}$ & Alkyl peroxynitrite, $\mathrm{ROONO}$ \\
Nitrogen dioxide, $\mathrm{NO}_{2}$ & \\
\hline
\end{tabular}

Chloroplasts convert light energy to energy for chemical bonds. Light absorption by the chlorophyll (Chl) molecules of Photosystems I and II (PSI and PSII) triggers a sequence of redox reactions along the thylakoid membrane. These reactions result in the oxidation of water, reduction of $\mathrm{NADP}^{+}$to $\mathrm{NADPH}$ and formation of a proton gradient across the thylakoid membrane. In chloroplasts, $\mathrm{O}_{2}$ appears due to light-dependent water-splitting catalyzed by PSII. The steady-state concentration of $\mathrm{O}_{2}$ inside intact chloroplasts in the light depends on the external concentration of $\mathrm{O}_{2}$. At low external $\mathrm{O}_{2}$ concentrations $(30 \mu \mathrm{M})$, the ratio of the internal to the external is about five, whereas at concentrations corresponding to those in air-saturated water $(\approx 258 \mu \mathrm{M})$, the $\mathrm{O}_{2}$ concentration of isolated chloroplasts is similar to that of the medium [1].

${ }^{1} \mathrm{O}_{2}$ is mainly formed via the interaction of $\mathrm{O}_{2}$ with the triplet excited state of chlorophyll $\left({ }^{3} \mathrm{Chl}\right)$. The reduction in $\mathrm{O}_{2}$ by reduced forms of electron carriers in the photosynthetic electron transfer chain (PETC) can produce $\mathrm{O}_{2}{ }^{\bullet-}$ and $\mathrm{H}_{2} \mathrm{O}_{2}$. The reaction of $\mathrm{O}_{2}$ with PETC is considered as the main source of ROS in chloroplasts, and light is essential for this ROS production. ROS can be interconverted by interaction with redox active compounds of the chloroplast, and $\mathrm{ROS}$ are produced both via $\mathrm{O}_{2}{ }^{-}$ mediated primary ROS generation mechanisms and ROS-mediated interconversion reactions.

ROS are unfavorable for chloroplast functions because ROS cause oxidative damage by reacting with biomolecules. Chloroplasts have ROS scavenging systems to prevent damage [2-5]. In addition to ROS-scavenging systems, chloroplasts have pathways, like non-photochemical quenching of excitation energy (NPQ), cyclic electron flow and plastid terminal oxidase (PTOX)-mediated chlororespiration, that diminish the appearance of long-lived redox active compounds [6-8]. All aerobic organisms have ROS-scavenging mechanisms to prevent ROS damage. Environmental stressors (high light, high or low temperature and others) enhance ROS production in chloroplasts and change the balance between ROS scavenging and ROS production. Imbalances between ROS production and scavenging cause changes in the redox state of the cell through a change in the levels of reduced and oxidized forms of antioxidants like ascorbate $\left(\mathrm{AscH}_{2}\right)$, glutathione and thiol-containing compounds. Changes in the redox levels of the antioxidants trigger reactions where antioxidants act as ROS processing and signaling mediators that cause changes in gene expression $[9,10]$. In particular, the formation of ROS in Mehler's reaction initiates light-signaling that depends on $\mathrm{AscH}_{2}$ and reduced glutathione (GSH) [11].

ROS production quenches excitation energy photochemically via the so-called water-water cycle that consists of the production of $\mathrm{O}_{2}$ in PSII, reduction in $\mathrm{O}_{2}$ to $\mathrm{O}_{2}{ }^{\bullet-}$ and $\mathrm{H}_{2} \mathrm{O}_{2}$, scavenging of ROS, and regeneration of the scavenger [12]. The primary function of the water-water cycle is to scavenge ROS. Besides ROS scavenging and the photochemical quenching of excitation energy, the water-water cycle generates a proton gradient across the thylakoid membrane for both ATP production and the enhancement of NPQ [13].

Aerobic metabolism inevitably leads to the formation of ROS, and chloroplasts have to spend metabolic energy to build and maintain the ROS metabolism. The chloroplast provides light sensor functions for the whole plant cell, and the chloroplast ROS network participate in this signaling. 
In the present review, we will mainly discuss the roles of ${ }^{1} \mathrm{O}_{2}, \mathrm{O}_{2}{ }^{\bullet-}, \mathrm{HO}_{2}{ }^{\bullet}, \mathrm{H}_{2} \mathrm{O}_{2}, \mathrm{HO}$ and lipid peroxides in chloroplast metabolism. $\mathrm{O}_{3}$, although it is biologically important, is only shortly discussed because this ROS is not found within cells. The review presents the main properties of ROS and their typical reactions, the formation of ROS in the photosynthetic electron transport chain and in the stroma of chloroplasts, and the ROS-scavenging systems of thylakoid membrane and stroma.

\section{ROS Properties and Basic Reactions}

\subsection{Singlet Oxygen, ${ }^{1} \mathrm{O}_{2}$}

Ground-state $\mathrm{O}_{2}$ is a triplet $\left({ }^{3} \Sigma^{+}{ }_{\mathrm{g}} \mathrm{O}_{2}\right)$ and can be converted to the singlet form via the absorption of energy that leads to spin inversion of one unpaired electron. Molecular oxygen has two singlet forms because two electrons with antiparallel spins may reside either in two different orbitals $\left({ }^{1} \Sigma^{+}{ }_{\mathrm{g}} \mathrm{O}_{2}\right)$ or both in one orbital $\left({ }^{1} \Delta \mathrm{gO}_{2}\right)$. The energy above the ground-state of $\mathrm{O}_{2}$ is 155 and $92 \mathrm{~kJ} / \mathrm{mol}$ for ${ }^{1} \Sigma^{+} \mathrm{gO}_{2}$ and ${ }^{1} \Delta \mathrm{gO}_{2}$, respectively [14]. ${ }^{1} \Sigma^{+}{ }_{\mathrm{gO}} \mathrm{O}_{2}$ is rapidly converted to ${ }^{1} \Delta \mathrm{gO}_{2}$ or ${ }^{3} \Sigma^{+} \mathrm{gO}_{2}$ and, in the liquid phase, the lifetime of ${ }^{1} \Sigma^{+}{ }_{\mathrm{g}} \mathrm{O}_{2}$ is only $10^{-11} \mathrm{~s}$ [14], which is too short for ${ }^{1} \Sigma^{+}{ }_{\mathrm{g}} \mathrm{O}_{2}$ to take part in biochemical reactions. Therefore, ${ }^{1} \mathrm{O}_{2}$ will be used here to designate ${ }^{1} \Delta \mathrm{gO}_{2}$. $\mathrm{O}_{2}$ will be used to designate ${ }^{3} \Sigma^{+}{ }_{\mathrm{g}} \mathrm{O}_{2}$.

\subsubsection{Formation of ${ }^{1} \mathrm{O}_{2}$}

The most common mechanism of ${ }^{1} \mathrm{O}_{2}$ generation is photosensitization, i.e., the reaction of $\mathrm{O}_{2}$ with a photoexcited sensitizer dye (S*). Both forms of ${ }^{1} \mathrm{O}_{2},{ }^{1} \Sigma^{+}{ }_{\mathrm{gO}} \mathrm{O}_{2}$ and ${ }^{1} \Delta \mathrm{gO}_{2}$, can be produced via the spin-conserved Reactions (1) and (2).

$$
\begin{gathered}
{ }^{1} \mathrm{~S}^{*}+\mathrm{O}_{2} \rightarrow{ }^{3} \mathrm{~S}+{ }^{1} \mathrm{O}_{2} \\
{ }^{3} \mathrm{~S}+\mathrm{O}_{2} \rightarrow{ }^{1} \mathrm{~S}+{ }^{1} \mathrm{O}_{2}
\end{gathered}
$$

The second reaction is more common because singlet excited states $\left({ }^{1} \mathrm{~S}^{*}\right)$ are usually short-lived and because only a few dye molecules have a large enough energy gap between the ${ }^{1} \mathrm{~S}^{*}$ and triplet states $\left({ }^{3} \mathrm{~S}\right)$ to convert $\mathrm{O}_{2}$ to ${ }^{1} \mathrm{O}_{2}$ [15]. ${ }^{3} \mathrm{Chl}$ reacts rapidly with $\mathrm{O}_{2}$ with a second-order rate constant close to $10^{9} \mathrm{M}^{-1} \mathrm{~s}^{-1}$, and the relative quantum yield of ${ }^{1} \mathrm{O}_{2}$ generation by chlorophyll $a(\mathrm{Chl} a)$ was around $80 \%$ when meso-tetraphenylporphyrin and tetra( $p$-sulfophenyl) porphyrin were used as standards [16]. The spin transition $\mathrm{O}_{2} \rightarrow{ }^{1} \Sigma^{+}{ }_{\mathrm{g}} \mathrm{O}_{2}$ is associated with the absorption band of gaseous $\mathrm{O}_{2}$ at $762 \mathrm{~nm}$. Absorption at $1268 \mathrm{~nm}$, in turn, was found for the transition $\mathrm{O}_{2} \rightarrow{ }^{1} \Delta \mathrm{gO}_{2}$ in liquids and in the atmosphere [17].

In addition to photosensitized generation, ${ }^{1} \mathrm{O}_{2}$ can be produced by several chemical reactions that usually involve reduced forms of oxygen like $\mathrm{H}_{2} \mathrm{O}_{2}, \mathrm{O}_{2}{ }^{\bullet-}$ and reactive oxygen derivatives like organic peroxides $(\mathrm{ROOH})$ and peroxyl radicals $\left(\mathrm{ROO}^{\bullet}\right)[14,18]$.

${ }^{1} \mathrm{O}_{2}$ is produced by decomposition of $\mathrm{H}_{2} \mathrm{O}_{2}$ via the Haber-Weiss mechanism (Reactions (3) and (4)) $[19,20]$.

$$
\begin{aligned}
& \mathrm{H}_{2} \mathrm{O}_{2}+\mathrm{O}_{2}{ }^{--} \rightarrow \mathrm{HO}^{\bullet}+\mathrm{HO}^{-}+\left(\mathrm{O}_{2} \text { or }{ }^{1} \mathrm{O}_{2}\right) \\
& \mathrm{H}_{2} \mathrm{O}_{2}+\mathrm{HO}_{2}{ }^{\bullet} \rightarrow \mathrm{HO}+\mathrm{H}_{2} \mathrm{O}+\left(\mathrm{O}_{2} \text { or }{ }^{1} \mathrm{O}_{2}\right)
\end{aligned}
$$

The rate constants of Reactions (3) and (4) in aqueous medium are 0.13 to $0.23 \mathrm{M}^{-1} \mathrm{~s}^{-1}$ and $0.5 \mathrm{M}^{-1} \mathrm{~s}^{-1}$, respectively [21-23]. It has been suggested that the biologically important oxidant produced by Reaction (3) is $\mathrm{HO}^{\bullet}$ rather than ${ }^{1} \mathrm{O}_{2}$ [24]. ${ }^{1} \mathrm{O}_{2}$ can also be produced by $\mathrm{O}_{2}{ }^{\bullet-}$ dismutation (Reaction (5)) or by electron transfer from $\mathrm{O}_{2}{ }^{\bullet-}$ to radical (A $\mathrm{A}^{\bullet}$ ) or non-radical (A) electron acceptors (Reactions (6) and (7)) [25-27].

$$
\begin{gathered}
\mathrm{O}_{2}^{\bullet-}+\mathrm{O}_{2}^{\bullet-}+2 \mathrm{H}^{+} \rightarrow \mathrm{H}_{2} \mathrm{O}_{2}+\left(\mathrm{O}_{2} \text { or }{ }^{1} \mathrm{O}_{2}\right) \\
\mathrm{O}_{2}^{\bullet-}+\mathrm{A}^{+} \rightarrow\left(\mathrm{O}_{2} \text { or }{ }^{1} \mathrm{O}_{2}\right)+\mathrm{A}^{\bullet} \text { or } \mathrm{O}_{2}^{\bullet-}+\mathrm{A}^{\bullet+} \rightarrow\left(\mathrm{O}_{2} \text { or }{ }^{1} \mathrm{O}_{2}\right)+\mathrm{A}
\end{gathered}
$$




$$
\mathrm{O}_{2}^{\bullet-}+\mathrm{HO}^{\bullet} \rightarrow \mathrm{HO}^{-}+{ }^{1} \mathrm{O}_{2}
$$

Efficient production of ${ }^{1} \mathrm{O}_{2}$ was found in a reaction of $\mathrm{O}_{2}{ }^{\bullet-}$ with benzoyl peroxide or lauroyl peroxide (Reaction (8)) [28].

$$
2 \mathrm{O}_{2}^{\bullet-}+\mathrm{RCOOCR} \rightarrow 2 \mathrm{RCO}_{2}^{-}+2^{1} \mathrm{O}_{2}
$$

${ }^{1} \mathrm{O}_{2}$ can be generated via the Russel mechanism (Reaction (9)), in which two ROO ${ }^{\bullet}$ radicals react to form a linear tetraoxide (ROOOOR) intermediate that rapidly decomposes to the corresponding ketone $(\mathrm{R}=\mathrm{O})$, alcohol $(\mathrm{R}-\mathrm{OH})$ and ${ }^{1} \mathrm{O}_{2}$ [29]. In fact, ROOOOR decomposition releases either ${ }^{1} \mathrm{O}_{2}$ or excited triplet carbonyl $\left(\mathrm{R}={ }^{3} \mathrm{O}^{*}\right)$. However, the relative yield of ${ }^{1} \mathrm{O}_{2}$ is $10 \%$, while the relative yield of $\mathrm{R}={ }^{3} \mathrm{O}^{*}$ is only $0.01 \%$ [30-32].

$$
\mathrm{ROO}^{\bullet}+\mathrm{ROO}^{\bullet} \Delta \mathrm{ROOOOR} \rightarrow \mathrm{R}-\mathrm{OH}+\mathrm{R}=\mathrm{O}+{ }^{1} \mathrm{O}_{2}
$$

${ }^{1} \mathrm{O}_{2}$ can be produced in the reaction of $\mathrm{O}_{2}$ with an $\mathrm{R}={ }^{3} \mathrm{O}^{*}$ (Reaction (10)), which can be formed by the decomposition of ROOOOR (Reaction (9)) [33].

$$
\mathrm{R}={ }^{3} \mathrm{O}^{*}+\mathrm{O}_{2} \rightarrow \mathrm{R}=\mathrm{O}+{ }^{1} \mathrm{O}_{2}
$$

Other specific ions, like the hypohalite ion $\mathrm{OCl}^{-}$and the molybdate ion $\mathrm{MoO}_{4}{ }^{2-}$, can react with $\mathrm{H}_{2} \mathrm{O}_{2}$, forming ${ }^{1} \mathrm{O}_{2}$ (Reactions (11)-(13)) [34-36]; these reactions are probably not of biological importance.

$$
\begin{gathered}
\mathrm{H}_{2} \mathrm{O}_{2}+\mathrm{H}^{+}+\mathrm{OCl}^{-} \rightarrow \mathrm{H}_{2} \mathrm{O}+\mathrm{HCl}+{ }^{1} \mathrm{O}_{2} \\
\mathrm{MoO}_{4}{ }^{2-}+\mathrm{H}_{2} \mathrm{O}_{2} \Delta \mathrm{MoO}_{6}{ }^{2-}+2 \mathrm{H}_{2} \mathrm{O} \\
\mathrm{MoO}_{6}{ }^{2-} \rightarrow \mathrm{MoO}_{4}{ }^{2-}+{ }^{1} \mathrm{O}_{2}
\end{gathered}
$$

\subsubsection{Physical Deactivation of ${ }^{1} \mathrm{O}_{2}$}

Both excited singlet states of oxygen are metastable and can lose excitation energy via radiative and non-radiative pathways. The latter is physical quenching of ${ }^{1} \mathrm{O}_{2}$. The radiative deactivation is the transition of ${ }^{1} \Delta \mathrm{gO}_{2}$ to $\mathrm{O}_{2}$ associated with light emission (hv; Reaction (14)).

$$
{ }^{1} \mathrm{O}_{2} \rightarrow \mathrm{O}_{2}+h v
$$

The phosphorescence spectrum has a major maximum at $1268 \mathrm{~nm}$ [37]. The phosphorescence is extremely weak, as the deactivation of ${ }^{1} \mathrm{O}_{2}$ mostly proceeds non-radiatively due to the collision of ${ }^{1} \mathrm{O}_{2}$ with another molecule. The quantum yield of luminescence is from $10^{-6}$ to $10^{-3}$ [32]. Non-radiative deactivation mechanisms include electronical-to-vibrational energy transfer, charge-transfer-induced quenching and electronic energy transfer. In the deactivation of ${ }^{1} \Sigma^{+} \mathrm{gO}_{2}$ and ${ }^{1} \Delta \mathrm{gO}_{2}$ by an electronic-to-vibrational process, the excitation energy of ${ }^{1} \mathrm{O}_{2}$ is converted into vibration of the $\mathrm{O}_{2}$ molecule and a quencher molecule Qr (Reaction (15)).

$$
{ }^{1} \mathrm{O}_{2}(v=0)+\mathrm{Qr}(v=0) \rightarrow \mathrm{O}_{2}(v=\mathrm{m})+\mathrm{Qr}(v=\mathrm{n})+\mathrm{E}_{\mathrm{mn}}
$$

where $\mathrm{E}_{\mathrm{mn}}$ is the energy difference between the reactants and the products and $v$ is the vibrational energy level of a molecule; $\mathrm{m}$ and $\mathrm{n}$ are vibrational modes.

The deactivation of ${ }^{1} \mathrm{O}_{2}$ by collisions of ${ }^{1} \mathrm{O}_{2}$ with other molecules limits the lifetime of ${ }^{1} \mathrm{O}_{2}$ in many solvents. The lifetime of ${ }^{1} \mathrm{O}_{2}$ for many organic solvents is within 8-100 $\mu$ s. The substitution of hydrogen with deuterium in the solvent molecule leads to a significant increase in the lifetime of ${ }^{1} \mathrm{O}_{2}$, usually by a factor of ten or more [17,38-40]. The second order rate constant for the deactivation of ${ }^{1} \mathrm{O}_{2}$ via an electronic-to-vibrational process varies widely, from $10^{-2}$ to $10^{6} \mathrm{M}^{-1} \mathrm{~s}^{-1}$ [17]. 
In addition to the electronic-vibrational non-radiative deactivation, ${ }^{1} \mathrm{O}_{2}$ can be deactivated via charge-transfer-induced quenching (Reaction (16)) and an electronic energy transfer mechanism (Reaction (17)).

$$
\begin{gathered}
{ }^{1} \mathrm{O}_{2}+{ }^{1} \mathrm{~A} \Delta{ }^{1}\left(\mathrm{O}_{2} \mathrm{~A}\right) \Delta \Delta^{3}\left(\mathrm{O}_{2} \mathrm{~A}\right) \rightarrow \mathrm{O}_{2}+{ }^{1} \mathrm{~A} \\
{ }^{1} \mathrm{O}_{2}+\mathrm{A} \rightarrow{ }^{3}\left(\mathrm{O}_{2} \mathrm{~A}\right) \rightarrow \mathrm{O}_{2}+{ }^{3} \mathrm{~A},
\end{gathered}
$$

where $\mathrm{A}$ is an acceptor.

Molecules with high triplet energies (more than $94 \mathrm{~kJ} \mathrm{~mol}^{-1}$ ) and low oxidation potential (midpoint redox potential $\left(E_{m}\right)$ around $1.9 \mathrm{~V}$ vs. Normal Hydrogen Electrode (NHE)) can deactivate ${ }^{1} \mathrm{O}_{2}$ with the charge-transfer mechanism. Second-order rate constants for deactivation of ${ }^{1} \mathrm{O}_{2}$ via the charge-transfer mechanism are within $10^{3}$ to $10^{9} \mathrm{M}^{-1} \mathrm{~s}^{-1}$ [17]. In the charge-transfer mechanism, the ${ }^{1}\left(\mathrm{O}_{2} \mathrm{~A}\right)$ complex finally dissociates to $\mathrm{A}$ and $\mathrm{O}_{2}$ without charge separation. Electronic energy-transfer quenching of ${ }^{1} \mathrm{O}_{2}$ occurs via the interaction of molecules with a lower triplet state energy than the energy of ${ }^{1} \mathrm{O}_{2}$. The deactivation of ${ }^{1} \mathrm{O}_{2}$ via the electronic energy-transfer mechanism is very efficient and its second-order rate constant is close to the diffusion-controlled limit. Carotenoids including $\beta$-carotene and lutein are the most efficient quenchers of ${ }^{1} \mathrm{O}_{2}$, and the second order rate constant for many carotenoids is about $10^{10} \mathrm{M}^{-1} \mathrm{~s}^{-1}[17,41]$.

\subsubsection{Chemical Reactions of ${ }^{1} \mathrm{O}_{2}$}

The term "chemical deactivation" of ${ }^{1} \mathrm{O}_{2}$ can be applied to reactions in which the products have less reactivity and toxicity towards cell metabolism than ${ }^{1} \mathrm{O}_{2}$. The redox potential relative to NHE for the pair ${ }^{1} \mathrm{O}_{2} / \mathrm{O}_{2}{ }^{\bullet-}$ is $0.65 \mathrm{~V}$ [42]. ${ }^{1} \mathrm{O}_{2}$ is an electrophilic agent and reacts with electron-rich organic molecules via three well-known mechanisms.

The ene reaction (Alder-ene reaction) is associated with the formation of a hydroperoxide (Reaction (18)).

$$
{ }^{1} \mathrm{O}_{2}+\mathrm{H}_{3} \mathrm{C}-\underset{\mathrm{H}}{\mathrm{C}}=\underset{\mathrm{H}}{\mathrm{C}}-\mathrm{CH}_{3} \longrightarrow-\underset{\mathrm{H}}{\mathrm{C}}-\underset{\mathrm{H}}{\mathrm{C}}=\mathrm{CH}_{2}
$$

Cycloaddition is associated with dioxetane formation (Reaction (19)).<smiles>CC(C)=C(C)C1(C)OOC1(C)C</smiles>

Cycloaddition is associated with aromatic compounds and formation of an endoperoxide via the Diels-Alder mechanism (Reaction (20)).<smiles>O=[N+]([O-])OC1C=CC2CCC1OO2</smiles>

${ }^{1} \mathrm{O}_{2}$ can react with the unsaturated fatty acids of membrane lipids to form both conjugated and non-conjugated diene hydroperoxides (Reaction (21)) with a second order rate constant of about $10^{4} \mathrm{M}^{-1} \mathrm{~s}^{-1}[4,43]$. 


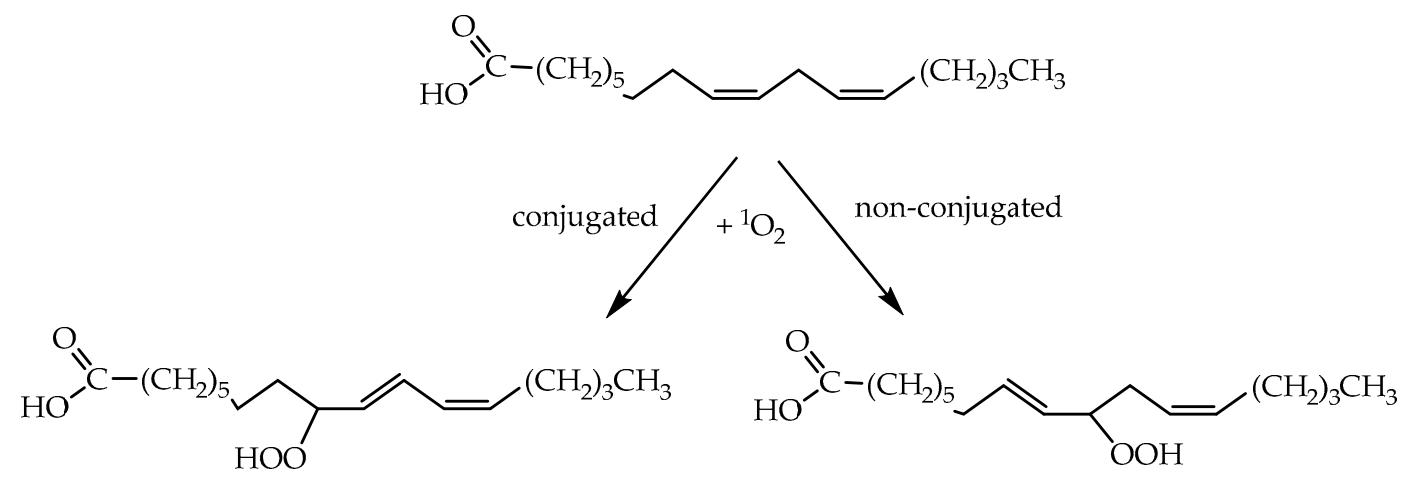

${ }^{1} \mathrm{O}_{2}$ can react with amino acids that have double bonds or an electron-rich sulfur atom, such as tryptophan, histidine, tyrosine, methionine and cysteine, to form corresponding peroxides. The second-order rate constant for reaction of ${ }^{1} \mathrm{O}_{2}$ with those amino acids is around $10^{7} \mathrm{M}^{-1} \mathrm{~s}^{-1}$ [44]

${ }^{1} \mathrm{O}_{2}$ can efficiently oxidize amines to imines with the formation of $\mathrm{HO}_{2}{ }^{\bullet}$ (Reaction (22)) [45].<smiles>[OH2+]CNCCC=N[18OH]</smiles>

${ }^{1} \mathrm{O}_{2}$ can oxidize electron-rich compounds like phenols to benzoquinones by an electron transfer mechanism (Reaction (23)) [46].

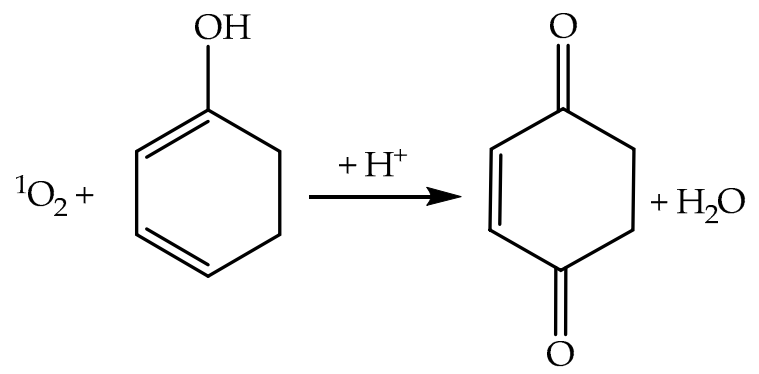

The oxidation of $\mathrm{AscH}_{2}$ (Reaction (24)) and plastoquinol $\left(\mathrm{PQH}_{2}\right)$ (Reaction (25)) by ${ }^{1} \mathrm{O}_{2}$ can proceed as a two-electron reduction of ${ }^{1} \mathrm{O}_{2}$ to $\mathrm{H}_{2} \mathrm{O}_{2}[47,48]$.

$$
\begin{gathered}
\mathrm{AscH}_{2}+{ }^{1} \mathrm{O}_{2} \rightarrow \mathrm{DHA}+\mathrm{H}_{2} \mathrm{O}_{2} \\
\mathrm{PQH}_{2}+{ }^{1} \mathrm{O}_{2} \rightarrow \mathrm{PQ}+\mathrm{H}_{2} \mathrm{O}_{2}
\end{gathered}
$$

where DHA and PQ are dehydroascorbate and plastoquinone, respectively.

The second-order rate constant for the reaction of ${ }^{1} \mathrm{O}_{2}$ with $\mathrm{AscH}_{2}$ depends on $\mathrm{pH}$ and varies from $10^{5} \mathrm{M}^{-1} \mathrm{~s}^{-1}$ to $10^{8} \mathrm{M}^{-1} \mathrm{~s}^{-1}$ [49]. Prenyllipids like $\mathrm{PQH}_{2}-9$ and $\alpha$-tocopherol react with ${ }^{1} \mathrm{O}_{2}$ with second-order rate constants of about $10^{8} \mathrm{M}^{-1} \mathrm{~s}^{-1}$ [50].

\subsubsection{Lifetime and Diffusion Distance of ${ }^{1} \mathrm{O}_{2}$}

Solvents and other deactivating compounds play significant roles in controlling the lifetime of ${ }^{1} \mathrm{O}_{2}$ and the lifetime, in turn, determines both the diffusion distance and the ability of ${ }^{1} \mathrm{O}_{2}$ to react with other substances. The lifetimes of ${ }^{1} \mathrm{O}_{2}$ in a pure lipid membrane and in the thylakoid membrane have been estimated to be $7 \mu$ s and $70 \mathrm{~ns}$, respectively [51]. Thus, the respective diffusion distances, approximated using the diffusion coefficient of $\mathrm{O}_{2}$, are 220 and $5.5 \mathrm{~nm}$. The very short lifetime in the thylakoid membrane may be caused by a high concentration of compounds deactivating ${ }^{1} \mathrm{O}_{2}$. In a 
nerve cell, the lifetime of ${ }^{1} \mathrm{O}_{2}$ is about $200 \mathrm{~ns}$, which leads to a diffusion distance of about $270 \mathrm{~nm}$ [52]. The lifetimes and diffusion distances of ${ }^{1} \mathrm{O}_{2}$ in different tissues have been recently reviewed [23].

\subsection{Superoxide Anion Radical, $\mathrm{O}_{2}^{\bullet-}$}

The $\mathrm{O}_{2}{ }^{\bullet-}$ is the one-electron reduced form of molecular oxygen. Detailed analyses of the properties and biological roles of $\mathrm{O}_{2}{ }^{\bullet-}$ are available in several comprehensive reviews [53-56]. $\mathrm{O}_{2}{ }^{\bullet-}$ is a deprotonation agent and can be protonated to $\mathrm{HO}_{2}{ }^{\bullet}$ (Reaction (26)).

$$
\mathrm{O}_{2}^{\bullet-}+\mathrm{H}^{+} \rightarrow \mathrm{HO}_{2}
$$

The deprotonation ability of $\mathrm{O}_{2}{ }^{\bullet-}$ depends strongly on the solvent. In aqueous solutions, $\mathrm{O}_{2}{ }^{\bullet-}$ is a weak deprotonation agent with pKa of 4.8 due to strong solvation of $\mathrm{O}_{2}{ }^{\bullet-}$. The free energy of hydration for $\mathrm{O}_{2}{ }^{\bullet-}$ was estimated to be around $355 \mathrm{~kJ} \mathrm{~mol}^{-1}$ [57]. Therefore, only $0.25 \%$ of $\mathrm{O}_{2}{ }^{\bullet-}$ is protonated at physiological $\mathrm{pH}$ values. In non-aqueous solutions like organic solvents, $\mathrm{O}_{2}{ }^{\bullet-}$ is a strong deprotonation agent. For example, in dimethylformamide (DMF), the pKa value of $\mathrm{HO}_{2} \bullet$ is around 12 [54]. However, in reality the protonation of $\mathrm{O}_{2}{ }^{\bullet-}$ in the presence of a protonated compound $\mathrm{AH}$ can accompany the reduction of $\mathrm{HO}_{2}{ }^{\bullet}$ to hydroperoxyl anion $\left(\mathrm{HO}_{2}{ }^{-}\right)$and occur via a two-step mechanism (Reactions (27) and (28)), which makes $\mathrm{O}_{2}{ }^{\bullet-}$ a much stronger deprotonation agent than would follow from its basicity.

$$
\begin{gathered}
\mathrm{O}_{2}^{\bullet-}+\mathrm{AH} \Delta \mathrm{HO}_{2}^{\bullet}+\mathrm{A}^{-} \\
\mathrm{O}_{2}^{\bullet-}+\mathrm{HO}_{2}^{\bullet} \rightarrow \mathrm{O}_{2}+\mathrm{HO}_{2}^{-}
\end{gathered}
$$

which sum up to

$$
2 \mathrm{O}_{2}^{\bullet-}+\mathrm{AH} \Delta \mathrm{O}_{2}+\mathrm{HO}_{2}^{-}+\mathrm{A}^{-} .
$$

The equilibrium constant of Reaction (29) is about $10^{9}$ [54]. Therefore, in the deprotonation process the pKa value of $\mathrm{O}_{2}{ }^{--}$should be considered equivalent to a base with pKa $24[53,54]$. The $E_{m}$ of the pair $\mathrm{O}_{2} / \mathrm{O}_{2}{ }^{\bullet-}$ is $\mathrm{pH}$-dependent, due to protonation of $\mathrm{O}_{2}{ }^{\bullet-}$ and formation of $\mathrm{HO}_{2}{ }^{\bullet}$. In an aqueous solution at $\mathrm{pH}$, the $E_{m}$ of the pair $\mathrm{O}_{2} / \mathrm{O}_{2}{ }^{\bullet-}$ is $-160--180 \mathrm{mV}$ vs. NHE, and the $E_{m}$ value becomes more positive under a low $\mathrm{pH}$, around $100 \mathrm{mV}[12,58]$. In aprotic media offering only a weak solvation of $\mathrm{O}_{2}{ }^{\bullet-}, \mathrm{O}_{2}{ }^{\bullet-}$ acts as a strong reductant and the redox potential of the pair $\mathrm{O}_{2} / \mathrm{O}_{2}{ }^{\bullet-}$ is estimated to range between -550 and $-600 \mathrm{mV}$ vs. NHE [54] in DMF and around $-640 \mathrm{mV}$ in acetonitrile $[59,60]$.

\subsubsection{Formation of $\mathrm{O}_{2}{ }^{\bullet-}$}

$\mathrm{O}_{2}{ }^{\bullet-}$ is mainly formed via the interaction of $\mathrm{O}_{2}$ with reduced compounds having a low redox potential (A) (Reaction (30)).

$$
\mathrm{A}^{-}+\mathrm{O}_{2} \Delta \mathrm{A}+\mathrm{O}_{2}^{\bullet-}
$$

$\mathrm{O}_{2}{ }^{\bullet-}$ can be formed in a potentially important equilibrium reaction with semiquinone anion radicals $\left(\mathrm{Q}^{\bullet-}\right)$ with the formation of the respective quinone $\mathrm{Q}$ (Reaction (31)).

$$
\mathrm{Q}^{\bullet-}+\mathrm{O}_{2} \Delta \mathrm{Q}+\mathrm{O}_{2}^{\bullet-}
$$

The equilibrium constant of Reaction (31) can be determined from the redox potentials of $\mathrm{Q} / \mathrm{Q}^{\bullet-}$ and $\mathrm{O}_{2} / \mathrm{O}_{2}{ }^{--}$. In aqueous solutions at $\mathrm{pH}$ 7, the equilibrium constant for Reaction (31) is estimated as $2 \times 10^{-5}$ for benzosemiquinone with a redox potential around $100 \mathrm{mV}$, and 26 for durosemiquinone with redox potential around $-260 \mathrm{mV}$ [61]. The formation of $\mathrm{O}_{2}{ }^{\bullet-}$ via Reaction (31) is favorable for $\mathrm{Q}^{\bullet-}$, with the redox potential of the $\mathrm{Q} / \mathrm{Q}^{\bullet-}$ pair lower than $160--180 \mathrm{mV}$ because, with this redox potential, the forward rate constant $\left(k_{\text {forward }}\right)$ of Reaction (31) is larger than the reverse rate constant $\left(k_{\text {reverse }}\right)$. Reaction (31) when $\mathrm{Q}^{\bullet-}$ is benzosemiquinone proceeds with $k_{\text {forward }}$ of $5 \times 10^{5} \mathrm{M}^{-1} \mathrm{~s}^{-1}$ and with $k_{\text {reverse }}$ of $10^{8} \mathrm{M}^{-1} \mathrm{~s}^{-1}$. For durosemiquinone, $k_{\text {forward }}$ and $k_{\text {reverse }}$ were estimated to be $2.2 \times 10^{8} \mathrm{M}^{-1} \mathrm{~s}^{-1}$ and 
$10^{7} \mathrm{M}^{-1} \mathrm{~s}^{-1}$, respectively [61]. However, if $\mathrm{O}_{2}^{\bullet-}$ is efficiently removed after Reaction (31), then the rate of formation depends only on $k_{\text {forward }}$.

\subsubsection{Reactions of $\mathrm{O}_{2}^{\bullet-}$}

Reactions of $\mathrm{O}_{2}{ }^{\bullet-}$ with organic and inorganic molecules can proceed in five ways: deprotonation reaction (protonation of $\mathrm{O}_{2}{ }^{\bullet-}$ by $\mathrm{H}^{+}$or the attraction of a proton from a proton donor), attraction of hydrogen, electron transfer reaction, nucleophilic substitution or addition, and addition to a metal or metal complex.

In electron transfer reactions, $\mathrm{O}_{2}{ }^{\bullet-}$ can act as both an oxidant and a reductant. In many cases, the electron transfer reaction involves a deprotonation reaction (deprotonation-oxidation mechanism). $\mathrm{O}_{2}{ }^{\bullet-}$ can reduce or oxidize organic and inorganic molecules like quinones and cytochromes (cyt) or transition metal ions in equilibrium reactions via a one-electron transfer mechanism, Reactions (31)-(33).

$$
\begin{gathered}
\mathrm{O}_{2}^{\bullet-}+\operatorname{cyt}\left(\mathrm{Fe}^{3+}\right) \Delta \mathrm{O}_{2}+\operatorname{cyt}\left(\mathrm{Fe}^{2+}\right) \\
\mathrm{O}_{2}^{\bullet-}+\mathrm{Fe}^{3+} \Delta \mathrm{O}_{2}+\mathrm{Fe}^{2+}
\end{gathered}
$$

In many cases, $\mathrm{O}_{2}{ }^{\bullet-}$ oxidizes organic and inorganic molecules by hydrogen attraction via the deprotonation-oxidation mechanism. Oxidation of $\mathrm{AscH}_{2}$ by $\mathrm{O}_{2}{ }^{\bullet-}$ in aqueous solution (Reaction (34)) proceeds as a two-step reaction (Reactions (35) and (36)) with a second-order rate constant of $3.3 \times 10^{5} \mathrm{M}^{-1} \mathrm{~s}^{-1}$ at $\mathrm{pH} 7.8$ [62-64].

$$
\begin{aligned}
& \mathrm{O}_{2}^{\bullet-}+\mathrm{AscH}_{2} \rightarrow \mathrm{H}_{2} \mathrm{O}_{2}+\mathrm{Asc}^{\bullet-} \\
& \mathrm{O}_{2}^{\bullet-}+\mathrm{AscH}_{2} \Delta \mathrm{HO}_{2}^{\bullet}+\mathrm{AscH}^{-} \\
& \mathrm{HO}_{2}^{\bullet}+\mathrm{AscH}^{-} \rightarrow \mathrm{H}_{2} \mathrm{O}_{2}+\mathrm{Asc}^{\bullet-}
\end{aligned}
$$

The same mechanism is suggested for oxidation by $\mathrm{O}_{2}{ }^{\bullet-}$ of thiols as in reduced GSH and lipophilic compounds as in $\alpha$-tocopherol, Reactions (37)-(40), respectively [64,65].

$$
\begin{gathered}
\mathrm{O}_{2}^{\bullet-}+\mathrm{GSH}^{\bullet}+\mathrm{HO}_{2}^{\bullet}+\mathrm{GS}^{-} \\
\mathrm{HO}_{2}^{\bullet}+\mathrm{GS}^{-} \Delta+\mathrm{HO}_{2}^{-}+\mathrm{GS}^{\bullet} \\
\mathrm{O}_{2}^{\bullet-}+\alpha \text {-Tocopherol-H } \Delta \mathrm{HO}_{2}^{\bullet}+\alpha \text {-Tocopherol } \\
\mathrm{HO}_{2}{ }^{-}+\alpha \text {-Tocopherol }
\end{gathered}
$$

In Reactions (37) and (38), $\mathrm{GS}^{-}$and GS ${ }^{\bullet}$ stand for deprotonated reduced glutathione and oxidized glutathione, respectively.

The second-order rate constant of the reaction of $\mathrm{O}_{2}{ }^{\bullet-}$ with $\alpha$-tocopherol incorporated into soybean or dimyristoyl phosphatidylcholine liposomal membranes was estimated to be $4.9 \times 10^{3} \mathrm{M}^{-1} \mathrm{~s}^{-1}$ [62] The second-order rate constant of the reaction of $\mathrm{O}_{2}{ }^{\bullet-}$ with GSH was estimated to be $10^{3} \mathrm{M}^{-1} \mathrm{~s}^{-1}[66,67]$.

The main mechanism of deactivation of $\mathrm{O}_{2}{ }^{\bullet-}$ is spontaneous or enzymatic dismutation (Reaction (5)). Non-enzymatic dismutation of $\mathrm{O}_{2}{ }^{\bullet-}$ usually proceeds in aqueous solution and very strongly depends on $\mathrm{pH}$ because the protonation of $\mathrm{O}_{2}{ }^{\bullet-}$ determines the rate. Dismutation can be considered as a two-step reaction: protonation of $\mathrm{O}_{2}{ }^{\bullet-}$, Reaction (41) and a radical-radical reaction between $\mathrm{O}_{2}^{\bullet-}$ and $\mathrm{HO}_{2}{ }^{\bullet}$ or between two molecules of $\mathrm{HO}_{2} \bullet$ - Reactions (42) and (43), respectively.

$$
\begin{gathered}
\mathrm{O}_{2}^{\bullet-}+\mathrm{H}^{+} \Delta \mathrm{HO}_{2}^{\bullet}, \mathrm{pKa}=4.8 \\
\mathrm{O}_{2}^{\bullet-}+\mathrm{HO}_{2}^{\bullet}+\mathrm{H}^{+} \rightarrow \mathrm{H}_{2} \mathrm{O}_{2}+\mathrm{O}_{2} \\
\mathrm{HO}_{2}^{\bullet}+\mathrm{HO}_{2}^{\bullet} \rightarrow \mathrm{H}_{2} \mathrm{O}_{2}+\mathrm{O}_{2}
\end{gathered}
$$


The second-order rate constant of the dismutation of $\mathrm{O}_{2}{ }^{\bullet-}$ has a maximum $\left(10^{8} \mathrm{M}^{-1} \mathrm{~s}^{-1}\right)$ at $\mathrm{pH} 4.8$, equal to the $\mathrm{pKa}$ value of $\mathrm{HO}_{2} \bullet$. The rate constant decreases with increasing $\mathrm{pH}$ and becomes very low, around $0.3 \mathrm{M}^{-1} \mathrm{~s}^{-1}$, at alkaline $\mathrm{pH}$. At physiological $\mathrm{pH}$, the rate constant is about $10^{5} \mathrm{M}^{-1} \mathrm{~s}^{-1}$ [68]. The enzymatic dismutation of $\mathrm{O}_{2}{ }^{\bullet-}$ is catalyzed by superoxide dismutase (SOD, EC 1.15.1.1). The SOD-catalyzed reaction proceeds as a sequence of oxidation and reduction of $\mathrm{O}_{2}{ }^{\bullet-}$ by a metal ion (M) of the SOD enzyme, Reactions (44) and (45).

$$
\begin{gathered}
\mathrm{M}^{(\mathrm{n}+1)+}-\mathrm{SOD}+\mathrm{O}_{2}^{\bullet-} \rightarrow \mathrm{M}^{\mathrm{n}+}-\mathrm{SOD}+\mathrm{O}_{2} \\
\mathrm{M}^{\mathrm{n}+}-\mathrm{SOD}+\mathrm{O}_{2}^{\bullet-}+2 \mathrm{H}^{+} \rightarrow \mathrm{M}^{(\mathrm{n}+1)+}-\mathrm{SOD}+\mathrm{H}_{2} \mathrm{O}_{2}
\end{gathered}
$$

The rate constant of $\mathrm{O}_{2}^{\bullet-}$ dismutation catalyzed by SOD is about $6.4 \times 10^{9} \mathrm{M}^{-1} \mathrm{~s}^{-1}$ [69].

$\mathrm{O}_{2}{ }^{\bullet-}$ is a powerful nucleophile in aprotic medium and can be involved in nucleophilic reactions with various organic compounds. $\mathrm{O}_{2}{ }^{\bullet-}$ reacts with alkyl halides (RX), acyl halides and acyl anhydrides to form $\mathrm{ROO}^{\bullet}$ intermediates through nucleophilic substitution reactions [54]. $\mathrm{O}_{2}{ }^{\bullet-}$ can add to positively charged carbon-carbon double bonds [70] and carbon-nitrogen double bonds [71]. For example, Reactions (46)-(48) illustrate the reaction of $\mathrm{O}_{2}{ }^{\bullet-}$ with $\mathrm{RX}$, acyl halide and anhydride, respectively. The peroxy and alkoxy radicals are more reactive than $\mathrm{O}_{2}^{\bullet-}$ itself.

$$
\mathrm{O}_{2}^{\bullet-}+\mathrm{RX} \rightarrow \mathrm{ROO}^{\bullet}+\mathrm{X}^{-}
$$
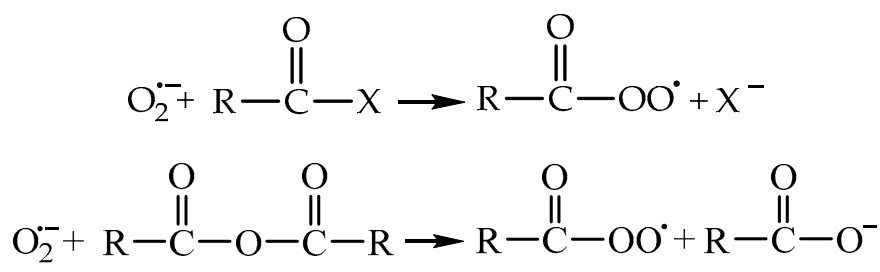

In addition to nucleophilic reactions with organic molecules, $\mathrm{O}_{2}{ }^{\bullet-}$ can bind to both transition metals and to metal complexes. For example, in PSII, the interaction of $\mathrm{O}_{2}{ }^{\bullet-}$ with a ferrous heme iron leads to the formation of a ferric-peroxo $\left(\left(\mathrm{Fe}^{3+}\right)-\mathrm{OO}^{-}\right)$complex which can be protonated to a ferric-hydroperoxo ((Fe $\left.\left.{ }^{3+}\right)-\mathrm{OOH}\right)$ complex, Reaction (49) and (50) [72].

$$
\begin{gathered}
\mathrm{O}_{2}^{\bullet-}+\mathrm{L}-\left(\mathrm{Fe}^{2+}\right) \rightarrow \mathrm{L}-\left(\mathrm{Fe}^{3+}\right)-\mathrm{OO}^{-}+\mathrm{H}^{+} \\
\mathrm{L}-\left(\mathrm{Fe}^{3+}\right)-\mathrm{OO}^{-}+\mathrm{H}^{+} \rightarrow \mathrm{L}-\left(\mathrm{Fe}^{3+}\right)-\mathrm{OOH}
\end{gathered}
$$

where $\mathrm{L}$ is a ligand.

\subsubsection{Lifetime and Diffusion Distance of $\mathrm{O}_{2}^{\bullet-}$}

The lifetime of $\mathrm{O}_{2}{ }^{\bullet-}$ is controlled by dismutation (Reaction (5)). Thus, in the absence of SOD, the lifetime of $\mathrm{O}_{2}{ }^{\bullet-}$ depends on $\mathrm{pH}$ in aqueous solutions and on the presence of a proton donor in aprotic media. $\mathrm{O}_{2}{ }^{\bullet-}$ is more stable in alkaline aqueous solutions $\left(t_{1 / 2}=50 \mathrm{~s}\right.$ at $\left.\mathrm{pH} 14\right)$, and the lifetime of $\mathrm{O}_{2}{ }^{\bullet-}$ decreases with decreasing $\mathrm{pH}\left(t_{1 / 2}=0.2 \mathrm{~s}\right.$ at $\left.\mathrm{pH} 10\right)$. The lifetime of $\mathrm{O}_{2}{ }^{\bullet-}$ prepared in a two-electrode cell in DMF was found to be $76 \mathrm{~min}$ at $0^{\circ} \mathrm{C}$ for $0.1 \mathrm{M} \mathrm{O}_{2}^{\bullet-}$, and around $35 \mathrm{~h}$ for the $\mathrm{O}_{2}^{\bullet-}$ concentrations from 0.001 to $0.01 \mathrm{M}$ [54]. In cells, the lifetime of $\mathrm{O}_{2}{ }^{\bullet-}$ is efficiently controlled by SOD, and the lifetime will depend on SOD activity. In the periplasm of Escherichia coli, the lifetime of $\mathrm{O}_{2}{ }^{--}$was estimated to be longer than $0.6 \mathrm{~s}$ using the rate of $\mathrm{O}_{2}{ }^{\bullet-}$ formation and the rate constant of its dismutation. The diffusion distance was calculated as $35 \mu \mathrm{m}$, assuming a general diffusion coefficient of small molecules of about $10^{5} \mathrm{~cm}^{2} \mathrm{~s}^{-1}[73]$. 


\subsection{Hydrogen Peroxide, $\mathrm{H}_{2} \mathrm{O}_{2}$}

$\mathrm{H}_{2} \mathrm{O}_{2}$ is the result of two-electron reduction of $\mathrm{O}_{2}$ and considered a major biological ROS. In cells, $\mathrm{H}_{2} \mathrm{O}_{2}$ is mostly present in the neutral form because its pKa is $11.8 . \mathrm{H}_{2} \mathrm{O}_{2}$ is a strong, two-electron oxidant with a standard redox potential $\left(E_{0}^{\prime}\right)$ of $1.32 \mathrm{~V}$ at $\mathrm{pH}$ 7.0. However, $\mathrm{H}_{2} \mathrm{O}_{2}$ reacts slowly or does not react with most biological molecules, including low-molecular-weight antioxidants, due to a high activation energy barrier [74]. Even if a reaction with $\mathrm{H}_{2} \mathrm{O}_{2}$ is thermodynamically favorable, it may be very slow.

Low-potential compounds reduce $\mathrm{H}_{2} \mathrm{O}_{2}$ with one electron, as the redox potential of $\mathrm{H}_{2} \mathrm{O}_{2} / \mathrm{HO}^{\bullet}$ is $0.3 \mathrm{~V}$ [12]. $\mathrm{H}_{2} \mathrm{O}_{2}$ can also act as an electrophile due to the polarizability of the $\mathrm{O}-\mathrm{O}$ bond. $\mathrm{H}_{2} \mathrm{O}_{2}$ has a permanent dipole moment of 2.26 Debye. The $\mathrm{O}-\mathrm{O}$ bond is relatively weak and susceptible to homolysis. $\mathrm{H}_{2} \mathrm{O}_{2}$ is decomposed by heating, radiolysis, photolysis, or by reaction with redox active transition metals [74].

\subsubsection{Formation of $\mathrm{H}_{2} \mathrm{O}_{2}$.}

Reduction of $\mathrm{O}_{2}$ to $\mathrm{O}_{2}{ }^{\bullet-}$ followed by its dismutation (Reaction (5)) is the main pathway for the formation of $\mathrm{H}_{2} \mathrm{O}_{2}$ in cells.

$\mathrm{H}_{2} \mathrm{O}_{2}$ can be formed via oxidation of a quinol by $\mathrm{O}_{2}$. For example, hydroanthraquinone is widely used for the commercial synthesis of $\mathrm{H}_{2} \mathrm{O}_{2}$, Reaction (51) [75].<smiles>[R]c1ccc2c(c1)C(=O)c1ccccc1C2=O</smiles>

$\mathrm{H}_{2} \mathrm{O}_{2}$ can be produced by a reaction of ${ }^{1} \mathrm{O}_{2}$ or $\mathrm{O}_{2}{ }^{\bullet-}$ with an electron donor, like $\mathrm{AscH}_{2}$, Reactions (24) and (34), respectively $[47,64]$.

The main reaction of ${ }^{1} \mathrm{O}_{2}$ with $\mathrm{PQH}_{2}$ in methanol was found to result in the formation of $\mathrm{PQ}$ and $\mathrm{H}_{2} \mathrm{O}_{2}$, Reaction (25) and the amount of $\mathrm{H}_{2} \mathrm{O}_{2}$ produced was essentially the same as the amount of oxidized $\mathrm{PQH}_{2}$ [48].

The firect formation of $\mathrm{H}_{2} \mathrm{O}_{2}$ in a reaction of $\mathrm{O}_{2}$ and $\mathrm{H}_{2}$ can occur over catalysts containing palladium ( $\mathrm{PdAu}, \mathrm{Pd}-\mathrm{SiO}_{2}, \mathrm{PdZn}$ and others), Reaction (52) [76].

$$
\mathrm{O}_{2}+\mathrm{H}_{2} \stackrel{\text { Pd-catalyst }}{\longrightarrow} \mathrm{H}_{2} \mathrm{O}_{2}
$$

No direct formation of $\mathrm{H}_{2} \mathrm{O}_{2}$ from $\mathrm{H}_{2}$ and $\mathrm{O}_{2}$ is expected in aerobic cells because the production of hydrogen requires anaerobic conditions [77]. $\mathrm{H}_{2}$ is consumed by the bidirectional hydrogenase in green algae [78], but an enzyme-catalyzing Reaction (52) has not been found.

\subsubsection{Reactions of $\mathrm{H}_{2} \mathrm{O}_{2}$}

Most biological molecules that do not bind transition metal ions do not react directly with $\mathrm{H}_{2} \mathrm{O}_{2}$. However, thiol and cysteine residues of proteins, as well as low-molecular-weight thiols, can directly react with $\mathrm{H}_{2} \mathrm{O}_{2}$ [67]. The reaction of $\mathrm{H}_{2} \mathrm{O}_{2}$ with thiols (RS) depends strongly on the $\mathrm{pK}_{\mathrm{a}}$ value of the thiol, because the reaction exclusively proceeds via the thiolate anion to form sulfenic acid ( $\mathrm{RSOH}$ ), Reaction (53).

$$
\mathrm{RS}^{-}+\mathrm{H}^{+}+\mathrm{H}_{2} \mathrm{O}_{2} \rightarrow \mathrm{RSOH}+\mathrm{H}_{2} \mathrm{O}
$$


The rate constants of Reaction (53) range from 0.16 to $10^{7} \mathrm{M}^{-1} \mathrm{~s}^{-1}$. Sulfenic acids have a lower pKa than the corresponding thiols [79]. Sulfenic acid can react with another thiol or $\mathrm{H}_{2} \mathrm{O}_{2}$ to give the corresponding disulfide (RSSR) or sulfinic acid $\left(\mathrm{RSO}_{2}{ }^{-}\right)$, Reactions (54) and (55), respectively. However, the second-order rate constant of Reaction (55) is about $10^{3}$ times lower than that of Reaction (54) $[74,80]$.

$$
\begin{gathered}
\mathrm{RSOH}+\mathrm{RSH} \rightarrow \mathrm{RSSR}+\mathrm{H}_{2} \mathrm{O} \\
\mathrm{RSO}^{-}+\mathrm{H}^{+}+\mathrm{H}_{2} \mathrm{O}_{2} \rightarrow \mathrm{RSO}_{2}^{-}+\mathrm{H}_{2} \mathrm{O}
\end{gathered}
$$

The second-order rate constants of Reaction (53) for free GSH, cysteine and thioredoxin (TRX) are $0.89 \mathrm{M}^{-1} \mathrm{~s}^{-1}, 2.9 \mathrm{M}^{-1} \mathrm{~s}^{-1}$ and $1.05 \mathrm{M}^{-1} \mathrm{~s}^{-1}$, respectively [74,81]. However, $\mathrm{H}_{2} \mathrm{O}_{2}$ can react efficiently with peroxiredoxins (PRX); the second order rate constant is $10^{7}-10^{8} \mathrm{M}^{-1} \mathrm{~s}^{-1}$ [74]. $\mathrm{H}_{2} \mathrm{O}_{2}$ reacts with pyruvate to form acetate and $\mathrm{CO}_{2}$ with a rate constant of $2.2 \mathrm{M}^{-1} \mathrm{~s}^{-1}$. The reaction of $\mathrm{H}_{2} \mathrm{O}_{2}$ proceeds via a two-electron pathway: (i) reversible formation of a tetrahedral intermediate; (ii) irreversible decomposition of the intermediate to $\mathrm{CO}_{2}$, acetate, and water, Reaction (56) [82].

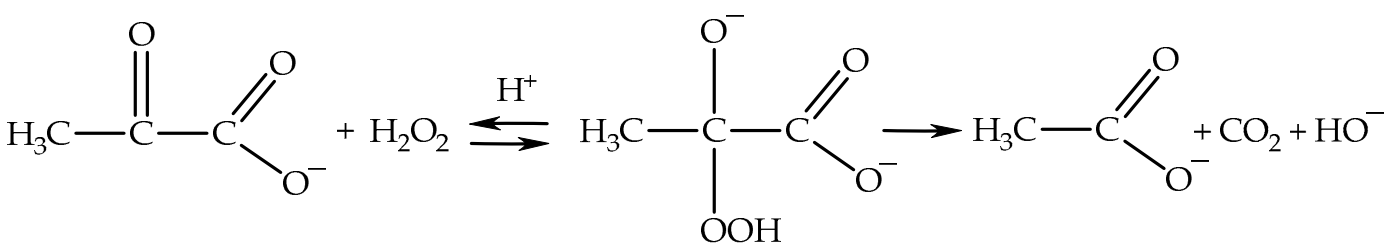

$\mathrm{H}_{2} \mathrm{O}_{2}$ reacts with carbon dioxide to form peroxymonocarbonate $\left(\mathrm{HCO}_{4}{ }^{-}\right)$with a second-order rate constant for the forward reaction of $2 \times 10^{-2} \mathrm{M}^{-1} \mathrm{~s}^{-1}$, Reaction (57) [74].

$$
\mathrm{H}_{2} \mathrm{O}_{2}+\mathrm{CO}_{2} \Delta \mathrm{HCO}_{4}^{-}+\mathrm{H}^{+}
$$

Carbonic anhydrase significantly accelerates Reaction (57) [83]. Transition metals (M) like iron and copper react with $\mathrm{H}_{2} \mathrm{O}_{2}$ via the Fenton mechanism, in which the transition metal cleaves the $\mathrm{O}-\mathrm{O}$ bond to form $\mathrm{HO}^{\bullet}$ and $\mathrm{HO}^{-}$, Reaction (58).

$$
\mathrm{M}^{+(\mathrm{n}-1)}+\mathrm{H}_{2} \mathrm{O}_{2} \rightarrow \mathrm{M}^{+\mathrm{n}}+\mathrm{OH}^{-}+\mathrm{HO}^{\bullet}
$$

Rate constants of the Fenton reaction depend on the metal or metal complex and are in the 5-20 $\times 10^{3} \mathrm{M}^{-1} \mathrm{~s}^{-1}$ range [84-87]. In addition to Reaction (58), the interaction of $\mathrm{H}_{2} \mathrm{O}_{2}$ with transition metals or metal complexes leads to the formation of a higher oxidation state of the metal as $\mathrm{L}-\mathrm{M}\left(\mathrm{H}_{2} \mathrm{O}_{2}\right)^{\mathrm{n}+}$, $\mathrm{L}-\mathrm{M}^{(\mathrm{n}+2)+}$ or L-MO ${ }^{(\mathrm{n}+2)+}$ Reactions (59)-(61) respectively, where $\mathrm{L}$ is a ligand of the metal $[74,88,89]$.

$$
\begin{gathered}
\text { L-M }{ }^{\mathrm{n}+}+\mathrm{H}_{2} \mathrm{O}_{2} \rightarrow \text { L-M- }\left(\mathrm{H}_{2} \mathrm{O}_{2}\right)^{\mathrm{n}+} \\
\text { L-M- }\left(\mathrm{H}_{2} \mathrm{O}_{2}\right)^{\mathrm{n}+} \rightarrow \text { L-M } \\
\text { L-M- }\left(\mathrm{H}_{2} \mathrm{O}_{2}\right)^{\mathrm{n}+2)+}+2 \mathrm{HO}^{-}
\end{gathered}
$$

$\mathrm{H}_{2} \mathrm{O}_{2}$ reacts rapidly with heme peroxidases, for example, myeloperoxidase and lactoperoxidase, with a second order rate constant in the range of $10^{7}-10^{8} \mathrm{M}^{-1} \mathrm{~s}^{-1}$ [90]. The rate constant of the reaction of $\mathrm{H}_{2} \mathrm{O}_{2}$ with ascorbate peroxidase (APX) was estimated to be $10^{7} \mathrm{M}^{-1} \mathrm{~s}^{-1}$ with $\mathrm{K}_{\mathrm{m}}$ for $\mathrm{H}_{2} \mathrm{O}_{2}$ of $80 \mu \mathrm{M}[91,92]$.

The scavenging of $\mathrm{H}_{2} \mathrm{O}_{2}$ by peroxidases (PX) proceeds via the peroxidase mechanism (Reactions (62)-(64)) [93].

$$
\begin{gathered}
\text { PX-Fe(III)-porphyrin }+\mathrm{H}_{2} \mathrm{O}_{2} \rightarrow \text { PX-Fe(IV)=O-porphyrin }{ }^{+}+\mathrm{H}_{2} \mathrm{O} \\
\text { PX-Fe(IV)=O- porphyrin }{ }^{+}+\mathrm{AH} \rightarrow \text { PX-Fe(IV)=O- porphyrin }+\mathrm{A}^{\bullet}+\mathrm{H}^{+}
\end{gathered}
$$




$$
\mathrm{PX}-\mathrm{Fe}(\mathrm{IV})=\mathrm{O} \text { - porphyrin }+\mathrm{AH} \rightarrow \mathrm{PX}-\mathrm{Fe}(\mathrm{III}) \text { - porphyrin }+\mathrm{A}^{\bullet}+\mathrm{OH}^{-},
$$

where $\mathrm{A}$ is a reductant, e.g., $\mathrm{AscH}_{2}$.

Catalase (CAT)-dependent scavenging of $\mathrm{H}_{2} \mathrm{O}_{2}$ occurs via a ping-pong mechanism, Reaction (65) and (66), where one $\mathrm{H}_{2} \mathrm{O}_{2}$ molecule is used as an electron donor.

$$
\begin{gathered}
\mathrm{H}_{2} \mathrm{O}_{2}+\mathrm{Fe}(\mathrm{III})-\mathrm{CAT} \rightarrow \mathrm{H}_{2} \mathrm{O}+\mathrm{Fe}(\mathrm{IV})=\mathrm{O}-\mathrm{CAT}^{+} \\
\mathrm{H}_{2} \mathrm{O}_{2}+\mathrm{Fe}(\mathrm{IV})=\mathrm{O}-\mathrm{CAT}^{+} \rightarrow \mathrm{H}_{2} \mathrm{O}+\mathrm{Fe}(\mathrm{III})-\mathrm{CAT}+\mathrm{O}_{2}
\end{gathered}
$$

\subsubsection{Lifetime and Diffusion Distance of $\mathrm{H}_{2} \mathrm{O}_{2}$}

$\mathrm{H}_{2} \mathrm{O}_{2}$ is a small and neutral molecule that can readily diffuse from the site of its production. However, the diffusion of $\mathrm{H}_{2} \mathrm{O}_{2}$ through membranes is hindered [94-96] and aquaporins may regulate the diffusion of $\mathrm{H}_{2} \mathrm{O}_{2}$ across membranes. $\mathrm{H}_{2} \mathrm{O}_{2}$ is rather stable and its lifetime in cells is limited by scavenging enzymes and other substances reacting with $\mathrm{H}_{2} \mathrm{O}_{2}$. The lifetime of $\mathrm{H}_{2} \mathrm{O}_{2}$ is 1-3 min in mammalian cells [97] and around $10 \mathrm{~s}$ in Arabidopsis guard cells [98].

\subsection{Hydroxyl Radical, $\mathrm{HO}^{\bullet}$}

$\mathrm{HO}^{\bullet}$ has one unpaired electron and is one of the most powerful oxidizing agents. $\mathrm{HO} \mathrm{O}^{\bullet}$ is able to react unselectively with surrounding organic molecules due to the very high positive redox potential, of the pair $\mathrm{HO}^{\bullet} / \mathrm{H}_{2} \mathrm{O}, E_{0}{ }^{\prime}$ of $2.3 \mathrm{~V}$ [99]. The rate constants of reactions of $\mathrm{HO}^{\bullet}$ with many molecules are estimated to be larger than $10^{9} \mathrm{M}^{-1} \mathrm{~s}^{-1}$ [100-102].

\subsubsection{Formation of $\mathrm{HO}^{\bullet}$}

The best-known reaction producing $\mathrm{HO}^{\bullet}$ is the Fenton reaction, in which the $\mathrm{O}-\mathrm{O}$ bond of $\mathrm{H}_{2} \mathrm{O}_{2}$ is cleaved by reaction with a transition metal ion (Reaction (58)). $\mathrm{HO}^{\bullet}$ is produced via the same mechanism in the reaction of $\mathrm{H}_{2} \mathrm{O}_{2}$ with $\mathrm{O}_{2}{ }^{\bullet-}$ (metal-catalyzed Haber-Weiss reaction), Reaction (3).

Another well-known means of $\mathrm{HO}^{\bullet}$ generation is through the photolysis of oxygen-containing species. In aqueous solution, the nitrate anion $\left(\mathrm{NO}_{3}{ }^{-}\right)$can absorb UV radiation and produce $\mathrm{HO}^{\bullet}$, Reactions ((67) and (69). The formation of $\mathrm{HO}^{\bullet}$ is also observed upon photolysis of the nitrite ion $\left(\mathrm{NO}_{2}{ }^{-}\right)$, Reactions (68) and (69) [102,103]. Due to the requirement of short-wavelength UV radiation, this process does not occur in biological systems.

$$
\begin{gathered}
\mathrm{NO}_{3}{ }^{-}+\mathrm{h} v \leftrightarrows+\left[\mathrm{O}^{\bullet-}-^{\bullet} \mathrm{NO}_{2}\right] \rightarrow \mathrm{O}^{\bullet-}+{ }^{\bullet} \mathrm{NO}_{2} \\
\mathrm{NO}_{2}{ }^{-}+\mathrm{h} v \rightarrow \mathrm{O}^{\bullet-}+{ }^{\bullet} \mathrm{NO}_{2} \\
\mathrm{O}^{\bullet-}+\mathrm{H}^{+} \leftrightarrows \mathrm{HO} \mathrm{H}^{\bullet}
\end{gathered}
$$

The photolysis of a $\mathrm{H}_{2} \mathrm{O}_{2}$ molecule gives two $\mathrm{HO}^{\bullet}$ with a quantum yield of approximately 0.5 in aqueous solutions, Reaction (70). $\mathrm{H}_{2} \mathrm{O}_{2}$ photolysis requires UV-C radiation because the molar absorption coefficient of $\mathrm{H}_{2} \mathrm{O}_{2}$ is very low above $300 \mathrm{~nm} . \mathrm{H}_{2} \mathrm{O}_{2}$ photolysis is an effective way of generating $\mathrm{HO}^{\bullet}$ in aqueous solutions [102,104].

$$
\mathrm{H}_{2} \mathrm{O}_{2} \Delta\left[\mathrm{HO}^{\bullet}-\mathrm{HO}^{\bullet}\right] \rightarrow 2 \mathrm{HO}^{\bullet}
$$

Another potential source of $\mathrm{HO}^{\bullet}$ is $\mathrm{O}_{3}$. The addition of an electron to an $\mathrm{O}_{3}$ molecule leads to the decomposition of $\mathrm{O}_{3}$ to $\mathrm{HO}^{\bullet}$ and $\mathrm{O}_{2}$ via the formation of an ozonide anion radical [105]. $\mathrm{O}_{3}$ can also be decomposed to $\mathrm{O}_{2}$ and $\mathrm{HO}^{\bullet}$ via reduction by exited chlorophyll $\left(\mathrm{Chl}^{*}\right)$, Reaction (71) [102].

$$
\mathrm{O}_{3}+\mathrm{Chl}^{*}+\mathrm{H}^{+} \rightarrow \mathrm{O}_{2}+\mathrm{HO}^{\bullet}+\mathrm{Chl}^{+}
$$

However, $\mathrm{O}_{3}$ has not been found inside plant cells. 
$\mathrm{O}_{3}$ reacts with $\mathrm{O}_{2}{ }^{\bullet-}$ to form $\mathrm{HO}^{\bullet}$ and $\mathrm{O}_{2}$ as final products, Reaction (72)-(74)

$$
\begin{gathered}
\mathrm{O}_{3}+\mathrm{O}_{2}^{\bullet-} \rightarrow \mathrm{O}_{3}^{\bullet-}+\mathrm{O}_{2} \\
\mathrm{O}_{3}^{\bullet-}+\mathrm{H}^{+} \rightarrow \mathrm{HO}_{3}^{\bullet} \\
\mathrm{HO}_{3}^{\bullet} \rightarrow \mathrm{HO}^{\bullet}+\mathrm{O}_{2}
\end{gathered}
$$

$\mathrm{HO}^{\bullet}$ can be also produced in a radical-radical reaction of $\mathrm{HO}_{2}{ }^{\bullet}$ with $\mathrm{RO}_{2}{ }^{\bullet}$, Reaction (75) [102].

$$
\mathrm{RO}_{2}^{\bullet}+\mathrm{HO}_{2}^{\bullet} \rightarrow \mathrm{RO}^{\bullet}+\mathrm{HO}^{\bullet}+\mathrm{O}_{2}
$$

\subsubsection{Reactions of $\mathrm{HO}^{\bullet}$}

$\mathrm{HO}^{\bullet}$ participates in several typical reactions:

abstraction of hydrogen atom from an organic molecule (RH) with the formation of $\mathrm{H}_{2} \mathrm{O}$ and radical $\left(\mathrm{R}^{\bullet}\right)$ of substrate $(76)$;

$$
\mathrm{HO}^{\bullet}+\mathrm{RH} \rightarrow \mathrm{H}_{2} \mathrm{O}+\mathrm{R}^{\bullet}
$$

addition to double bonds with the formation of a hydroxylated radical (77);

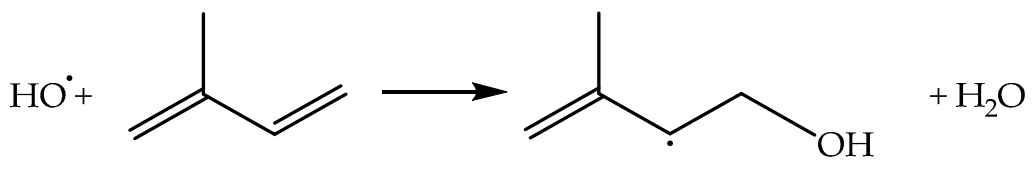

electron transfer reactions leading to the formation of a neutral radical (78) or a cation radical (79) [106]; $\mathrm{SCN}^{-}$is the thiocyanate ion.<smiles>COc1cc(N)cc([IH]Cc2cc(OC)ccc2N)c1</smiles>

Formation of an aromatic-OH adduct due to a reaction of an aromatic compound with $\mathrm{HO}^{\bullet}$ is one of the methods for $\mathrm{HO}^{\bullet}$ detection with high-performance liquid chromatography-mass spectrometry. For example, $\mathrm{HO}^{\bullet}$ can react with phenylalanine to form isomers of tyrosine, Reaction (80) [107]. Isomers of tyrosine are rather stable and not normally present in proteins, and can serve as $\mathrm{HO}^{\bullet}$ traps in biological samples [108]. 
<smiles>NC(Cc1ccccc1)C(=O)O</smiles><smiles>NC(Cc1ccccc1O)C(=O)O</smiles>

ortho-tyrosine<smiles>CCCc1cccc(O)c1</smiles>

meta-tyrosine

$\mathrm{HO}^{\bullet}$ interacts with many metal (M) cations via an electron transfer Reaction (81), with a rate constant of $\sim 10^{8} \mathrm{M}^{-1} \mathrm{~s}^{-1}$ [100].

$$
\mathrm{HO}{ }^{\bullet}+\mathrm{M}^{\mathrm{n}+} \rightarrow \mathrm{M}^{(\mathrm{n}+1)+}+\mathrm{OH}^{-}
$$

$\mathrm{HO}^{\bullet}$ initiates lipid peroxidation, resulting in hydrogen abstraction from a pentyl group of an unsaturated fatty acid, and the formation of a radical that interacts with $\mathrm{O}_{2}$ to form an $\mathrm{ROO}{ }^{\bullet}$ with a rate constant of $\sim 10^{8} \mathrm{M}^{-1} \mathrm{~s}^{-1}$ [109], Reaction (82).

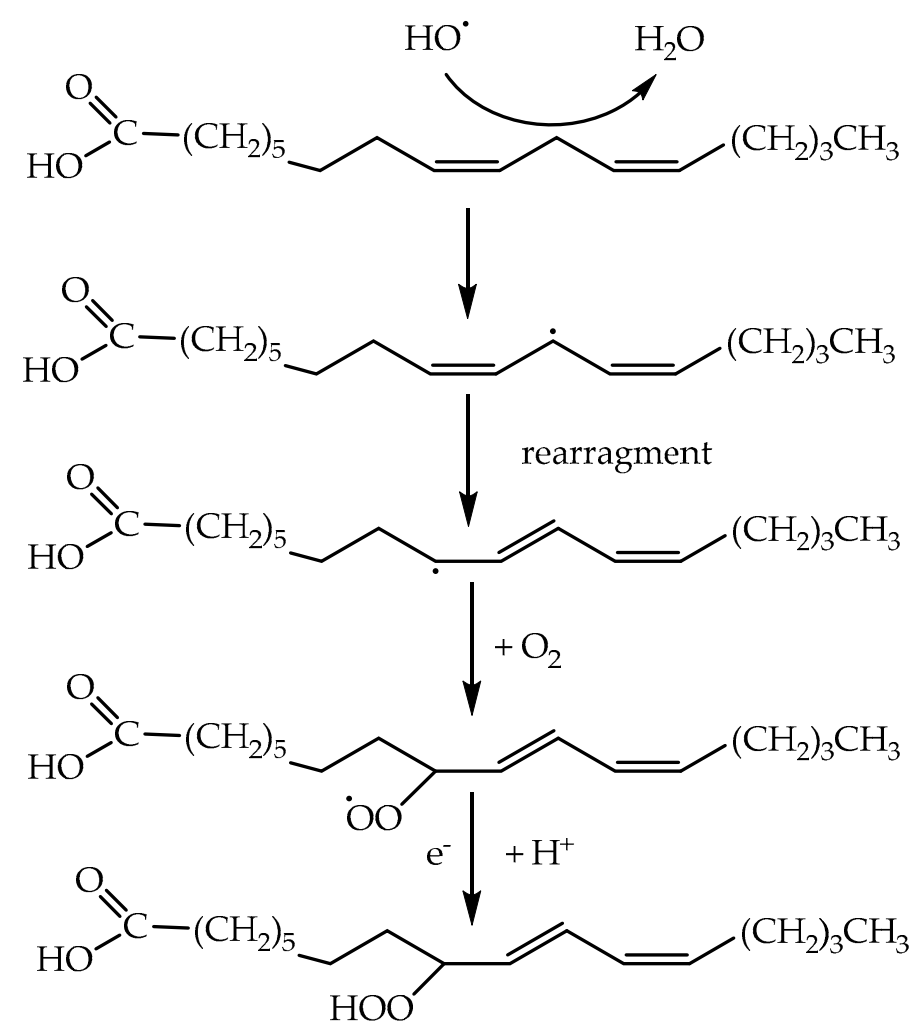




\subsubsection{Lifetime and Diffusion Distance of $\mathrm{HO}^{\bullet}$}

The lifetime of $\mathrm{HO}^{\bullet}$ in aqueous solution has been estimated to range from picoseconds to nanoseconds. The self-diffusion coefficient of $\mathrm{HO}^{\bullet}$ in water has been estimated to be $2.8 \times 10^{-5} \mathrm{~cm}^{2} \mathrm{~s}^{-1}$, and consequently the diffusion distance of $\mathrm{HO}^{\bullet}$ is a few molecular diameters from the site of origin [110,111].

\section{Production of ROS in Chloroplasts}

Chloroplasts have a high metabolic activity accompanied with intensive formation of redox active compounds, which are able to react with oxygen to produce ROS. Most ROS production in the chloroplast occurs by the components of the light reactions. Photorespiration is responsible for $70 \%$ of total $\mathrm{H}_{2} \mathrm{O}_{2}$ production in the leaves of $\mathrm{C} 3$ plants [112,113], but this reaction runs in peroxisomes outside of the chloroplast.

\subsection{ROS Production in Chloroplast Stroma}

\subsubsection{Formation of ${ }^{1} \mathrm{O}_{2}$ in the Stroma}

The chloroplast stroma is not considered as a significant source of ${ }^{1} \mathrm{O}_{2}$, although disintegration of the antenna complexes under stress conditions and disturbances in $\mathrm{Chl}$ synthesis and the accumulation of its precursors may lead to ${ }^{1} \mathrm{O}_{2}$ production in the stroma [114]. The lack of FLU, a nuclear-encoded chloroplast protein that plays a key role during the negative feedback control of Chl biosynthesis, leads to the accumulation of protochlorophyllide in plastids and, consequently, to photosensitized generation of ${ }^{1} \mathrm{O}_{2}$ [115]. It has been recently shown that lipoxygenase localized in the chloroplast is responsible for ${ }^{1} \mathrm{O}_{2}$ formation [116]. Lipoxygenase initiates lipid oxidation to corresponding lipid peroxides, which decompose to lipid peroxyl radicals ( $\left.\mathrm{LOO}^{\bullet}\right)$. $\mathrm{LOO}^{\bullet}$ can react with each other, forming a cyclic endoperoxide (dioxetane) intermediate. Dioxetane, in turn, can decompose via the Russel mechanism to form ${ }^{1} \mathrm{O}_{2}$, Reaction (9).

Theoretically, the Haber-Weiss mechanism (Reactions (3) and (4)) can cause the formation of ${ }^{1} \mathrm{O}_{2}$ in the stroma, but the rate of this reaction is expected to be low due to very efficient scavenging of $\mathrm{O}_{2}{ }^{\bullet-}$ by chloroplasts [12] and the low rate constant of Reactions (3) and (4) [21].

\subsubsection{Formation of Reduced Forms of Oxygen, $\mathrm{O}_{2}{ }^{\bullet-}, \mathrm{H}_{2} \mathrm{O}_{2}, \mathrm{HO} \mathrm{O}^{\bullet}$, by Fd in the Stroma}

Ferredoxin (Fd) and free flavins (FL) and flavoenzymes are considered as the main stromal components involved in $\mathrm{O}_{2}$ reduction and $\mathrm{ROS}$ formation. $\mathrm{Fd}$ is involved in electron transfer from the acceptor side of PSI to $\mathrm{NADP}^{+}$in a reaction catalyzed by Fd-NADP ${ }^{+}$reductase (FNR) (EC 1.18.1.2) [117]. $\mathrm{Fd}$ is a soluble $10 \mathrm{kDa}$ protein [118] containing a $2 \mathrm{Fe}-2 \mathrm{~S}$ center [119]. The leaf-type Fd from higher plants has an $E_{m}$ vs. NHE (at $\mathrm{pH} 8.0$ ) from -390 to $-425 \mathrm{mV}$ [120]. The redox potential of $\mathrm{Fd}_{\mathrm{ox}} / \mathrm{Fd}_{\text {red }}$ is much more negative than the redox potential of $\mathrm{O}_{2} / \mathrm{O}_{2}{ }^{\bullet-}(-160--180 \mathrm{mV})$ in aqueous solutions, and the reduction in $\mathrm{O}_{2}$ by $\mathrm{Fd}$ is thermodynamically very favorable. It was suggested that the oxidation of $\mathrm{Fd}$ can occur via 2-step reaction with the formation of the $\mathrm{Fd}_{-} \mathrm{O}_{2}{ }^{--}$complex [121], Reactions (83) and (84).

$$
\begin{aligned}
& \mathrm{Fd}(\mathrm{II})+\mathrm{O}_{2} \Delta \mathrm{Fd}(\mathrm{II})-\mathrm{O}_{2} \\
& \mathrm{Fd}(\mathrm{II})-\mathrm{O}_{2} \Delta \mathrm{Fd}(\mathrm{III})-\mathrm{O}_{2}{ }^{\bullet-}
\end{aligned}
$$

The subsequent dissociation of the $\mathrm{Fd}(\mathrm{III})-\mathrm{O}_{2}{ }^{\bullet-}$ yields $\mathrm{O}_{2}{ }^{\bullet-}$. The involvement of $\mathrm{Fd}$ in $\mathrm{O}_{2}$ reduction has been studied by the addition of $\mathrm{Fd}$ to a suspension of thylakoid membranes in the light. In this case, $\mathrm{Fd}$ is reduced by PSI. Fd increased the rate of $\mathrm{O}_{2}$ consumption in response to an increase in $\mathrm{Fd}$ concentration. The rate of $\mathrm{O}_{2}$ consumption was saturated at $60 \mu \mathrm{M} \mathrm{Fd}$ and became sevenfold higher than in the absence of $\mathrm{Fd}[122,123]$. On the other hand, $\mathrm{Fd}$ did not stimulate the formation of $\mathrm{O}_{2}{ }^{\bullet-}$ measured using $\mathrm{O}_{2}{ }^{\bullet-}$ traps such as epinephrine or cytochrome $c$ [124]. This suggests that the formation 
of $\mathrm{O}_{2}{ }^{\bullet-}$ by exogenous $\mathrm{Fd}$ is very slow in comparison to the formation of $\mathrm{O}_{2}^{\bullet-}$ by thylakoid-bound photoreductants. This correlates with the finding that the rate of direct oxidation of $\mathrm{Fd}$ by $\mathrm{O}_{2}$ was rather low, with a second-order rate constant of $10^{3} \mathrm{M}^{-1} \mathrm{~s}^{-1}$ for chemically (dithionite as reductant) reduced $\mathrm{Fd}$ [125]. Recent studies show that $\mathrm{O}_{2}$ reduction in a thylakoid suspension in the presence of $\mathrm{Fd}$ is a result of $\mathrm{O}_{2}$ reduction by both a membrane-bound reductant and $\mathrm{Fd}$. The distribution of electron flow from Fd and membrane-bound reductant to $\mathrm{O}_{2}$ is sensitive to light intensity and NADP ${ }^{+}$ but not to $\mathrm{Fd}$ concentration. Furthermore, Fd stimulates the reduction in $\mathrm{O}_{2}$ by membrane-bound reductants [126]. Interestingly, $\mathrm{NADP}^{+}$very strongly inhibits $\mathrm{O}_{2}$ reduction by $\mathrm{Fd}$ but stimulates $\mathrm{O}_{2}$ reduction by a thylakoid-membrane-bound reductant [126]. These results suggest that Fd has a minor role in the direct reduction of $\mathrm{O}_{2}$ in vivo.

Catalase, added to a suspension of illuminated thylakoid membranes, almost completely suppressed Fd-dependent $\mathrm{O}_{2}$ consumption, suggesting that $\mathrm{H}_{2} \mathrm{O}_{2}$ is the final product of $\mathrm{O}_{2}$ reduction by $\mathrm{Fd}$. This is clear from the well-known stoichiometry between $\mathrm{O}_{2}$ consumption and $\mathrm{O}_{2}$ evolution in isolated thylakoids when a reduction in $\mathrm{O}_{2}$ occurs by electrons originally arising from water-splitting in PSII without any electron acceptors or ROS traps, Reactions (85)-(89). In this case, $\mathrm{H}_{2} \mathrm{O}_{2}$ is produced via dismutation of $\mathrm{O}_{2}^{\bullet-}[127,128]$.

$$
\begin{array}{cc}
2 \mathrm{H}_{2} \mathrm{O} \rightarrow \mathrm{O}_{2}+4 \mathrm{H}^{+}+4 \mathrm{e}^{-} & \text {water splitting in PSII } \\
4 \mathrm{Fd}(\mathrm{III})+4 \mathrm{e}^{-} \rightarrow 4 \mathrm{Fd}(\mathrm{II}) & \text { Fd reduction in PSI, } \\
4 \mathrm{Fd}(\mathrm{II})+\mathrm{O}_{2} \rightarrow 4 \mathrm{Fd}(\mathrm{III})+4 \mathrm{O}_{2}^{\bullet-} & \mathrm{O}_{2}^{\bullet-} \text { formation, } \\
4 \mathrm{O}_{2}^{\bullet-}+4 \mathrm{H}^{+} \rightarrow 2 \mathrm{H}_{2} \mathrm{O}_{2}+2 \mathrm{O}_{2} & \mathrm{O}_{2}^{\bullet-} \text { dismutation, } \\
2 \mathrm{H}_{2} \mathrm{O}_{2} \rightarrow 2 \mathrm{H}_{2} \mathrm{O}+\mathrm{O}_{2} & \mathrm{H}_{2} \mathrm{O}_{2} \text { decomposition, }
\end{array}
$$

Reaction (84) is included only to describe an experiment with isolated thylakoids. Chloroplasts do not contain CAT and, in chloroplasts, $\mathrm{H}_{2} \mathrm{O}_{2}$ is scavenged by APX (Reactions (62)-(64)) [12]. Fd-mediated photosynthetic $\mathrm{O}_{2}$ consumption is inhibited by SOD, suggesting that autoxidation of Fd is involved in both the reduction of $\mathrm{O}_{2}$ to $\mathrm{O}_{2}{ }^{\bullet-}$ and of $\mathrm{O}_{2}{ }^{\bullet-}$ to $\mathrm{H}_{2} \mathrm{O}_{2}$, Reactions (90) and (91) [129].

$$
\begin{gathered}
\mathrm{Fd}(\mathrm{II})+\mathrm{O}_{2} \rightarrow \mathrm{Fd}(\mathrm{III})+\mathrm{O}_{2}^{\bullet-} \\
\mathrm{Fd}(\mathrm{II})+\mathrm{O}_{2}^{\bullet-}+2 \mathrm{H}^{+} \rightarrow \mathrm{Fd}(\mathrm{III})+\mathrm{H}_{2} \mathrm{O}_{2}
\end{gathered}
$$

The reduction in $\mathrm{O}_{2}{ }^{\bullet-}$ by $\mathrm{Fd}$ can produce $\mathrm{H}_{2} \mathrm{O}_{2}$ in the chloroplast stroma. The very low stimulation of $\mathrm{O}_{2}{ }^{\bullet-}$ production by $\mathrm{Fd}$ in comparison to $\mathrm{O}_{2}$ consumption [124,127] could result from Reaction (91). It is also possible that $\mathrm{Fd}$ stimulates $\mathrm{O}_{2}$ reduction in chloroplasts through a more complicated process than the direct reduction in $\mathrm{O}_{2}$.

\subsubsection{Formation of Reduced Forms of Oxygen, $\mathrm{O}_{2}^{\bullet-}, \mathrm{H}_{2} \mathrm{O}_{2}, \mathrm{HO}^{\bullet}$, by Flavins in the Stroma}

The reduction in $\mathrm{O}_{2}$ by FLs can also produce ROS in the stroma, as FLs react with $\mathrm{O}_{2}$ to form $\mathrm{O}_{2}{ }^{\bullet-}$ and $\mathrm{H}_{2} \mathrm{O}_{2}$. Free FLs are oxidized by $\mathrm{O}_{2}$ via the formation of an intermediate complex containing a radical pair that can decompose with the formation of a flavin semiquinone radical $\left(\mathrm{FLH}^{\bullet}\right)$ and $\mathrm{O}_{2}^{\bullet-}$, Reaction (92). The radical pair may also be transformed to a flavin hydroperoxide (FLHOOH) that can decompose to a FL and $\mathrm{H}_{2} \mathrm{O}_{2}$, Reaction (93) [130-134].

$$
\begin{gathered}
\mathrm{FLH}^{-}+\mathrm{O}_{2} \rightarrow\left[\mathrm{FLH}^{\bullet}-\mathrm{OO}^{\bullet-}\right] \rightarrow \mathrm{FLH}^{\bullet}+\mathrm{O}_{2}^{\bullet-} \\
{\left[\mathrm{FLH}^{\bullet}-\mathrm{OO}^{\bullet-}\right]+\mathrm{H}^{+} \rightarrow \mathrm{FLHOOH} \rightarrow \mathrm{FL}+\mathrm{H}_{2} \mathrm{O}_{2}}
\end{gathered}
$$

The second-order rate constant of Reaction (92) is estimated to be only $2.5 \times 10^{2} \mathrm{M}^{-1} \mathrm{~s}^{-1}[133,134]$. The formation of FLH ${ }^{\bullet}$ (Reaction (92)) can also initiate complex autocatalytic FL oxidation. In solution, 
some amount of the $\mathrm{FLH}^{\bullet}$ is formed in a mixture of oxidized and reduced $\mathrm{FL}\left(\mathrm{FLH}_{2}\right)$ via an equilibrium reaction, Reaction (94).

$$
\mathrm{FLH}_{2}+\mathrm{FL} \Delta 2 \mathrm{FLH}^{\bullet}
$$

With free FLs, the second-order rate constants for forward and backward Reaction (94) are $10^{6} \mathrm{M}^{-1} \mathrm{~s}^{-1}$ and $5 \times 10^{8} \mathrm{M}^{-1} \mathrm{~s}^{-1}$, respectively [133]. Thus, the equilibrium constant of Reaction (94) is $2 \times 10^{-3}$. Only $1-5 \%$ of the radical is stabilized in an equimolar mixture of oxidized and reduced FL $[134,135]$. The flavin semiquinone radical can exist in neutral $\left(\mathrm{FLH}^{\bullet}\right)$ or anionic form $\left(\mathrm{FL}^{\bullet-}\right)$, with a $\mathrm{pKa}$ of $\approx 8.5$ (Reaction (95)).

$$
\mathrm{FLH}^{\bullet} \Delta \mathrm{FL}^{\bullet-}+\mathrm{H}^{+}
$$

The next steps of the autocatalytic process are described by Reactions (96)-(101), in which the oxidation of $\mathrm{FLH}^{\bullet}$ or $\mathrm{FL}^{\bullet-}$ by $\mathrm{O}_{2}$ produces $\mathrm{O}_{2}{ }^{\bullet-}$, Reaction (96) and (97), and then $\mathrm{O}_{2}{ }^{\bullet-}$ or $\mathrm{HO}_{2}{ }^{\bullet}$ can react with $\mathrm{FLH}_{2}$ to form $\mathrm{FLH}^{\bullet}$ or $\mathrm{FL}^{\bullet-}$ and $\mathrm{H}_{2} \mathrm{O}_{2}$, Reaction (98) and (99). $\mathrm{O}_{2}{ }^{\bullet-}$ and $\mathrm{HO}_{2}{ }^{\bullet}$ can also react with $\mathrm{FLH}^{\bullet}$ to form $\mathrm{FL}$ and $\mathrm{HO}_{2}{ }^{-}$or $\mathrm{H}_{2} \mathrm{O}_{2}$, Reaction (100) and (101).

$$
\begin{gathered}
\mathrm{FLH}^{\bullet}+\mathrm{O}_{2} \rightarrow \mathrm{FL}+\mathrm{O}_{2}^{\bullet-}+\mathrm{H}^{+} \rightarrow \mathrm{FL}+\mathrm{HO}_{2} \\
\mathrm{FL}^{\bullet-}+\mathrm{O}_{2} \rightarrow \mathrm{FL}+\mathrm{O}_{2}^{\bullet-} \\
\mathrm{FLH}_{2}+\mathrm{O}_{2}^{\bullet-} \rightarrow \mathrm{FL}^{\bullet-}+\mathrm{H}_{2} \mathrm{O}_{2} \\
\mathrm{FLH}_{2}+\mathrm{HO}_{2}^{\bullet} \rightarrow \mathrm{FLH}^{\bullet}+\mathrm{H}_{2} \mathrm{O}_{2} \\
\mathrm{FLH}^{\bullet}+\mathrm{O}_{2}^{\bullet-} \rightarrow \mathrm{FL}+\mathrm{HO}_{2}^{-} \\
\mathrm{FLH}^{\bullet}+\mathrm{HO}_{2}^{\bullet} \rightarrow \mathrm{FL}+\mathrm{H}_{2} \mathrm{O}_{2}
\end{gathered}
$$

The second-order rate constant for the reaction of $\mathrm{O}_{2}$ with $\mathrm{FLH}^{\bullet}$ (Reaction (96)) is around $10^{4} \mathrm{M}^{-1} \mathrm{~s}^{-1}$ and that of the reaction of $\mathrm{O}_{2}$ with $\mathrm{FL}^{--}$(Reaction (97)) is much larger, around $10^{8} \mathrm{M}^{-1} \mathrm{~s}^{-1}$ [133]. The $E_{m}$ at $\mathrm{pH} 7$ for FL/FLH ${ }^{\bullet}$ of FL mononucleotide is estimated to be $-313 \mathrm{mV}$ vs. NHE, which is more negative than the redox potential of $\mathrm{O}_{2} / \mathrm{O}_{2}{ }^{--}(-160 \mathrm{mV})$ in aqueous solution [134,136]. As predicted from the redox potentials, the reaction of $\mathrm{FL}^{\bullet-}$ with $\mathrm{O}_{2}$ is

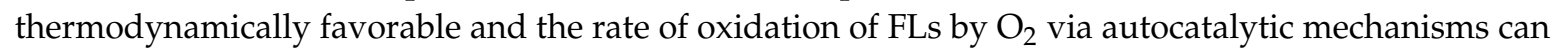
strongly depend on both the stability and pKa value of $\mathrm{FLH}^{\bullet}$. Free flavins can therefore be involved in the formation of ROS in the chloroplast stroma.

Flavoenzymes can also be involved in the production of $\mathrm{O}_{2}{ }^{--}$and $\mathrm{H}_{2} \mathrm{O}_{2}$ in chloroplasts. The reactivity of FLs in flavoenzymes is modulated by the protein environment of reduced FLs and the second-order rate constant of $\mathrm{O}_{2}$ reduction by flavoenzymes varies from $2 \mathrm{M}^{-1} \mathrm{~s}^{-1}$ to $2 \times 10^{6} \mathrm{M}^{-1} \mathrm{~s}^{-1}$ [134]. The redox potential of flavoenzymes vs. NHE varies from -16 to $-263 \mathrm{mV}$ and -60 to $-231 \mathrm{mV}$ for $\mathrm{FL} / \mathrm{FLH}^{\bullet}$ and for $\mathrm{FLH}^{\bullet} / \mathrm{FLH}_{2}$, respectively [134]. The reactivity of flavoenzymes towards $\mathrm{O}_{2}$ may differ by several orders of magnitude between flavoenzymes having similar redox potentials [134]. Such very high differences are due to the protein environment, which affects both $\mathrm{O}_{2}$ movement and the binding of $\mathrm{O}_{2}$ to the active site. In addition, the polarity of the protein environment in the active site can change the redox potential of $\mathrm{O}_{2} / \mathrm{O}_{2}{ }^{\bullet-}$ because the redox potential of $\mathrm{O}_{2} / \mathrm{O}_{2}{ }^{\bullet-}$ becomes very negative $\left(\approx-600 \mathrm{mV}\right.$ vs. NHE) in a non-polar solvent [55]. The reduction in $\mathrm{O}_{2}$ by a FL in a non-polar active site is thus unlikely [134]. The reactivity of flavoenzymes towards $\mathrm{O}_{2}$ depends on the stabilization of the semiquinone in the active site because semiquinones show higher reactivity with $\mathrm{O}_{2}$ than fully reduced FLs [133]. The reactivities of flavoenzymes with $\mathrm{O}_{2}$ can be limited by a substrate that acts as a specific electron acceptor of the flavoenzyme. Some flavoenzymes, like glucose oxidase and xanthine oxidase, employ $\mathrm{O}_{2}$ as a natural acceptor, forming both $\mathrm{H}_{2} \mathrm{O}_{2}$ and $\mathrm{O}_{2}{ }^{\bullet-}$ with high efficiency $[137,138]$. The mechanism of $\mathrm{O}_{2}$ reduction by flavoenzymes has recently been reviewed in detail [139]. 
Some stromal flavoenzymes, such as FNR, monodehydroascorbate reductase (MDAR), glutathione reductase (GR) and glycolate oxidase, can efficiency reduce $\mathrm{O}_{2}$ to $\mathrm{O}_{2}{ }^{\bullet-}$ in the absence of the specific substrate $[12,140]$. The flavoenzymes are reduced and oxidized by their specific electron donors and acceptors with high rates. For example, MDAR is reduced by $\mathrm{NAD}(\mathrm{P}) \mathrm{H}$ with a second-order rate constant of $1.8 \times 10^{8} \mathrm{M}^{-1} \mathrm{~s}^{-1}$ [141], and the reduced MDAR can be oxidized by monodehydroascorbate radical ( $\mathrm{AscH}^{\bullet}$ and its anionic form $\left(\mathrm{Asc}^{\bullet-}\right)$, abbreviated as MDA) with a second-order rate constant of $2.6 \times 10^{8} \mathrm{M}^{-1} \mathrm{~s}^{-1}$ [142]. The flavoenzymes MDAR, GR, FNR and glycolate oxidase can, after reduction by $\mathrm{Fd}$ or $\mathrm{NAD}(\mathrm{P}) \mathrm{H}$, efficiently reduce $\mathrm{O}_{2}$ to form $\mathrm{O}_{2}{ }^{--}$as a primary product with a maximum rate in isolated thylakoids of $300 \mu \mathrm{mol}$ of $\mathrm{O}_{2}{ }^{\bullet-}(\mathrm{mg} \mathrm{Chl})^{-1} \mathrm{~h}^{-1}$. The $\mathrm{K}_{\mathrm{m}}$ value for $\mathrm{O}_{2}$ in the reaction with MDAR was $100 \mu \mathrm{M}$, while the $\mathrm{K}_{\mathrm{m}}$ for $\mathrm{O}_{2}$ reduction by thylakoid membranes was $10 \mu \mathrm{M}$ [140]. In the work of Goetze and Carpentier [143] the addition of FNR to a thylakoid suspension increased $\mathrm{H}_{2} \mathrm{O}_{2}$ formation by $33 \%$. The rates of $\mathrm{O}_{2}$ consumption in the absence and presence of FNR were 28 and $37 \mu \mathrm{mol}(\mathrm{mg} \mathrm{Chl})^{-1} \mathrm{~h}^{-1}$, respectively, which imply (in a system that produces $\mathrm{O}_{2}$ at PSII) $\mathrm{O}_{2}{ }^{\bullet-}$ production rates of $112 \mu \mathrm{mol}(\mathrm{mg} \mathrm{Chl})^{-1} \mathrm{~h}^{-1}$ and $148 \mu \mathrm{mol}(\mathrm{mg} \mathrm{Chl})^{-1} \mathrm{~h}^{-1}$, respectively [143]. However, the autoxidation rates of the MDAR, glutathione reductase and FNR that can be reduced by $\mathrm{NAD}(\mathrm{P}) \mathrm{H}$ are extremely slow $[141,144]$, suggesting that the high rates of $\mathrm{O}_{2}$ reduction by photoreduced flavoenzymes result from the formation of a stable semiquinone. Photoreduction of the flavoenzymes, added to thylakoid membranes, can occur at the $\mathrm{F}_{\mathrm{A}} / \mathrm{F}_{\mathrm{B}}$ (4Fe-4S clusters of PSI) [140]. The prosthetic group of MDAR can be reduced by $\mathrm{F}_{\mathrm{A}} / \mathrm{F}_{\mathrm{B}}$ to the semiquinone form, as the $E_{m}$ of $\mathrm{F}_{\mathrm{A}} / \mathrm{F}_{\mathrm{A}}{ }^{-}$and $\mathrm{F}_{\mathrm{B}} / \mathrm{F}_{\mathrm{B}}{ }^{-}$ pairs are -479 and $-539 \mathrm{mV}$, respectively [145]. The stable semiquinones of flavoenzymes can be oxidized by $\mathrm{O}_{2}$ with a high rate [133]. In leaves, the photoreduction rate of $\mathrm{O}_{2}$ was estimated to be 18-26 $\mu \mathrm{mol} \mathrm{O} \mathrm{O}_{2}\left(\mathrm{~m}^{-2}\right.$ of leaf area) $\mathrm{s}^{-1}$ [146] which gives a rate of $\mathrm{O}_{2}{ }^{\bullet-}$ production of 240-350 $\mu \mathrm{mol}(\mathrm{mg}$ $\mathrm{Chl})^{-1} \mathrm{~h}^{-1}$ assuming $\left.0.6 \mathrm{mmol} \mathrm{Chl} \mathrm{(m} \mathrm{leaf} \mathrm{area)}\right)^{-2}$ [147]. Thus, flavoenzymes may contribute to the high rates of $\mathrm{O}_{2}$ photoreduction in chloroplasts.

In cyanobacteria $[148,149]$, flavodiiron proteins reduce oxygen to water without ROS production. A substantial fraction of the total photosynthetic electron flow may be directed to this route [150]. Flavodiiron proteins have later been found from all oxygenic phototrophs except for angiosperms and some non-green algae (for review, see [151]).

\subsubsection{Formation of $\mathrm{H}_{2} \mathrm{O}_{2}$ in the Stroma}

In most cases, the reduction in $\mathrm{O}_{2}$ by $\mathrm{Fd}$ or by flavoenzymes yields $\mathrm{O}_{2}{ }^{\bullet-}$ as the primary product $[127,140]$ and $\mathrm{H}_{2} \mathrm{O}_{2}$ is usually formed via the dismutation of $\mathrm{O}_{2}{ }^{\bullet-}$ [152]. The dismutation of $\mathrm{O}_{2}{ }^{--}$in Reaction (5) is a major mechanism of $\mathrm{H}_{2} \mathrm{O}_{2}$ formation in the stroma. At physiological $\mathrm{pH}$, the rate constant for $\mathrm{O}_{2}{ }^{\bullet-}$ dismutation is about $10^{5} \mathrm{M}^{-1} \mathrm{~s}^{-1}$ [68]. SOD catalyzes the disproportionation of $\mathrm{O}_{2}^{\bullet-}$ at a diffusion-controlled rate, as the second-order rate constant was estimated to be $2.2 \times 10^{8} \mathrm{M}^{-1} \mathrm{~s}^{-1}$ for stromal conditions [152]. $\mathrm{H}_{2} \mathrm{O}_{2}$ can also be formed via a reaction of $\mathrm{O}_{2}{ }^{\bullet-}$ with a reduced stromal compound like $\mathrm{AscH}_{2}, \mathrm{GSH}$ or Fd $[127,152]$. The yields of these reactions are very small in the presence of SOD. The second-order rate constants of reduction of $\mathrm{O}_{2}{ }^{\bullet-}$ with $\mathrm{AscH}_{2}$ and GSH were estimated to be $3.3 \times 10^{5} \mathrm{M}^{-1} \mathrm{~s}^{-1}$ and $10^{3} \mathrm{M}^{-1} \mathrm{~s}^{-1}$, respectively $[62,66]$.

In chloroplasts, $\mathrm{H}_{2} \mathrm{O}_{2}$ is efficiently scavenged by an enzyme-catalyzed reduction in $\mathrm{H}_{2} \mathrm{O}_{2}$ by $\mathrm{AscH}_{2}$ to form $\mathrm{H}_{2} \mathrm{O}$ and DHA (see Section 5.1). The reaction is catalyzed by both stromal and thylakoid-bound APXs [5,152]. Accumulation of $\mathrm{H}_{2} \mathrm{O}_{2}$ can lead to the generation of $\mathrm{HO}^{\bullet}$ via the Fenton reaction (Reaction (58)) if the scavenging of $\mathrm{H}_{2} \mathrm{O}_{2}$ by the antioxidant enzymes is not fast enough for the efficient removal of $\mathrm{H}_{2} \mathrm{O}_{2}$. The Fenton reaction is possible in the chloroplast because up to $80 \%$ of cellular $\mathrm{Fe}$ in leaf cells is found in chloroplasts [153]. The involvement of free Fe in Fenton reaction is limited, since the Fe is stored in a redox inactive form as ferritin [154,155]. However, Fe can be activated and released from ferritin via interaction of ferritin with $\mathrm{O}_{2}{ }^{--}$[156]. In addition to free transition metals, $\mathrm{Fd}$ can be involved in the production of $\mathrm{HO}^{\bullet}[157,158]$. The second-order rate constant for the reaction of reduced Fd with $\mathrm{H}_{2} \mathrm{O}_{2}$ was found to be $5 \times 10^{3} \mathrm{M}^{-1} \mathrm{~s}^{-1}$ [121], which is two orders of magnitude higher than the second-order rate constant of $\mathrm{HO}^{\bullet}$ production in the Fenton reaction, $84 \mathrm{M}^{-1} \mathrm{~s}^{-1}$ [84]. 


\subsection{Formation of ROS in Thylakoid Membranes}

The PETC employs three membrane protein complexes: PSI, PSII, their respective light-harvesting complexes (LHCI and LHCII), and the cytochrome b6/f complex (Cyt b6f, a plastoquinol-plastocyanin-oxidoreductase). Electron transfer between the complexes involves two mobile electron carriers, PQ and plastocyanin (PC). The liposoluble PQ mediates electron flow from PSII to Cyt b6f complex, and the water-soluble lumenal protein PC mediates electron flow from Cyt b6f to PSI. ROS are formed in several sites of the PETC, including PSII, PSI, the PQ pool and the light-harvesting complexes (LHC).

\subsubsection{Formation of ${ }^{1} \mathrm{O}_{2}$ in Thylakoids}

The production of ${ }^{1} \mathrm{O}_{2}$ in plants occurs mainly by the interaction of $\mathrm{O}_{2}$ with excited states of Chls (where ${ }^{1} \mathrm{Chl}^{*}$ and ${ }^{3} \mathrm{Chl}$ are the excited singlet and triplet states of $\mathrm{Chl}$, respectively) via spin-conserved reactions, (Reactions (102) and (103)).

$$
\begin{aligned}
{ }^{1} \mathrm{Chl}^{*}+\mathrm{O}_{2} & \rightarrow{ }^{3} \mathrm{Chl}+{ }^{1} \mathrm{O}_{2} \\
{ }^{3} \mathrm{Chl}+\mathrm{O}_{2} & \rightarrow{ }^{1} \mathrm{Chl}+{ }^{1} \mathrm{O}_{2}
\end{aligned}
$$

Reaction (102) is negligible because the lifetime of ${ }^{1} \mathrm{Chl}^{*}$ is very short $\left(\sim 10^{-8} \mathrm{~s}\right)$ [137]. The lifetime of ${ }^{3} \mathrm{Chl}$ is around $10^{-3} \mathrm{~s}$ under anaerobic conditions [16,45]. In solution, the quenching of ${ }^{3} \mathrm{Chl}$ by $\mathrm{O}_{2}$ mostly occurs via ${ }^{1} \mathrm{O}_{2}$ generation with a second-order rate constant of $2 \times 10^{9} \mathrm{M}^{-1} \mathrm{~s}^{-1}$ [16]. ${ }^{3} \mathrm{Chl}$ is formed both in the LHCs and in the reaction centers (RC) of PSII and PSI. In the LHCs, ${ }^{3} \mathrm{Chl}$ is formed by intersystem crossing (ISC) from ${ }^{1} \mathrm{Chl}^{*}[114,159]$ and in the RCs by charge recombination. In PSII, the charge recombination between $\mathrm{P}_{680^{+}}$(the primary donor) and $\mathrm{Q}_{\mathrm{A}}{ }^{-}$(bound quinone) produces ${ }^{3} \mathrm{P} 680[114,160] .{ }^{3} \mathrm{P} 680$ is formed through a time-dependent "virtual triplet state" of the primary radical pair $\mathrm{P}_{680^{+}}$Pheophytin (Pheo) ${ }^{-}$[161]. A triplet state of P700, the primary donor of PSI, can also be formed via charge recombination [162].

Chls are mostly bound to LHCII and CP47 and CP43 proteins of PSII and the PSA A/B proteins of PSI. According to the high concentration of $\mathrm{Chl}$ in chloroplasts, around $60 \mathrm{mM}$ [163], a significant formation of ${ }^{3} \mathrm{Chl}$ via ISC in LHCs should be observed. However, there is no experimental evidence for the production of ${ }^{1} \mathrm{O}_{2}$ by the formation of ${ }^{3} \mathrm{Chl}$ in LHCs in vivo [114]. The formation of both ${ }^{3} \mathrm{Chl}$ and ${ }^{1} \mathrm{O}_{2}$ has been observed in isolated LHCs. The formation of ${ }^{1} \mathrm{O}_{2}$ was found in isolated LHCII with an electron paramagnetic resonance (EPR) measurement of 2,2,6,6-tetramethylpiperidine as a spin trap of ${ }^{1} \mathrm{O}_{2}[164,165]$. The appearance of long-lived ${ }^{3} \mathrm{Chl}$ in LHCs has been suggested to result from a small population of Chls that are substantially uncoupled from the matrix of LHC [166,167]. In a reconstructed Chl-protein complex, light-dependent ${ }^{1} \mathrm{O}_{2}$ formation is lower by a factor of four compared to free $\mathrm{Chl}$ [168]. As the isolated protein does not contain pigments that would effectively quench ${ }^{3} \mathrm{Chl}$ or ${ }^{1} \mathrm{O}_{2}$, it was suggested that the low ${ }^{1} \mathrm{O}_{2}$ formation is caused by the tight packing of $\mathrm{Chl}$ molecules inside the hydrophobic zone of the pigment-protein complex where the interaction of ${ }^{3} \mathrm{Chl}$ with $\mathrm{O}_{2}$ is limited [168]. The same situation can probably be realized in LHCs where Chls are tightly packed. Furthermore, LHCs contain carotenoids that efficiently quench ${ }^{3} \mathrm{Chl}$. In addition, the highly efficient transfer of excitation energy to the RC lowers the probability of ISC. Thus, ${ }^{1} \mathrm{O}_{2}$ can only be formed in LHCs in sites where $\mathrm{Chl}$ is weakly bound to the protein matrix and ${ }^{3} \mathrm{Chl}$ cannot be efficiently quenched by carotenoids.

The main source of ${ }^{1} \mathrm{O}_{2}$ appears to be $\mathrm{O}_{2}$ reacting with ${ }^{3} \mathrm{P} 680$. As in the case of antenna complexes, the formation of ${ }^{1} \mathrm{O}_{2}$ in the RC also depends on two factors: the lifetime of ${ }^{3} \mathrm{P} 680$ and the probability that $\mathrm{O}_{2}$ reacts with ${ }^{3} \mathrm{P} 680$. Assuming that the accessibility of $\mathrm{O}_{2}$ to ${ }^{3} \mathrm{P} 680$ is not changed significantly in different conditions; the yield of ${ }^{1} \mathrm{O}_{2}$ generation in the RC of PSII is mainly limited by the rate of ${ }^{3} \mathrm{P} 680$ formation. The formation of ${ }^{3} \mathrm{P} 680$ proceeds via charge separation and charge recombination. The formation of the excited singlet state ${ }^{1} \mathrm{P} 680^{*}$ is followed by the formation of the radical pair 
[P680 ${ }^{+} \mathrm{Pheo}^{-}$] [169]. In the next step, an electron from $\mathrm{Pheo}^{-}$is transferred to $\mathrm{Q}_{\mathrm{A}}$ and the pair $\left[\mathrm{P}_{680}{ }^{+} \mathrm{PheoQ}_{\mathrm{A}}{ }^{-}\right]$is formed. $\mathrm{P} 680^{+} \mathrm{Pheo}^{-}$can recombine to yield ${ }^{3} \mathrm{P} 680$, and the formation of ${ }^{1} \mathrm{O}_{2}$ with a high yield was observed in an isolated PSII RC lacking $\mathrm{Q}_{\mathrm{A}}$ and a functional donor side $[114,170,171]$. In thylakoid membranes where both the donor and acceptor side are functional, electron transfer to $\mathrm{Q}_{\mathrm{A}}$ and then to $\mathrm{Q}_{\mathrm{B}}$ prevents the formation of a long-lived primary radical pair [172]. However, pairs $\left[\mathrm{P}_{680}{ }^{+} \mathrm{Pheo}^{-}\right]$and $\left[\mathrm{P}_{680}{ }^{+} \mathrm{PheoQ}_{\mathrm{A}}{ }^{-}\right]$recombine when forward electron transfer is impossible. A fraction of the recombination of the pair $\left[\mathrm{P}_{680}{ }^{+} \mathrm{PheoQ}_{\mathrm{A}}{ }^{-}\right.$] produces $\left[\mathrm{P} 680^{+} \mathrm{Pheo}^{-} \mathrm{Q}_{\mathrm{A}}\right][173]$. Originally, $\left[\mathrm{P}_{680}{ }^{+} \mathrm{Pheo}^{-}\right]$is formed from $\left[{ }^{1} \mathrm{P} 680^{*} \mathrm{Pheo}\right]$ in a virtual singlet state ${ }^{1}\left[\mathrm{P} 680^{+} \mathrm{Pheo}^{-}\right]$that recombines to ${ }^{1} \mathrm{P} 680^{*}$. However, the long lifetime of the state $\left[\mathrm{P} 680^{+} \mathrm{PheoQ}_{\mathrm{A}}{ }^{-}\right]$destroys spin correlation, and therefore the recombination $\left[\mathrm{P}_{680}{ }^{+} \mathrm{Pheo}_{\mathrm{A}}{ }^{-}\right]$to $\left[\mathrm{P} 680^{+} \mathrm{Pheo}^{-} \mathrm{Q}_{\mathrm{A}}\right]$ often produces a virtual triplet state of the primary radical pair ${ }^{3}\left[\mathrm{P}_{680}{ }^{+} \mathrm{Pheo}^{-} \mathrm{Q}_{\mathrm{A}}\right]$ that has such a spin configuration that its recombination to an excited state of the primary donor produces a triplet, ${ }^{3} \mathrm{P} 680$ [174]. At $40 \mathrm{~K}$, the triplet state is mainly localized on the monomeric chlorophyll $\mathrm{Chl}_{\mathrm{D} 1}$ [175], while, at $25^{\circ} \mathrm{C}$, about $30 \%$ of this state is associated with the chlorophyll $\mathrm{P}_{\mathrm{D} 1}$ [176]. Thus, the site of ${ }^{1} \mathrm{O}_{2}$ production is mainly localized in the D1 protein of PSII. The formation of ${ }^{3} \mathrm{P} 680$ has a high probability because the two $\beta$-carotene molecules of the PSII RC are located far from $C_{\mathrm{D} 1}$ and $\mathrm{P}_{\mathrm{D} 1}$, at $19.9 \AA$ and around $30 \AA$, respectively [174,177]. Such a long distance does not allow for the direct quenching of ${ }^{3} \mathrm{P} 680$ [178].

${ }^{1} \mathrm{O}_{2}$ generation by photosynthetic samples has been measured using several methods, including the spin traps 2,2,6,6-tetramethylpiperidine [179-185], 2,2,6,6-tetramethyl-4-piperidone [183,184,186], 3-[N-( $\beta$-diethylaminoethyl)-N-dansyl]aminomethyl-2,2,5,5-tetramethyl-2,5-dihydro-1H-pyrrole [187-189], trans-1-(2'-methoxyvinyl)pyrene [190], histidine [191-193] and Singlet Oxygen Sensor Green [190,194,195]. The $1270 \mathrm{~nm}$ luminescence has been used to measure ${ }^{1} \mathrm{O}_{2}$ generation by isolated RC complexes [171,196]. The methods of ${ }^{1} \mathrm{O}_{2}$ measurement were recently reviewed [23].

The absolute rate of ${ }^{1} \mathrm{O}_{2}$ production can be estimated by comparing the signal strength (e.g., $1270 \mathrm{~nm}$ luminescence intensity, fluorescence yield, the yield of 2,2,6,6-tetramethylpiperidine-1yl) oxyl or EPR signal amplitude) with the signal obtained from a sensitizer chemical with a known ${ }^{1} \mathrm{O}_{2}$ yield. The main limitation of such an estimation is that, in photosynthetic material, ${ }^{1} \mathrm{O}_{2}$ may be effectively quenched before reacting with the sensor, and therefore all estimates of ${ }^{1} \mathrm{O}_{2}$ yield of photosynthetic material represent a lower limit. At the PPFD (photosynthetic photon flux density) of $2000 \mu \mathrm{mol} \mathrm{m} \mathrm{m}^{-2}$, histidine-dependent $\mathrm{O}_{2}$ uptake measurements showed that isolated PSII RCs (6 Chl/RC, [197]) produce ${ }^{1} \mathrm{O}_{2}$ at a rate of $4000 \mu \mathrm{mol}{ }^{1} \mathrm{O}_{2}(\mathrm{mg} \mathrm{Chl})^{-1} \mathrm{~h}^{-1}$, with a quantum yield 0.16 [191]. The yield of ${ }^{1} \mathrm{O}_{2}$ per ${ }^{3} \mathrm{P} 680$ is very high, as the quantum yield of ${ }^{3} \mathrm{P} 680$ formation in the same preparations was 0.3 [191,198]. 2,2,6,6-tetramethylpiperidine measurements at the same PPFD showed that isolated thylakoid membranes produced $3.73 \times 10^{-71} \mathrm{O}_{2}$ molecules per Chl molecule s ${ }^{-1}$, and the quantum yield of ${ }^{1} \mathrm{O}_{2}$ formation was $2.59 \times 10^{-4}$ [185]. Assuming 490 and 173 Chls per PSII and PSI, respectively [197], and a PSII:PSI ratio of 1 [199], the ratio of Chl to RC of PSII is 663 for a plant thylakoid membrane. Thus, isolated RCs and thylakoids produce, at PPFD $2000 \mu \mathrm{mol} \mathrm{m}^{-2} \mathrm{~s}^{-1}$, 21,600 and $0.89{ }^{1} \mathrm{O}_{2}$ per $\mathrm{RC}$ per $\mathrm{h}$, respectively. The large difference probably reflects differences in both the actual ${ }^{1} \mathrm{O}_{2}$ production rate and in the experimental method. In cyanobacteria illuminated at PPFD $2300 \mu \mathrm{mol} \mathrm{m} \mathrm{m}^{-2} \mathrm{~s}^{-1}$ in deuterium oxide, a decrease in $\mathrm{O}_{2}$ concentration in the presence of histidine showed ${ }^{1} \mathrm{O}_{2}$ production of approximately $27 \mu \mathrm{mol}(\mathrm{mg} \mathrm{Chl})^{-1} \mathrm{~h}^{-1}$ [192], suggesting that ${ }^{1} \mathrm{O}_{2}$ production in vivo may actually be of the same order of magnitude as the maximum rate of $\mathrm{O}_{2}$ evolution. A similar conclusion was drawn from measurements with isolated RCs [191].

Inactivation of the oxygen-evolving complex (OEC) of PSII leads to an increase in the redox potential of the $\mathrm{Q}_{\mathrm{A}} / \mathrm{Q}_{\mathrm{A}}{ }^{-}$pair, so that ${ }^{3} \mathrm{P} 680$ is no longer formed, and therefore virtually no ${ }^{1} \mathrm{O}_{2}$ can be produced through recombination reactions. However, even in this situation, some ${ }^{1} \mathrm{O}_{2}$ production can be expected because inactivation of the Mn-cluster leads to the oxidation of organic molecules, presumably by $\mathrm{P}_{680^{+}}$or TyrZ ${ }^{\bullet+}$ (the redox active tyrosine residue in the D1 protein), and the formation of organic hydroperoxides [200]. Recently, ${ }^{1} \mathrm{O}_{2}$ formation has been detected in Mn-depleted PSII 
membranes and correlated with $\mathrm{R}^{\bullet}$ formation on the donor side of PSII. It was proposed that ${ }^{1} \mathrm{O}_{2}$ is formed via the Russell mechanism, Reactions (9), (104) and (105) [201,202].

$$
\begin{gathered}
\left.{\mathrm{P} 680^{\bullet+}}^{(\text {or TyrZ }}{ }^{\bullet}\right)+\mathrm{RH} \rightarrow \mathrm{P} 680(\operatorname{TyrZ})+\mathrm{R}^{\bullet} \\
\mathrm{R}^{\bullet}+\mathrm{O}_{2} \rightarrow \mathrm{ROO}^{\bullet}
\end{gathered}
$$

Thus, the formation of ${ }^{1} \mathrm{O}_{2}$ associated with PETC can proceed both via the interaction of $\mathrm{O}_{2}$ with ${ }^{3} \mathrm{Chl}$ and decomposition of ROOOOR (Reaction (9)). The formation of ${ }^{1} \mathrm{O}_{2}$ can occur in at least three sites of PETC: (1) LHCs; (2) RC of PSII; and (3) the donor side of the PSII (Figure 1).

(A) Light-harvesting antenna

(B) PSII reaction center

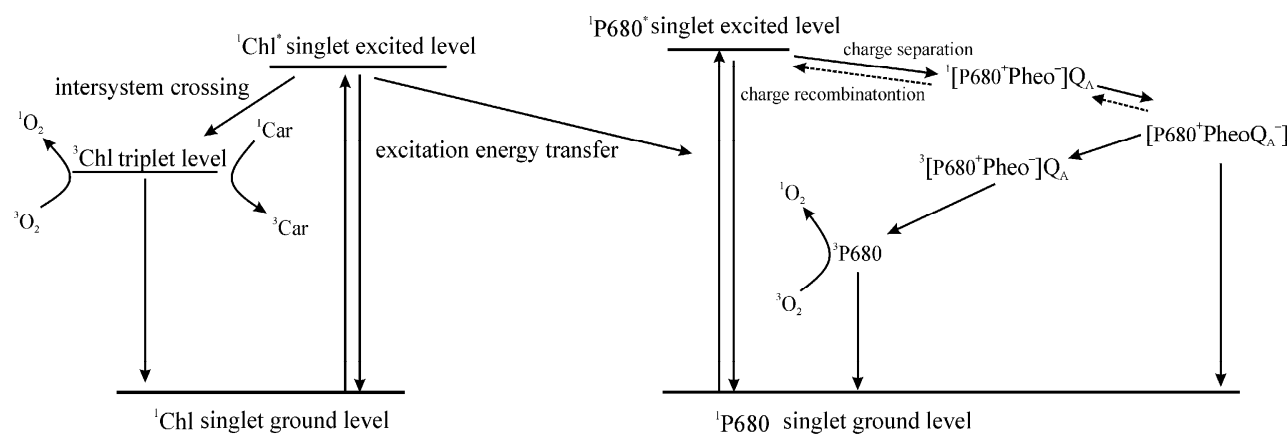

(C) PSII donor side

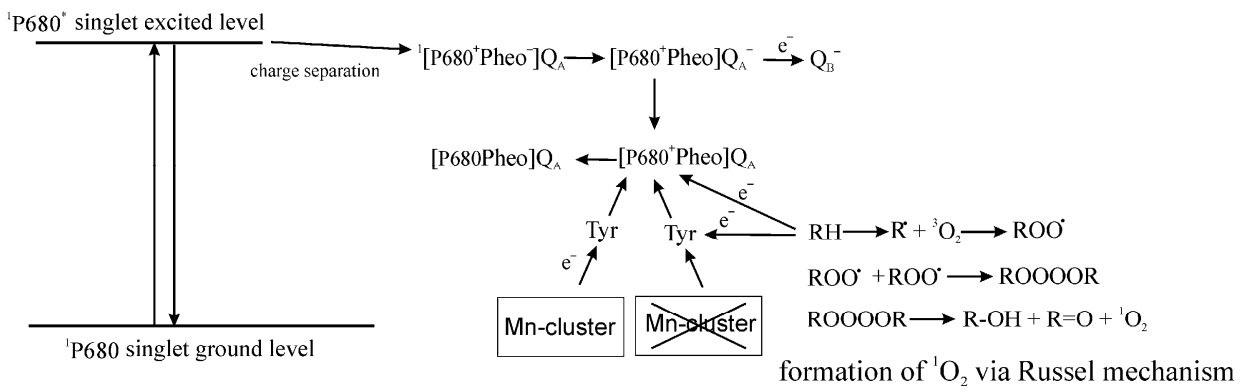

Figure 1. Singlet oxygen $\left({ }^{1} \mathrm{O}_{2}\right)$ generation in the antenna complex $(\mathbf{A})$ and in the reaction center of PSII via charge recombination reactions (B). Proposed mechanism for the formation of ${ }^{1} \mathrm{O}_{2}$ on the donor side of PSII via formation of organic peroxyl radicals (C). (A) In the antenna complex, the absorption of a photon by a molecule of $\mathrm{Chl}$ leads to the formation of a singlet excited state, ${ }^{1} \mathrm{Chl}^{*}$, that can transform to the triplet state ${ }^{3} \mathrm{Chl}$ via intersystem crossing. The formation of ${ }^{1} \mathrm{O}_{2}$ via intersystem crossing has been demonstrated to occur in isolated LHCII $[164,165]$. (B) In the reaction centre of PSII, $\left[\mathrm{P} 680^{+} \mathrm{Pheo}^{-}\right]$is originally formed via electron transfer from ${ }^{1} \mathrm{P} 680^{*}$ to Pheo in a virtual singlet state ${ }^{1}\left[\mathrm{P}_{680}{ }^{+} \mathrm{Pheo}^{-}\right]$that recombines to ${ }^{1} \mathrm{P} 680^{*}$. Charge recombination of $\left.\mathrm{P} 680^{+} \mathrm{PheoQ}_{\mathrm{A}}{ }^{-}\right]$causes the formation of ${ }^{1}\left[\mathrm{P}_{680}{ }^{+} \mathrm{Pheo}^{-}\right]$. The long lifetime of the state $\left[\mathrm{P}_{680}{ }^{+} \mathrm{PheoQ}_{\mathrm{A}}{ }^{-}\right]$destroys spin correlation, and therefore the recombination $\left[\mathrm{P}_{680}{ }^{+} \mathrm{PheoQ}_{\mathrm{A}}{ }^{-}\right]$to ${ }^{1}\left[\mathrm{P}_{680}{ }^{+} \mathrm{Pheo}^{-} \mathrm{Q}_{\mathrm{A}}\right]$ often produces a "virtual triplet state" of the primary radical pair, i.e., a radical pair with such a spin configuration that, in its recombination to an excited state of the primary donor, produces a triplet, ${ }^{3} \mathrm{P} 680$ [172-174]. (C) On the donor side of PSII, carbon centered radicals $\left(\mathrm{R}^{\bullet}\right)$ can be formed via the oxidation of lipids and proteins by $\mathrm{P}_{680^{+}}$if electron donation from Mn-cluster to $\mathrm{P} 680^{+}$does not function. $\mathrm{R}^{\bullet}$ are able to react with $\mathrm{O}_{2}$ to form peroxyl radical (ROO ${ }^{\bullet}$ ). Two peroxyl radicals react with each other to form linear tetraoxide (ROOOOR) that decomposes to ${ }^{1} \mathrm{O}_{2}$, carbonyl $(\mathrm{R}=\mathrm{O})$ and alcohols $(\mathrm{R}-\mathrm{OH})$ via the Russell mechanism [200-202]. 
PSI is not considered as a site of ${ }^{1} \mathrm{O}_{2}$ production, although theoretically the formation of ${ }^{3} \mathrm{Chl}$ can occur through charge recombination between $\mathrm{P} 700^{+}$and its electron acceptors. In isolated PSI membrane fragments, the recombination of $\left[\mathrm{P} 700^{+} \mathrm{A}_{0}{ }^{-}\right]$in the presence of dithionite was found to lead to the formation of the triplet state in PSI RCs with a quantum yield of approximately $30 \%$ [203]. In PSI particles, the flash-induced absorption changes at $820 \mathrm{~nm}$ are attributed to the formation of ${ }^{3} \mathrm{P} 700$ via conversion of the cation-anion biradical pair $\left[\mathrm{P} 700^{+} \mathrm{A}_{0}^{-}\right]$, with a yield approaching approximately $50 \%$ for $10 \mathrm{~ns}$ [204]. It was found that an increase in absorption at $820 \mathrm{~nm}$ is immediately followed by a multiphasic decay, including a major fast phase within 5-10 $\mu$ s and an intermediate phase (about $10-15 \%$ of the signal) within $2 \mathrm{~ms}$ [204]. Interestingly, $\mathrm{O}_{2}$ does not affect the decay. It can be speculated that this indicates that $\mathrm{O}_{2}$ is unable to efficiently quench ${ }^{3} \mathrm{P} 700$ in isolated PSI complexes and thereby produce ${ }^{1} \mathrm{O}_{2}$. It seems that, even if ${ }^{3} \mathrm{P} 700$ is formed in PSI, its quenching by $\mathrm{O}_{2}$ is minimized. It has also been suggested that charge recombination mainly occurs between $\mathrm{P} 700^{+}$and phylloquinone $\mathrm{A}_{1}{ }^{-}$, which minimizes the formation of ${ }^{3} \mathrm{P} 700$ triplet [205]. ${ }^{1} \mathrm{O}_{2}$ could be detected in PSII membrane fragments and PSII core complexes but not in PSI particles under the same conditions [181]. However, isolated PSI-LHCI supercomplexes of Arabidopsis produced ${ }^{1} \mathrm{O}_{2}$ at a rate of approximately one tenth of that measured in PSII-LHCII supercomplexes, and the rate of ${ }^{1} \mathrm{O}_{2}$ production by PSI-LHCI supercomplexes of the low-carotene szl1 mutant was approximately one fourth of that measured in PSII-LHCII supercomplexes [206]. There is also some evidence that the Fe-S centers of PSI produce ${ }^{1} \mathrm{O}_{2}$ [207].

\subsubsection{Oxygen Reduction in PETC}

The first evidence that $\mathrm{O}_{2}$ can accept electrons from PETC was observed by Mehler who found that $\mathrm{O}_{2}$ was consumed and $\mathrm{H}_{2} \mathrm{O}_{2}$ evolved under the illumination of broken chloroplasts [208]. Light-dependent $\mathrm{O}_{2}$ consumption as an indicator of Mehler's reaction has been reported also in vivo in algae and cyanobacteria $[209,210]$, and in isolated intact chloroplasts with the capacity for $\mathrm{CO}_{2}$ fixation [211,212]. Later studies have shown that $\mathrm{O}_{2}$ reduction occurs in different sites of the PETC (including both PSII and PSI), and illumination of thylakoids triggers the appearance of several forms of reduced $\mathrm{O}_{2}$, including $\mathrm{O}_{2}{ }^{\bullet-}, \mathrm{HO}_{2}{ }^{\bullet}, \mathrm{H}_{2} \mathrm{O}_{2}$ and $\mathrm{HO} \mathrm{C}^{\bullet}$ [213]. Because the acceptor side of PSI is the major site of $\mathrm{O}_{2}$ reduction in thylakoid membranes (see reviews [213-215]), the term "Mehler's reaction" has become synonymous with $\mathrm{O}_{2}$ reduction at the acceptor side of PSI, with $\mathrm{H}_{2} \mathrm{O}_{2}$ as the final product.

\subsubsection{Formation of Reduced Forms of Oxygen, $\mathrm{O}_{2}{ }^{\bullet-}, \mathrm{H}_{2} \mathrm{O}_{2}, \mathrm{HO}{ }^{\bullet}$, in PSII}

Although ${ }^{1} \mathrm{O}_{2}$ is the main ROS produced in PSII, $\mathrm{O}_{2}{ }^{\bullet-}, \mathrm{H}_{2} \mathrm{O}_{2}$ and $\mathrm{HO} \mathrm{O}^{\bullet}$ have also been found to be formed $[160,174]$. The contribution of PSII to the generation of $\mathrm{O}_{2}{ }^{\bullet-}$ in the intact chloroplast is generally small [216]. The $\mathrm{O}_{2}$ consumption associated with $\mathrm{O}_{2}$ reduction by PSII membranes capable of water-splitting is about $1 \mu \mathrm{mol} \mathrm{O}{ }_{2}(\mathrm{mg} \mathrm{Chl})^{-1} \mathrm{~h}^{-1}$ or $4 \mu \mathrm{mol} \mathrm{O}_{2}{ }^{\bullet-}(\mathrm{mg} \mathrm{Chl})^{-1} \mathrm{~h}^{-1}$ when $\mathrm{O}_{2}$ is the only electron acceptor [128]. The rate of $\mathrm{O}_{2}$ reduction is higher in disintegrated PSII complexes, which might suggest that, during stress conditions in vivo, when the structure and functional activity of PSII are disturbed, more $\mathrm{O}_{2}{ }^{\bullet-}, \mathrm{H}_{2} \mathrm{O}_{2}$, or $\mathrm{HO}^{\bullet}$ is produced in PSII $[217,218]$.

Of the redox active components of PSII, the Pheos and $\mathrm{Q}_{A}$ and $\mathrm{Q}_{B}$ may be able to reduce $\mathrm{O}_{2}$. Formation of $21 \mathrm{mmol} \mathrm{O}_{2}{ }^{\bullet-}(\mathrm{mg} \mathrm{Chl})^{-1} \mathrm{~h}^{-1}$, measured as an SOD-dependent cytochrome $c$ reduction, was observed in D1/D2/cytochrome b559 (cyt b559) complexes illuminated at $200 \mathrm{~W} \mathrm{~m}^{-2}$ in the presence of an artificial electron donor [217]. D1/D2/cyt b559 complexes lack $\mathrm{Q}_{\mathrm{A}}$ and the Mn-cluster, and therefore the result suggests that $\mathrm{Pheo}_{\mathrm{D} 1}{ }^{-}$(Pheo bound to the D1 protein) can be involved in the generation of $\mathrm{O}_{2}{ }^{\bullet-}$. However, the reaction of $\mathrm{O}_{2}$ with $\mathrm{Pheo}_{\mathrm{D} 1}{ }^{-}$is expected to be negligible in native RCs because of the very short lifetime of $\mathrm{Pheo}_{\mathrm{D} 1}{ }^{-}$(Table 2). The redox potential of $\mathrm{Pheo}_{\mathrm{D} 2} / \mathrm{Pheo}_{\mathrm{D} 2}{ }^{-}$ (Pheo bound to the $\mathrm{D} 2$ protein) is $80-210 \mathrm{mV}$ more negative than that of $\mathrm{Pheo}_{\mathrm{D} 1} / \mathrm{Pheo}_{\mathrm{D} 1}{ }^{-}$[219] and therefore, if $\mathrm{Pheo}_{\mathrm{D} 2}{ }^{-}$is formed, it would have a low enough redox potential to reduce $\mathrm{O}_{2}$. 
Table 2. Redox midpoint potentials and lifetimes of primary and secondary electron acceptors in PSII. The values were taken from [220-233].

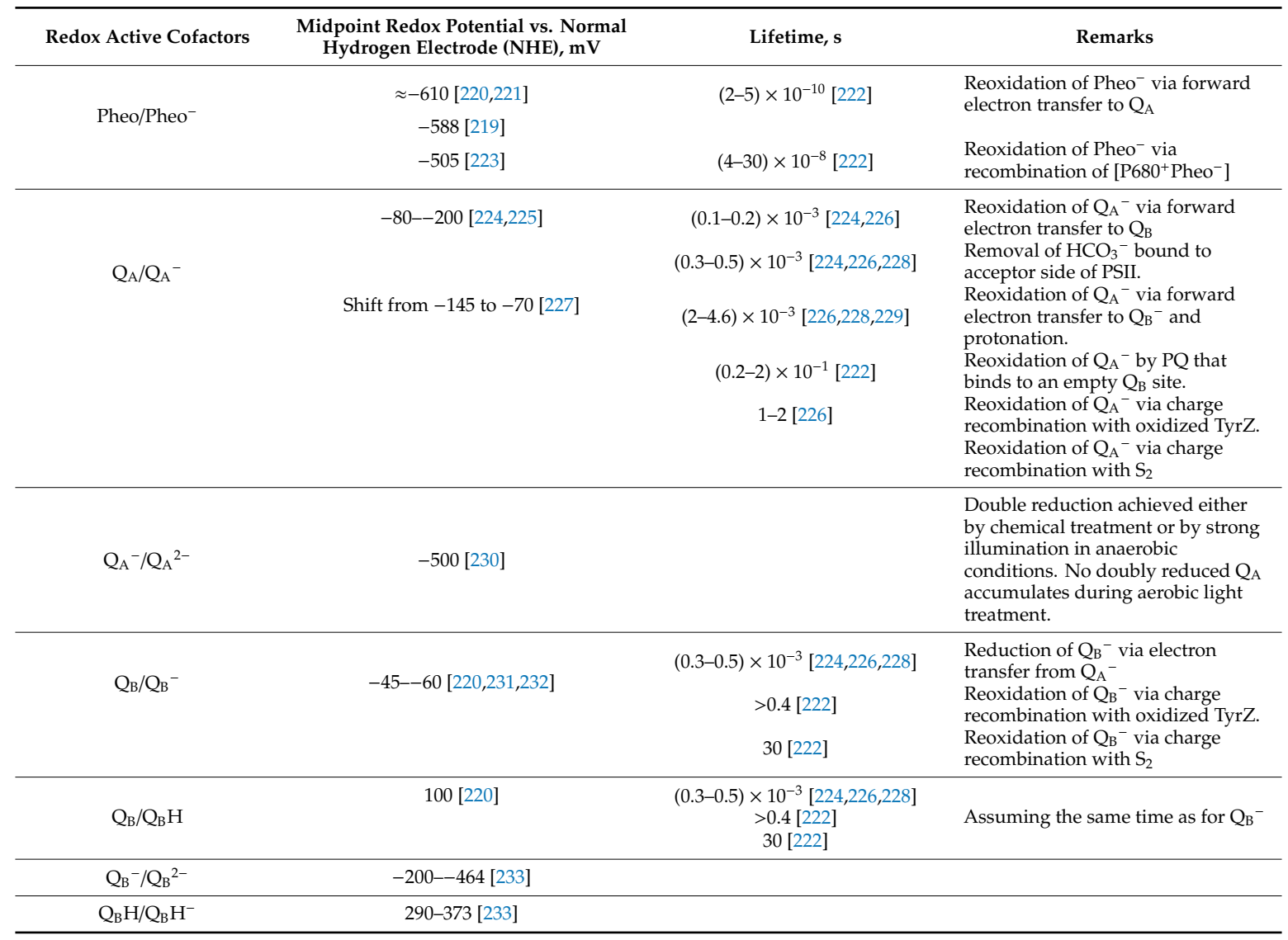

It is difficult to tell whether $\mathrm{Q}_{\mathrm{A}}{ }^{-}$can reduce $\mathrm{O}_{2}$, as the $E_{m}$ of the pair $\mathrm{O}_{2} / \mathrm{O}_{2}{ }^{--}$depends on the hydrophobicity of the environment $[12,54,58-60]$. If the environment of $\mathrm{O}_{2}$ is equivalent to an aqueous solution, $Q_{A}{ }^{-}$would have a low enough potential to reduce $\mathrm{O}_{2}$, whereas the redox potential of $\mathrm{O}_{2} / \mathrm{O}_{2}{ }^{--}$ in a hydrophobic environment is so low that $\mathrm{Q}_{\mathrm{A}}{ }^{-}$would be a poor reductant, although its lifetime is long enough for chemical reactions (Table 2). However, the participation of $\mathrm{Q}_{\mathrm{A}}{ }^{-}$in $\mathrm{O}_{2}$ reduction has been suggested [160,234-236]. $\mathrm{O}_{2}{ }^{\bullet-}$ production was found to increase in the presence of an inhibitor of electron transfer at the $\mathrm{Q}_{\mathrm{B}}$ site of PSII, DCMU (3-(3,4-di-chlorophenyl)-1,1-dimethyl urea), which was explained by the fact that DCMU increases the lifetime of $\mathrm{Q}_{\mathrm{A}}{ }^{-}$[236].

The production of $\mathrm{O}_{2}{ }^{--}$by both PSII with a functional Mn-cluster and by $\mathrm{Ca}^{2+}$ and $\mathrm{Cl}^{-}$-depleted PSII was detected using 5-diethoxyphosphoryl-5-methyl-1-pyrroline- $N$-oxide as a spin trap [235]. The generation of $\mathrm{O}_{2}{ }^{--}$at $\mathrm{Q}_{\mathrm{A}}$ may occur due to the flexibility of the redox potential of $\mathrm{Q}_{\mathrm{A}} / \mathrm{Q}_{\mathrm{A}}{ }^{-}$, that has been reported to range from -80 to $-200 \mathrm{mV}$ (Table 2) and to depend on the structural and functional state of PSII. A shift in the redox potential of the $\mathrm{Q}_{\mathrm{A}} / \mathrm{Q}_{\mathrm{A}}{ }^{-}$to a negative direction may cause the enhanced production of $\mathrm{O}_{2}{ }^{\bullet-}$ in a PsbS (a chloroplast-localized protein required for NPQ) knock-out mutant [237].

Double-reduced $\mathrm{Q}_{\mathrm{A}}$ has a very negative redox potential (Table 2) and can reduce $\mathrm{O}_{2}$. However, $\mathrm{Q}_{\mathrm{A}}{ }^{2-}$ can only be formed by chemical treatment or by strong illumination in the absence of $\mathrm{O}_{2}$ [238]. Thus, the involvement of $\mathrm{Q}_{\mathrm{A}}{ }^{2-}$ in $\mathrm{O}_{2}$ reduction seems unlikely.

Reduced $Q_{B}$ is less likely to reduce $\mathrm{O}_{2}$ than $\mathrm{Q}_{A}{ }^{-}$because the redox potential of $\mathrm{Q}_{\mathrm{B}} / \mathrm{Q}_{\mathrm{B}}{ }^{-}$is around $-45 \mathrm{mV}$ (Table 2). Although $\mathrm{Q}_{\mathrm{B}}{ }^{-}$has a much longer lifetime than $\mathrm{Q}_{\mathrm{A}}{ }^{-}$when electron donation from $\mathrm{Q}_{\mathrm{A}}{ }^{-}$does not occur (Table 2), the quinone in the $\mathrm{Q}_{\mathrm{B}}$ site is involved in proton-coupled electron transfer, and the redox potential of $\mathrm{Q}_{\mathrm{B}}{ }^{-}$becomes positive when the quinone is protonated (Table 2). The possible generation of $\mathrm{O}_{2}{ }^{\bullet-}$ by quinones at $\mathrm{Q}_{\mathrm{A}}$ and $\mathrm{Q}_{\mathrm{B}}$ pockets is illustrated in Figure 2A. 
(A)

Probable sites of oxygen reduction in PSII

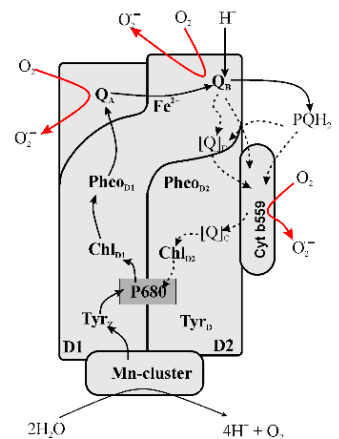

(B)

Formation of $\mathrm{H}_{2} \mathrm{O}_{2}$ and $\mathrm{HO}^{\circ}$ in PSII

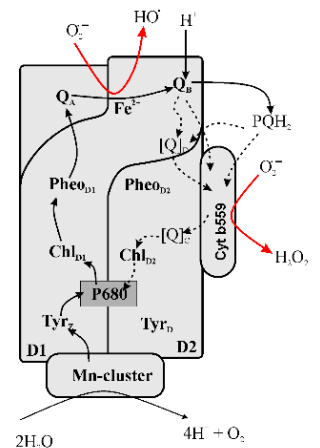

(C)

Formation of organic hydroperoxides in PSII

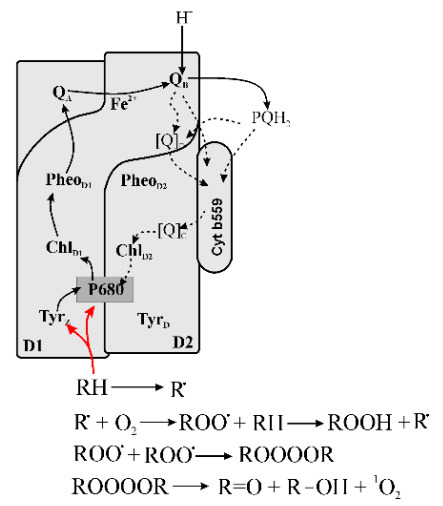

Figure 2. Formation of reactive oxygen species (ROS) in PSII. (A) Formation of superoxide $\left(\mathrm{O}_{2}{ }^{\bullet-}\right)$ can occur with the interaction of $\mathrm{O}_{2}$ with a semiquinone anion radicals at the $\mathrm{Q}_{A}$ and $\mathrm{Q}_{B}$ sites, when the electron flow from $Q_{B}$ to the PQ pool is limited. The low potential form of cyt b559 can reduce $\mathrm{O}_{2}$ to $\mathrm{O}_{2}{ }^{\bullet-}$ inside the thylakoid membrane [234-236]. (B) Formation of $\mathrm{H}_{2} \mathrm{O}_{2}$ and $\mathrm{HO} \bullet$. Cyt b559 can catalyze the formation of $\mathrm{H}_{2} \mathrm{O}_{2}$ inside the thylakoid membrane by a $\mathrm{O}_{2}{ }^{\bullet-}$ dismutation mechanism $[72,160]$. $\mathrm{O}_{2}{ }^{\bullet-}$ can reduce cyt b559 $\left(\mathrm{Fe}^{3+}\right)$ to cyt b559 $\left(\mathrm{Fe}^{2+}\right) . \mathrm{O}_{2}{ }^{\bullet-}+$ cyt b559 $\left(\mathrm{Fe}^{3+}\right) \Delta \mathrm{O}_{2}+$ cyt b559 $\left(\mathrm{Fe}^{2+}\right)$. The following interaction of $\mathrm{HO}_{2}{ }^{\bullet}$ with Cyt b559 $\left(\mathrm{Fe}^{2+}\right)$ leads to the formation of a ferric-hydroperoxo intermediate of cyt b559 ( $\left.\mathrm{Fe}^{3+}-\mathrm{OOH}\right)$ which can spontaneously decompose to cyt b559 $\left(\mathrm{Fe}^{3+}\right)$ and $\mathrm{H}_{2} \mathrm{O}_{2} . \mathrm{HO}_{2}{ }^{\bullet}+$ cyt b559 $\left(\mathrm{Fe}^{2+}\right) \rightarrow$ cyt b559 $\left(\mathrm{Fe}^{3+}-\mathrm{OOH}\right)+\mathrm{H}^{+} \rightarrow$ cyt b559 $\left(\mathrm{Fe}^{3+}\right)+\mathrm{H}_{2} \mathrm{O}_{2}$. The formation of $\mathrm{H}_{2} \mathrm{O}_{2}$ in a cyt b559-dependent way requires the protonation of $\mathrm{O}_{2}{ }^{\bullet-}$ to form $\mathrm{HO}_{2}{ }^{\bullet}$. The interaction of $\mathrm{O}_{2}{ }^{\bullet-}$ with $\mathrm{Fe}^{2+}$ on the acceptor side of PSII can result in the formation of a ferric-peroxo intermediate $\left[\mathrm{Fe}^{3+}-\mathrm{OO}^{-}\right]$that can be protonated to a ferric-hydroperoxo intermediate $\left[\mathrm{Fe}^{3+}-\mathrm{OOH}\right] . \mathrm{O}_{2}{ }^{\bullet-}+\left[\mathrm{Fe}^{2+}\right]$ $\rightarrow\left[\mathrm{Fe}^{3+}-\mathrm{OO}^{-}\right]+\mathrm{H}^{+} \rightarrow\left[\mathrm{Fe}^{3+}-\mathrm{OOH}\right] .\left[\mathrm{Fe}^{3+}-\mathrm{OOH}\right]$ can be reduced by an electron from $\mathrm{Q}_{\mathrm{A}}^{-}$, which causes its decomposition to a ferric-oxo intermediate $\left[\mathrm{Fe}^{3+}-\mathrm{O}^{-}\right]$and $\mathrm{HO}^{\bullet} \cdot \mathrm{Q}_{\mathrm{A}}{ }^{-}+\left[\mathrm{Fe}^{3+}-\mathrm{OOH}\right] \rightarrow$ $\mathrm{Q}_{\mathrm{A}}+\left[\mathrm{Fe}^{3+}-\mathrm{O}^{-}\right]+\mathrm{HO}^{\bullet}$. (C) Formation of organic hydroperoxides on the donor side of PSII. Charge separation when the OEC is inactive leads to the formation of $\mathrm{P}_{680^{\bullet+}}$ and TyrZ ${ }^{\bullet}$ which have a long lifetime and are therefore able to interact with surrounding molecules such as Chls, carotenoids and amino acids. The interaction of $\mathrm{P}_{680^{\bullet+}}$ or TyrZ ${ }^{\bullet}$ with an organic molecule (RH) can proceed via a radical chain mechanism [200-202].

In untreated chloroplasts, cyt b559 is found in high potential (HP), intermediate potential (IP) and low potential (LP) forms [239]. A very low potential (VLP) form was observed in isolated RCs of PSII [240] and seems to be an isolation artefact. The $E_{m}$ values of the three forms of cyt b559 are (see review [239]):

- $\quad$ HP form: 350-450 mV;

- IP form: 150-260 mV;

- LP form: $-50-110 \mathrm{mV}$.

The ratio between the forms is variable and depends on isolation procedure. For example, modification of the donor side of PSII by removal of the Mn-cluster leads to the conversion of the HP form to the LP form [241]. In intact chloroplasts, the ratio of HP to LP forms was found to be 58 to 31 , with respective redox potentials of 383 and $77 \mathrm{mV}$ [242]. In untreated PSII membranes, the ratio HP:IP:LP was estimated as 44:31:25, with redox potentials of 375, 228 and $57 \mathrm{mV}$, respectively [243,244]. In isolated thylakoid membranes, $85 \%$ of cyt b559 was in the HP form [245]. The values measured from intact chloroplasts may best reflect the situation in vivo.

Cyt b559 has been suggested to be involved in cyclic electron transfer around PSII, where PQ bound in the specific binding pockets $\mathrm{Q}_{\mathrm{D}}$ and $\mathrm{Q}_{\mathrm{C}}$ acts as both an electron donor and an electron acceptor [239]. This idea is supported by the finding that $\mathrm{PQH}_{2}$ can reduce cyt b559 in both intact 
chloroplasts [246] and in PSII RC preparates [247]. The photoreduction of cyt b559 was found in isolated thylakoids and was inhibited by DCMU [248]. In Triton X-100-solubilized PSII particles, which mostly have the LP form of cyt b559, short-chain PQs stimulated both photoreduction and dark oxidation of cyt b559 [248].

The involvement of cyt b559 in electron transfer reactions of PSII indicates that cyt b559 is a redox active component that can potentially reduce $\mathrm{O}_{2}$. It has been shown that fast, dark reoxidation of the PQ pool in thylakoid membranes is not caused by direct oxidation of $\mathrm{PQH}_{2}$ by $\mathrm{O}_{2}$, and it was suggested that the LP form of cyt b559 can transfer an electron to $\mathrm{O}_{2}$ and thereby act as a $\mathrm{PQH}_{2}: \mathrm{O}_{2}$ oxidoreductase [248]. In isolated PSII membranes, $\mathrm{O}_{2}$ has been shown to compete with prenylquinones for oxidation of the LP form of cyt b559, suggesting that LP cyt b559 can form $\mathrm{O}_{2}{ }^{\bullet-}$ [249]. Exogenously added short-chain quinones significantly enhance $\mathrm{O}_{2}{ }^{\bullet-}$ production by PSII [245]. This finding was interpreted to indicate that these quinones reduce LP cyt b559, which then undergoes spontaneous autoxidation, resulting in $\mathrm{O}_{2}{ }^{\bullet-}$ formation.

However, the reduction in $\mathrm{O}_{2}$ by LP cyt b559 is thermodynamically unfavorable, taking into account that the redox potential of the LP form is usually within $20-110 \mathrm{mV}$ in untreated membranes, although sometimes an LP form with a negative potential is observed [239]. To explain $\mathrm{O}_{2}$ reduction via an apparently thermodynamically unlikely reaction, it has been suggested that the $E_{0}{ }^{\prime}$ of $\mathrm{O}_{2} / \mathrm{O}_{2}{ }^{\bullet-}$ should be calculated by the Nernst equation, due to differences in concentrations of $\mathrm{O}_{2}$ and $\mathrm{O}_{2}{ }^{\bullet-}$ [160]. According to the Nernst equation, and assuming concentrations of $250 \mu \mathrm{M}$ and $500 \mathrm{nM}$ for $\mathrm{O}_{2}$ and $\mathrm{O}_{2}{ }^{\bullet-}$, respectively, the redox potential becomes close to $0 \mathrm{mV}$. Thus, the electron transfer from LP cyt 559 to $\mathrm{O}_{2}$ becomes feasible. However, it seems that the comparison of standard middle point potentials is more correct, as cyt b559 is bound within a protein matrix, and a considerable difference in the local concentrations of $\mathrm{O}_{2}$ and $\mathrm{O}_{2}{ }^{\bullet-}$ is questionable.

A possible alternative solution is that cyt b559 mediates the formation of semiquinones at $Q_{D}$ and $\mathrm{Q}_{\mathrm{C}}$ sites. Experimental evidence of the reduction in $\mathrm{O}_{2}$ by a loosely bound plastosemiquinone anion radical $\left(\mathrm{PQ}^{\bullet-}\right)$ at the $\mathrm{Q}_{\mathrm{C}}$ site was provided by Yadav et al. [250]. The authors showed that $\mathrm{PQ}^{\bullet-}$ can be formed by a one electron reduction in $P Q$ at the $Q_{B}$ site and one electron oxidation of $\mathrm{PQH}_{2}$ by cyt b559 at the $Q_{C}$ site. Because a PQ molecule has been crystallographically detected in the $Q_{C}$ site [251], PQ might be tightly bound within the $Q_{C}$ pocket and act as an electron carrier from cyt b559 to P680. The environment of the $Q_{D}$ pocket is probably flexible and lipophilic and can facilitate a $\mathrm{PQ} / \mathrm{PQH}_{2}$ exchange. In this case, the $\mathrm{PQ}$ pool can serve as an electron donor for cyt b559. It might be proposed that the formation of $\mathrm{O}_{2}{ }^{\bullet-}$ in a cyt b559-dependent pathway couples cyt b559 and quinones and depends on the redox state of the PQ pool (Figure 2A). The rate constant of cyt b559-mediated reduction of $\mathrm{O}_{2}$ was estimated to be about $10^{-6} \mathrm{M}^{-1} \mathrm{~s}^{-1}$ inside the thylakoid membrane, assuming that the reaction proceeds as a second-order chemical reaction [252].

The formation of $\mathrm{O}_{2}{ }^{\bullet-}$ in PSII causes the formation of $\mathrm{H}_{2} \mathrm{O}_{2}$ via spontaneous dismutation (Reaction (5)) [234] or via a cyt b559-dependent catalytic reaction [253]. In isolated RCs of PSII, cyt b559 was found to exhibit SOD activity [217]. As proposed by Pospišil [160], the catalytic formation of $\mathrm{H}_{2} \mathrm{O}_{2}$ by cyt b559 proceeds as a two-step reduction-oxidation reaction involving two molecules of $\mathrm{O}_{2}{ }^{\bullet-}$. The first step is reduction of cyt b559 $\left(\mathrm{Fe}^{3+}\right)$ to cyt b559 $\left(\mathrm{Fe}^{2+}\right)$, Reaction (106). The second step is the oxidation of cyt b559 $\left(\mathrm{Fe}^{2+}\right)$ by $\mathrm{HO}_{2}{ }^{\bullet}$, the protonated form of $\mathrm{O}_{2}{ }^{\bullet-}$, with formation of cyt b559 $\left(\mathrm{Fe}^{3+}\right.$ ) and $\mathrm{H}_{2} \mathrm{O}_{2}$, Reaction (107).

$$
\begin{gathered}
\mathrm{O}_{2}^{\bullet-}+\operatorname{cytb559}\left(\mathrm{Fe}^{3+}\right) \rightarrow \mathrm{O}_{2}+\text { cyt b559 }\left(\mathrm{Fe}^{2+}\right) \\
\mathrm{HO}_{2}^{\bullet}+\text { cyt b559 }\left(\mathrm{Fe}^{2+}\right) \rightarrow \mathrm{H}_{2} \mathrm{O}_{2}+\text { cyt b559 }\left(\mathrm{Fe}^{3+}\right)
\end{gathered}
$$

According to this mechanism, the catalytic disproportionation of $\mathrm{O}_{2}{ }^{--}$should be $\mathrm{pH}$-dependent because the protonated form of $\mathrm{O}_{2}{ }^{\bullet-}$ is needed.

In addition to its formation by the dismutation of $\mathrm{O}_{2}{ }^{\bullet-}, \mathrm{H}_{2} \mathrm{O}_{2}$ might also appear during incomplete oxidation of $\mathrm{H}_{2} \mathrm{O}$ by the Mn-cluster. It has been suggested that incomplete oxidation of $\mathrm{H}_{2} \mathrm{O}$ can occur 
during the two-electron oxidation of water by the Mn-cluster at the transition from the $\mathrm{S}_{2}$ state to the $\mathrm{S}_{0}$ state [234,254]. However, the two-electron oxidation of water during the transition of the Mn-cluster from $\mathrm{S}_{3}$ to $\mathrm{S}_{1}$ does not result in the formation of $\mathrm{H}_{2} \mathrm{O}_{2}$ [255].

In PSII, the Fenton mechanism involving a metal (M) cation, Reaction (58), can also function, leading to the formation of $\mathrm{HO}^{\bullet}$.

In PSII, $\mathrm{HO}^{\bullet}$ can be formed both in the dark and in the light. $\mathrm{HO}^{\bullet}$ formation was shown when PSII membrane particles were heated in the dark [256]. The authors suggested that this process is associated with heat-induced changes of the PSII donor side and proceeds via the Fenton mechanism. The formation of $\mathrm{HO}^{\bullet}$ was suppressed by $\mathrm{CAT}$ and metal chelators, indicating that the appearance of $\mathrm{HO}^{\bullet}$ is related to the decomposition of $\mathrm{H}_{2} \mathrm{O}_{2}$. However, a high concentration of CAT, around $5000 \mathrm{U} / \mathrm{mL}$, was required to suppress the appearance of $\mathrm{HO}^{\bullet}$. Exogenous calcium and chloride prevented the appearance of $\mathrm{HO}^{\bullet}$. Furthermore, no $\mathrm{HO}^{\bullet}$-related EPR signal was observed after removal of the Mn-cluster by Tris-treatment of PSII membranes [257]. These data confirm that the Mn-cluster is likely involved in $\mathrm{HO}^{\bullet}$ formation in PSII under heat stress in the dark.

The light-dependent formation of $\mathrm{HO}^{\bullet}$ occurs in untreated PSII membranes [235,258-260]. Experimental results suggest that $\mathrm{HO}^{\bullet}$ can be produced in the light by two pathways: firstly, by the well-known Fenton mechanism and secondly, by the reduction of a peroxide bound to the non-heme iron on the acceptor side of PSII [72]. The formation of $\mathrm{HO}^{\bullet}$ at the non-heme iron is initiated by the binding of $\mathrm{O}_{2}{ }^{\bullet-}$ and formation of an $\mathrm{O}_{2}{ }^{\bullet-}$-iron complex that can be protonated to a ferric-hydroperoxo complex, Reactions (49) and (50). The ferric-hydroperoxo complex can be decomposed via reduction by $\mathrm{Q}_{\mathrm{A}}{ }^{-}$with the formation of $\mathrm{HO}^{\bullet}$ and a ferric-oxo $\left(\left(\mathrm{Fe}^{3+}\right)-\mathrm{O}^{-}\right)$complex, Reaction (108).

$$
\mathrm{L}-\left(\mathrm{Fe}^{3+}\right)-\mathrm{OOH}+\mathrm{Q}_{\mathrm{A}}^{-} \rightarrow \mathrm{L}-\left(\mathrm{Fe}^{3+}\right)-\mathrm{O}^{-}+\mathrm{HO}^{\bullet}+\mathrm{Q}_{\mathrm{A}}
$$

where L is a ligand. Reaction (108) can be considered as a Fenton reaction proceeding with a bound hydroperoxide. The possible sites of formation in PSII are shown in Figure 2B.

The formation of bound hydroperoxides has been found to occur on the donor side of the PSII (Figure 2C). The mechanism is associated with the formation of a long-lived species, having a high positive redox potential in PSII. In PSII membranes holding an intact Mn-cluster, the $\mathrm{O}_{2}$ consumption rate is very low, around $1 \mu \mathrm{mol} \mathrm{O} 2\left(\mathrm{mg}\right.$ of $\mathrm{Chl}^{-1} \mathrm{~h}^{-1}$ [128], but the rate becomes 6-fold higher in alkaline-treated and Mn-depleted PSII membranes [261]. $\mathrm{O}_{2}$ consumption was found to be associated, at least partially, with the generation of a component with positive charge(s) on the donor side of PSII, as the electron donors diphenylcarbazide and ferrocyanide suppressed the rate of $\mathrm{O}_{2}$ consumption caused by disruption of the donor side of PSII. A further study revealed that the removal of Mn from the OEC of PSII leads to $\mathrm{O}_{2}$ photoconsumption with a maximum at the first flash, with a yield comparable to the yield of $\mathrm{O}_{2}$ evolution on the third flash measured in the PSII samples before Mn removal [262]. Inactivation of the OEC can lead to the formation of both $\mathrm{P} 680^{\bullet+}$ and TyrZ $\mathrm{Z}^{\bullet}$ In the absence of electron donation from the OEC, both will have a long lifetime, and will therefore be able to interact with surrounding molecules such as Chls, carotenoids and amino acids. Based on these results, it has been proposed that the formation of peroxides on the donor side of PSII proceeds via a radical chain mechanism, starting with ${\mathrm{P} 680^{\bullet+}}^{\bullet}$ or TyrZ ${ }^{\bullet}$ ), Reactions (104), (105) and (109).

$$
\mathrm{ROO}^{\bullet}+\mathrm{RH} \rightarrow \mathrm{ROOH}+\mathrm{R}^{\bullet}
$$

The evidence of $\mathrm{ROOH}$ production on the donor side of PSII was obtained using the specific fluorescence probe SPY-HP [200]. In this work, highly lipophilic peroxides (LOOH) and relatively hydrophilic ones $(\mathrm{ROOH})$, were distinguished by the rate of reaction with Spy-HP. The formation rates of both $\mathrm{LOOH}$ and $\mathrm{ROOH}$ were estimated to be $0.022 \mu \mathrm{mol} \mathrm{LOOH}(\mu \mathrm{mol} \mathrm{RC})^{-1} \mathrm{~s}^{-1}$ and $1.11 \mu \mathrm{mol}$ $\mathrm{ROOH}(\mu \mathrm{mol} \mathrm{RC})^{-1} \mathrm{~s}^{-1}$, respectively [200]. The formation of carbon centred radicals, in turn, was found in PSII membranes with EPR spin-trapping technique when PSII membranes were treated by high light and heating. It has recently been found that exposure of Mn-depleted PSII membranes to 
high light results in the formation of protein radicals located mainly in the D1, D2, CP43 and CP47 proteins [202]. The formation of protein radicals is suppressed by diphenylcarbazide, indicating that protein radicals were formed by the oxidation of proteins by $\mathrm{P} 680^{\bullet+}$ or TyrZ ${ }^{\bullet}$. The formation of protein radicals was correlated with the formation of hydroperoxides measured with the SPY-HP probe. The formation of $\mathrm{R}^{\bullet}$ can initiate chain propagation reactions, and thereby lead to accumulation of $\mathrm{ROOH}$ (Reactions (105) and (109)).

\subsubsection{Formation of Reduced Forms of Oxygen, $\mathrm{O}_{2}{ }^{\bullet-}, \mathrm{H}_{2} \mathrm{O}_{2}, \mathrm{HO}^{\bullet}$, in PSI}

The acceptor side of PSI is believed to be the predominant site of $\mathrm{O}_{2}$ reduction in thylakoid membranes, as $\mathrm{O}_{2}$ reduction depends on the PSI activity (see reviews [12,213-215]). It has been shown that both the photoreduction of cytochrome $c$ and photooxidation of epinephrine, which have been used as traps for $\mathrm{O}_{2}^{\bullet-}$, were inhibited by SOD. This indicates that the reduction in $\mathrm{O}_{2}$ proceeds via univalent reduction, and $\mathrm{O}_{2}{ }^{\bullet-}$ was identified as the primary product in illuminated thylakoids [124,263]. The predominant role of PSI in $\mathrm{O}_{2}$ reduction was shown in experiments with specific inhibitors that block PETC at different sites, and using a PSI-deficient mutant. The photoproduction of $\mathrm{O}_{2}{ }^{--}$in thylakoids is inhibited by DCMU and can be restored by the addition of $\mathrm{AscH}_{2}$ and $N, N, N^{\prime}, N^{\prime}$-tetramethyl-p-phenylenediamine, to provide electron donation to PC and P700, respectively $[124,263,264]$. This indicates that the contribution of PSII to the photoproduction of $\mathrm{O}_{2}$ in thylakoids is small. A slight influence of $\mathrm{O}_{2}$ on the steady-state level of Chl fluorescence in a PSI-deficient mutant of Oenothera $s p$. was attributed to insignificant leakage of electrons from PETC to $\mathrm{O}_{2}$, due to the suppression of Mehler's reaction [265]. On the other hand, a significant rate of $\mathrm{O}_{2}$ reduction by thylakoids was observed in the presence of dibromothymoquinone (DBMIB) and dinitrophenylether of 2-iodo-4-nitrothymol (DNP-INT), inhibitors of $\mathrm{PQH}_{2}$ oxidation by Cyt b6f, $[128,266]$. It was found that the contribution of other sites of PETC, besides PSI, to $\mathrm{O}_{2}$ reduction increased with an increase in light intensity, and at high intensities achieved $60 \%$ of total $\mathrm{O}_{2}$ reduction in PETC. These data suggest that PSI is not the only site of $\mathrm{O}_{2}$ reduction in thylakoid membranes, but other sites of PETC can contribute to $\mathrm{O}_{2}$ reduction [128]. Thus, experiments with isolated PSI membranes can provide more correct measurements of activity of PSI in the photoproduction of $\mathrm{O}_{2}^{\bullet-}$.

The electron transport chain within PSI (Figure 3) consists of two quasisymmetrical branches (A and $B$ ) containing six $C h l$, two phylloquinones $\left(A_{1}\right)$, and three $4 F e-4 S$ clusters $\left(F_{X}, F_{A}\right.$, and $\left.F_{B}\right)$. Two Chl $a$ molecules have been assigned to the spectroscopically characterized primary acceptor $\mathrm{A}_{0}$. Another pair of $\mathrm{Chl} a$ molecules is located between P700 and $\mathrm{A}_{0}$ and assigned as accessory Chls that may participate in excitation and/or electron transfer (for more details, see review [267]).

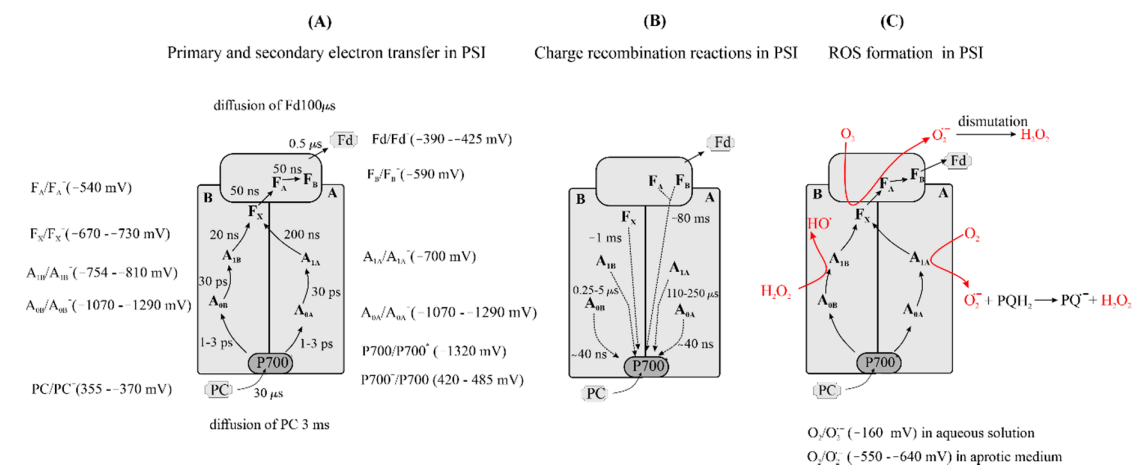

Figure 3. (A) Forward electron transfer chain, lifetimes and midpoint redox potentials of the cofactors of PSI; (B) charge recombination reactions and recombination lifetimes of the cofactors of PSI; the values were taken from [145,268-271]; (C) possible means of ROS formation in PSI [152,266,272-275]. PC is plastocyanin; $\mathrm{P} 700$ is a dimer of $\mathrm{Chl} a$ molecules, the primary electron donor; $\mathrm{A}_{0 \mathrm{~A}}$ and $\mathrm{A}_{0 \mathrm{~B}}$ are $\mathrm{Chl} a$ molecules located in branches $A$ and $B$, respectively, both act as primary electron acceptors; $A_{1 A}$ and $A_{1 B}$ are phylloquinone molecules located in branch $\mathrm{A}$ and $\mathrm{B}$, respectively, both acting as electron acceptors; $\mathrm{F}_{\mathrm{X}}$, a $4 \mathrm{Fe}-4 \mathrm{~S}$ cluster, a secondary electron acceptor; $\mathrm{F}_{\mathrm{A}}$ and $\mathrm{F}_{\mathrm{B}}, 4 \mathrm{Fe}-4 \mathrm{~S}$ clusters, terminal electron acceptors. 
The mechanism of $\mathrm{O}_{2}$ reduction in PSI is still under debate. It was suggested that $\mathrm{O}_{2}{ }^{\bullet-}$ production within the thylakoid membranes most likely occurs via autooxidation of the membrane-bound primary electron acceptors in PSI, possibly $4 \mathrm{Fe}-4 \mathrm{~S}$ clusters $\left(\mathrm{F}_{\mathrm{X}}, \mathrm{F}_{\mathrm{A}}\right.$, and $\left.\mathrm{F}_{\mathrm{B}}\right)$ [152]. The $E_{m}$ of $\mathrm{F}_{\mathrm{A}} / \mathrm{F}_{\mathrm{A}}{ }^{-}$and $\mathrm{F}_{\mathrm{B}} / \mathrm{F}_{\mathrm{B}}{ }^{-}$ and $\mathrm{F}_{\mathrm{X}} / \mathrm{F}_{\mathrm{X}}{ }^{-}$vs. NHE were estimated to be $-479,-539$, and $-650 \mathrm{mV}$, respectively (Figure 3) [145]. The reduction in $\mathrm{O}_{2}$ by $\mathrm{F}_{X}$ is thermodynamically favorable but kinetically less likely than a reduction in $\mathrm{O}_{2}$ by $\mathrm{F}_{\mathrm{A}}{ }^{-}$or $\mathrm{F}_{\mathrm{B}}{ }^{-}$, as the lifetime of $\mathrm{F}_{\mathrm{X}}{ }^{-}$is less than 50 ns (Figure 3). When $\mathrm{F}_{\mathrm{A}}$ and $\mathrm{F}_{\mathrm{B}}$ clusters are reduced, the lifetime of $\mathrm{F}_{\mathrm{X}}$ is limited by charge recombination $\left[\mathrm{P} 700^{+} \mathrm{F}_{\mathrm{X}}{ }^{-}\right]$and estimated to be $\sim 250 \mu \mathrm{s}$ [276].

Electron transfer from $\mathrm{F}_{\mathrm{B}}{ }^{-}$to $\mathrm{Fd}$ occurs within $1 \mu \mathrm{s}$, and therefore the oxidation of $\mathrm{F}_{\mathrm{A}}{ }^{-}$and $\mathrm{F}_{\mathrm{B}}{ }^{-}$by $\mathrm{O}_{2}$ in an aqueous region is not kinetically favorable in the presence of oxidized Fd (Figure 3). The lifetimes of $\mathrm{F}_{\mathrm{A}}{ }^{-}$and $\mathrm{F}_{\mathrm{B}}{ }^{-}$become much longer if $\mathrm{Fd}$ is mostly reduced or its diffusion to the $\mathrm{F}_{\mathrm{A}}$ and $\mathrm{F}_{\mathrm{B}}$ sites is limited. The charge recombination of $\left[\mathrm{P} 700^{+} \mathrm{F}_{\mathrm{A}}{ }^{-}\right]$and $\left[\mathrm{P} 700^{+} \mathrm{F}_{\mathrm{B}}{ }^{-}\right]$has a lifetime of about $50 \mathrm{~ms}$ when no extrinsic electron acceptors and donors are present [277]. The rate of $\mathrm{O}_{2}{ }^{\bullet-}$ production by PSI in both isolated thylakoids and isolated PSI complexes ranges from 15 to $30 \mu \mathrm{mol}{ }_{2}{ }^{\bullet-}$ (mg $\mathrm{Chl})^{-1} \mathrm{~h}^{-1}$, corresponding to $2.5-4.5 \mathrm{O}_{2}{ }^{\bullet-}$ per P700 s${ }^{-1}$ if the ratio of P700 to total amount of Chl is 1 to 600 for isolated thylakoid membranes $[124,264]$. The rate of $\mathrm{O}_{2}{ }^{\bullet-}$ production is at least one order of magnitude higher in PSI subchloroplast fragments in the presence of the surfactant Triton X-100 than in its absence [278]. The $\mathrm{K}_{\mathrm{m}}$ value for $\mathrm{O}_{2}$ in photoreduction by PSI was estimated to be $2-3 \mu \mathrm{M}$ in both thylakoid membranes and PSI subchloroplast fragments and the second order rate constant for $\mathrm{O}_{2}$ reduction by the electron acceptors of PSI was calculated to be $1.5 \times 10^{7} \mathrm{M}^{-1} \mathrm{~s}^{-1}$ [278]. In another work, the $\mathrm{K}_{\mathrm{m}}$ value for $\mathrm{O}_{2}$ was estimated to equal to $\sim 8$ and $\sim 3 \mu \mathrm{M}$ for thylakoids, in the absence and in the presence of Triton X-100, respectively [279].

Experiments with $\mathrm{O}_{2}{ }^{\bullet-}$-dependent protein iodination showed that $\mathrm{O}_{2}{ }^{\bullet-}$ can also be produced in the aprotic interior of the thylakoid membrane close to the RC of PSI [272]. Thus, not only $\mathrm{F}_{\mathrm{A}}$ and $\mathrm{F}_{\mathrm{B}}$, but also $\mathrm{F}_{\mathrm{X}}$ and $\mathrm{A}_{1}$, might be involved in $\mathrm{O}_{2}{ }^{--}$production within the thylakoid membrane. It has been suggested that $\mathrm{O}_{2}{ }^{--}$mediates cyclic electron transfer by donating electrons to Cyt b6f or to $\mathrm{P} 700^{+}$, and this cycle would explain why the observed rate of $\mathrm{O}_{2}{ }^{\bullet-}$ production is low in intact PSI [12]. The increase in $\mathrm{O}_{2}{ }^{\bullet-}$ production in PSI subchloroplast fragments in the presence of Triton X-100 could result from the prevention of the putative $\mathrm{O}_{2}{ }^{\bullet-}$ mediated cyclic electron flow around PSI, due to the disintegration of the supermolecular structure of PSI by Triton X-100 [12]. The increase in $\mathrm{O}_{2}{ }^{--}$production in the presence of ammonium ions, and amines is considered as evidence of an $\mathrm{O}_{2}{ }^{\bullet-}$-mediated cyclic electron flow in PSI [272], as these substances supply protons to the membranes and accelerate the dismutation of $\mathrm{O}_{2}{ }^{\bullet-}$. The dismutation of $\mathrm{O}_{2}{ }^{\bullet-}$ prevents the $\mathrm{O}_{2}{ }^{\bullet-}$-mediated cyclic electron flow, thereby increasing the detectable production of $\mathrm{O}_{2}{ }^{\bullet-}$. Thus, dismutation of $\mathrm{O}_{2}{ }^{\bullet-}$ in thylakoid membranes and cyclic electron flow in isolated PSI complexes would explain why the rate of $\mathrm{O}_{2}{ }^{\bullet-}$ production is similar in these two preparations.

It has recently been suggested that the reduction in $\mathrm{O}_{2}{ }^{--}$by $\mathrm{F}_{\mathrm{A}}, \mathrm{F}_{\mathrm{B}}$ and $\mathrm{F}_{X}$ occurs in a lipophilic region [273]. As the dielectric constant in the immediate environment of the $\mathrm{F}_{\mathrm{A}}$ and $\mathrm{F}_{\mathrm{B}}$ centers is 5.4 [280], the redox potential of $\mathrm{O}_{2} / \mathrm{O}_{2}{ }^{--}$in aprotic medium $(-550$ and $-600 \mathrm{mV}$ vs. NHE [54] in DMF) should be used in comparisons of the redox potentials of PSI cofactors and $\mathrm{O}_{2} / \mathrm{O}_{2}{ }^{\bullet-}$. Thus, the difference in the redox potentials of $\mathrm{O}_{2} / \mathrm{O}_{2}{ }^{\bullet-}$ and PSI redox cofactors $\mathrm{F}_{\mathrm{A}} / \mathrm{F}_{\mathrm{A}}{ }^{-}$and $\mathrm{F}_{\mathrm{B}} / \mathrm{F}_{\mathrm{B}}{ }^{-}$would make the reduction of $\mathrm{O}_{2}$ by $\mathrm{F}_{\mathrm{A}}$ and $\mathrm{F}_{\mathrm{B}}$ thermodynamically less favorable. If we assume that $\mathrm{O}_{2}{ }^{\bullet-}$ is produced via $\mathrm{O}_{2}$ reduction by $\mathrm{F}_{A}$ and $\mathrm{F}_{\mathrm{B}}$ in a lipophilic environment, then the differences in redox potentials would easily explain why the rate of $\mathrm{O}_{2}{ }^{\bullet-}$ production is low in PSI subchloroplast fragments. In this case, the effect of Triton $\mathrm{X}-100$ would be to make the immediate area of $\mathrm{F}_{\mathrm{A}}$ and $\mathrm{F}_{\mathrm{B}}$ less lipophilic, which would shift the redox potential of $\mathrm{O}_{2} / \mathrm{O}_{2}{ }^{\bullet-}$ toward positive values.

According to the $E_{m}, \mathrm{Fx}$ and $\mathrm{A}_{1}$ would be favorable reductants of $\mathrm{O}_{2}$, even in an aprotic environment, as the $E_{m}$ values of the pairs $\mathrm{A}_{1} / \mathrm{A}_{1}{ }^{-}$located on the A- and B-branches of PSI electron transfer chain are -0.7 and $-0.81 \mathrm{mV}$, respectively (Figure 3). Indeed, phylloquinone $\mathrm{A}_{1}$ stimulated the flash-induced photoconsumption of $\mathrm{O}_{2}$ when added to thylakoid membranes from which $\mathrm{A}_{1}$ had been partially removed [266]. It was suggested that $\mathrm{A}_{1}$ could be the main reductant in $\mathrm{O}_{2}{ }^{\bullet-}$ production in 
PSI. However, results regarding the importance of the phylloquinone in $\mathrm{O}_{2}{ }^{\bullet-}$ production vary. Firstly, the stimulation of $\mathrm{O}_{2}$ photoconsumption by addition of $\mathrm{A}_{1}$ was observed only on the first flash [266]. The appearance of $\mathrm{O}_{2}{ }^{\bullet-}$ on the outside and inside of thylakoid membranes was tested with hydrophilic and lipophilic cyclic hydroxylamines that react with $\mathrm{O}_{2}{ }^{\bullet-}$, forming nitroxide radicals with a specific EPR spectrum [274]. In this work, a significant effect of SOD on the formation of both hydrophilic and lipophilic nitroxide radicals suggested that $90 \%$ of $\mathrm{O}_{2}{ }^{\bullet-}$ is formed at the membrane surface or outside of the membrane. On the other hand, evidence of the participation of $\mathrm{A}_{1}$ in $\mathrm{O}_{2}{ }^{\bullet-}$ formation was obtained with PSI complexes isolated from menB mutant, a phylloquinone-less knockout strain of the gene encoding 1,4-hydroxynaphthoyl-CoA-synthase of the cyanobacterium Synechocystis sp. PCC 6803. The mutant contains $\mathrm{PQ}$ at the phylloquinone-binding site $\mathrm{A}_{1}$ [275]. In the mutant, the redox potential of $P Q$ bound to the $A_{1}$ site was $-553--693 \mathrm{mV}$, close to the redox potential of $F_{X} / F_{X}{ }^{-}$and about $100 \mathrm{mV}$ more positive than that of $\mathrm{A}_{1} / \mathrm{A}_{1}{ }^{-}$[281]. $\mathrm{O}_{2}$ photoconsumption in isolated PSI complexes of the mutant was found to be slower than in the wild type [275]. The low rate of $\mathrm{O}_{2}$ photoconsumption in the mutant was explained by the difference in the redox potentials of $P Q$ and $A_{1}$, and the results suggest that $A_{1}$ is the main site of $\mathrm{O}_{2}$ reduction in PSI. $N, N, N^{\prime}, N^{\prime}$-Tetramethyl-p-phenylenediamine and $\mathrm{AscH}_{2} \mathrm{were}$ used as electron donors.

$\mathrm{A}_{1}{ }^{-}$, located in the B-branch of PSI, decays within 20 ns by electron transfer to $\mathrm{F}_{\mathrm{X}}$, whereas electron transfer from the A-branch $\mathrm{A}_{1}{ }^{-}$takes $170 \mathrm{~ns}$ (Figure 3). $\mathrm{A}_{1}{ }^{-}$can accumulate in high light when electron transfer from $\mathrm{A}_{1}{ }^{-}$to $\mathrm{F}_{\mathrm{X}}$ is limited. In this case, the electron flow from $\mathrm{F}_{\mathrm{A}}$ and $\mathrm{F}_{\mathrm{B}}$ to the MDA radical can prevent the accumulation of $\mathrm{A}_{1}{ }^{-}$, which minimizes the interaction of $\mathrm{O}_{2}$ with $\mathrm{A}_{1}{ }^{-}$. MDA is formed mainly by a reaction between APX and $\mathrm{AscH}_{2}$ (Reactions (62)-(64)). MDA can also be formed by a reaction between $\mathrm{AscH}_{2}$ and $\mathrm{O}_{2}{ }^{\bullet-}$, and MDA is an effective electron acceptor of PSI, effectively competing with methyl viologen [282]. The reduction in MDA by PSI occurs via reduced $\mathrm{Fd}$ [283]. In summary, a number of $\mathrm{AscH}_{2}$-related reactions can influence the photoreduction of $\mathrm{O}_{2}$ by PSI (Reactions (34), (62)-(64) and (110)-(113)), and the large number of reactions and reactants makes it difficult to estimate the importance of $\mathrm{AscH}_{2} / \mathrm{MDA} / \mathrm{DHA}$ in $\mathrm{O}_{2}$ reduction in PSI.

$$
\begin{gathered}
\mathrm{PSI}^{\mathrm{red}}+\mathrm{O}_{2} \rightarrow \mathrm{PSI}^{\mathrm{ox}}+\mathrm{O}_{2}^{\bullet-} \\
\mathrm{O}_{2}^{\bullet-}+\mathrm{AscH}_{2} \rightarrow \mathrm{H}_{2} \mathrm{O}_{2}+\mathrm{MDA} \\
\mathrm{PSI}^{\mathrm{red}}+\mathrm{MDA}+\mathrm{H}^{+} \rightarrow \mathrm{PSI}^{\mathrm{ox}}+\mathrm{AscH}^{-} \\
\mathrm{MDA}+\mathrm{MDA}+2 \mathrm{H}^{+} \rightarrow \mathrm{AscH}_{2}+\mathrm{DHA}
\end{gathered}
$$

From data presented by Kozuleva et al. [275], the rate of $\mathrm{O}_{2}{ }^{\bullet-}$ production by PSI can be estimated to be $2.5 \mathrm{O}_{2}{ }^{\bullet-}$ per P700 s${ }^{-1}$ according to the $\mathrm{O}_{2}$ consumption rate $\left(250 \mu \mathrm{mol} \mathrm{O} 2(\mathrm{mg} \mathrm{Chl})^{-1} \mathrm{~h}^{-1}\right)$ assuming 40 molecules of $\mathrm{Chl}$ per P700 in isolated PSI complexes [278]. If the production of $\mathrm{O}_{2}^{\bullet-}$ by PSI proceeds as an elementary second-order reaction, then the second-order rate constant is about $10^{4} \mathrm{M}^{-1} \mathrm{~s}^{-1}$ for a saturated concentration of $\mathrm{O}_{2}$ in aqueous solution. $4 \mathrm{Fe}-4 \mathrm{~S}$ clusters of PSI can have a low efficiency toward $\mathrm{O}_{2}$ reduction, and the second-order rate constant of the reaction of $\mathrm{O}_{2}$ with Fe-S proteins like $\mathrm{Fd}$ is about $10^{3} \mathrm{M}^{-1} \mathrm{~s}^{-1}$ [121]. However, the rate of $\mathrm{O}_{2}$ reduction by PSI was saturated to above $20 \mu \mathrm{M}$ of $\mathrm{O}_{2}$, with the second-order rate constant $1.5 \times 10^{7} \mathrm{M}^{-1} \mathrm{~s}^{-1}$ at a high light intensity [278]. The reaction of $\mathrm{O}_{2}$ with semiquinones having low redox potential proceeds with rate constants in the range of $10^{8}-10^{9} \mathrm{M}^{-1} \mathrm{~s}^{-1}$ [61]. These data may suggest that cooperation between $4 \mathrm{Fe}-4 \mathrm{~S}$ clusters and phylloquinones $\mathrm{A}_{1}$ can provide flexibility for the $\mathrm{O}_{2}{ }^{\bullet-}$ formation inside and outside of the thylakoid membrane. In high light, $\mathrm{O}_{2}{ }^{\bullet-}$ formation by $\mathrm{A}_{1}$ becomes more important, which leads to the accumulation of $\mathrm{O}_{2}{ }^{\bullet-}$ within the membrane.

In the aqueous phase, the dismutation of $\mathrm{O}_{2}{ }^{\bullet-}$ is catalyzed by SOD (Reaction (5)). Intramembranous formation of $\mathrm{O}_{2}{ }^{\bullet-}$, in turn, can lead to the formation of $\mathrm{H}_{2} \mathrm{O}_{2}$ within the thylakoid membrane due to the reaction of $\mathrm{O}_{2}^{\bullet-}$ with $\mathrm{PQH}_{2}$, Reaction (114) [128,264,266]. 


$$
\mathrm{PQH}_{2}+\mathrm{O}_{2}{ }^{\bullet-} \rightarrow \mathrm{PQ}^{\bullet-}+\mathrm{H}_{2} \mathrm{O}_{2}
$$

The second-order rate constant for the reaction of $\mathrm{O}_{2}{ }^{\bullet-}$ with $\mathrm{PQH}_{2}$ was estimated to be $4 \times 10^{4} \mathrm{M}^{-1} \mathrm{~s}^{-1}$ in acetonitrile [252]. The accumulation of $\mathrm{H}_{2} \mathrm{O}_{2}$ in a thylakoid suspension in the presence of cytochrome $c$, that reacts with $\mathrm{O}_{2}{ }^{--}$in aqueous phase (Reaction (31)) preventing the dismutation of $\mathrm{O}_{2}{ }^{\bullet-}$, was attributed to the formation of $\mathrm{H}_{2} \mathrm{O}_{2}$ within the thylakoid membrane via Reaction (114) [284].

The formation of $\mathrm{H}_{2} \mathrm{O}_{2}$ may contribute to the production of $\mathrm{HO}^{\bullet}$ near PSI via the Fenton and Haber-Weiss reactions (Reactions (3) and (58)).

It was shown that the formation of $\mathrm{HO}^{\bullet}$ in broken chloroplasts was suppressed by DCMU and it was suggested that $\mathrm{HO}^{\bullet}$ is predominantly produced in PSI via the reduction in $\mathrm{H}_{2} \mathrm{O}_{2}$ by protein-bound iron in PSI, as the metal chelator Desferal did not suppress $\mathrm{HO}^{\bullet}$ production [157]. The formation of $\mathrm{HO}^{\bullet}$ via the reaction of $\mathrm{O}_{2}{ }^{\bullet-}$ with the terminal acceptors $\mathrm{F}_{\mathrm{X}}, \mathrm{F}_{\mathrm{A}}$, and $\mathrm{F}_{\mathrm{B}}$ of PSI was recently suggested [285]. However, this route of $\mathrm{HO} \mathrm{O}^{\bullet}$ formation requires the dismutation of $\mathrm{O}_{2}{ }^{\bullet-}$ to form $\mathrm{H}_{2} \mathrm{O}_{2}$ as an intermediate. In the presence of $\mathrm{PQH}_{2}$, the production of $\mathrm{O}_{2}{ }^{\bullet-}$ would lead to the accumulation of $\mathrm{H}_{2} \mathrm{O}_{2}$ within the thylakoid membrane. The redox potential of $\mathrm{H}_{2} \mathrm{O}_{2} /\left(\mathrm{HO}^{\bullet},{ }^{-} \mathrm{OH}\right)$ is $400-600 \mathrm{mV}$ in organic solvents [286], and therefore the presence of $\mathrm{H}_{2} \mathrm{O}_{2}$ in the vicinity of the $\mathrm{A}_{1}$ site, with a much more negative redox potential (Figure 3), would lead to the formation of $\mathrm{HO}^{\bullet}$ in a Fenton-type reaction of $\mathrm{H}_{2} \mathrm{O}_{2}$ with phylloquinone $\mathrm{A}_{1}{ }^{\bullet-}$ (Reaction (115)) [252].

$$
\mathrm{A}_{1}{ }^{\bullet-}+\mathrm{H}_{2} \mathrm{O}_{2} \rightarrow \mathrm{A}_{1}+\mathrm{HO}^{\bullet}+{ }^{-} \mathrm{OH}
$$

\subsubsection{Formation of Reduced Forms of Oxygen, $\mathrm{O}_{2}{ }^{\bullet-}, \mathrm{H}_{2} \mathrm{O}_{2}, \mathrm{HO}{ }^{\bullet}$, in the PQ Pool and by Cyt b6f}

PQ is a prenyllipid consisting of 2,3-dimethyl-1,4-benzoquinone and a side chain of nine isoprenyl units attached to Position 5. The total amount of PQ in leaves is in the range 25-40 molecules per P700 [248,287-289]. PQ has been found in thylakoid membranes, the envelope of the chloroplast and plastoglobules. [290-294]. The ratio of PQ in the envelope and PQ in the thylakoid membrane was found to be 2:5 [293]. The PQ involved in electron transfer in the thylakoid membrane is called the photoactive PQ and its amount is in the range 6-15 PQ per P700, assuming that the ratio of P700 and $\mathrm{Chl}$ is $1 / 600$ [248,288,295-298]. PQ can be present in three forms: $\mathrm{PQ}, \mathrm{PQ}^{\bullet-}$, and $\mathrm{PQH}_{2}$. Both reduced forms can exist in protonated and deprotonated forms: $\mathrm{PQH}^{\bullet}$ or $\mathrm{PQ}^{\bullet-}$, and $\mathrm{PQH}_{2}, \mathrm{PQH}^{-}$or $\mathrm{PQ}^{2-}$. The $\mathrm{pK}_{1}$ and $\mathrm{pK}_{2}$ values of $\mathrm{PQH}_{2}$ in aqueous solutions are 10.8 and 12.9; the $\mathrm{pKa}$ value of $\mathrm{PQH}^{\bullet}$ is 5.9 [299]. The above data were measured for plastoquinone-1, which has only one prenyl group attached to Position 5 of 2,3-dimethyl-1,4-benzoquinone.

Significant PSI-independent $\mathrm{O}_{2}$ reduction was observed in a thylakoid suspension in the presence of the DNP-INT, that prevents the oxidation of $\mathrm{PQH}_{2}$ by Cyt b6f $[128,236,266]$. In the work of Kruk et al. [266], significant $\mathrm{O}_{2}$ reduction was also demonstrated in the presence of DBMIB, another inhibitor of oxidation of $\mathrm{PQH}_{2}$ by the Cyt b6f. DBMIB was found to strongly inhibit $\mathrm{O}_{2}{ }^{\bullet-}$ production, whereas the formation of $\mathrm{H}_{2} \mathrm{O}_{2}$ was only partially inhibited. Furthermore, the rate of $\mathrm{H}_{2} \mathrm{O}_{2}$ production increased with the concentration of DBMIB [300]. On other hand, the removal, by a repeated freeze-thaw procedure, of $\mathrm{PC}$, suppressed $\mathrm{O}_{2}$ reduction by thylakoid membranes. In addition, the PC-inhibitor $\mathrm{HgCl}_{2}$ significantly suppressed $\mathrm{O}_{2}$ reduction [266]. These data may suggest that the suppression of PSI-independent $\mathrm{O}_{2}$ reduction requires a strong inhibition procedure that may cause unspecific damage to the photosynthetic apparatus. In the work of Cleland and Grace [236], the production of $\mathrm{O}_{2}{ }^{\bullet-}$ in the presence of DNP-INT was attributed to $\mathrm{O}_{2}$ reduction by $\mathrm{Q}_{\mathrm{A}}{ }^{-}$. However, Khorobrykh and Ivanov [128] showed that PSI-independent $\mathrm{O}_{2}$ consumption in thylakoids was suppressed by DCMU, and $\mathrm{O}_{2}$ consumption by isolated PSII membranes was low. Thus, PSI-independent $\mathrm{O}_{2}$ consumption in thylakoid membranes in the presence of DNP-INT was interpreted as $\mathrm{O}_{2}$ reduction occurring in the PQ pool. The amount of detectable $\mathrm{O}_{2}{ }^{\bullet-}$, measured using cytochrome $\mathrm{c}$ as a trap of $\mathrm{O}_{2}{ }^{\bullet-}$, was found to be about $25 \%$ of the amount of $\mathrm{O}_{2}{ }^{\bullet-}$ estimated from the $\mathrm{O}_{2}$ consumption rate [128]. This indicates that $\mathrm{O}_{2}$ 
reduction occurs mainly inside the thylakoid membrane, where $\mathrm{O}_{2}{ }^{\bullet-}$ can be consumed in concomitant reactions. It has been proposed that $\mathrm{O}_{2}$ reduction in the PQ pool develops as a two-stage autocatalytic process that starts by the production of $\mathrm{PQH}^{\bullet}$ via dismutation (Reaction (116)) and is followed by the deprotonation of $\mathrm{PQH}^{\bullet}$ and subsequent oxidation of $\mathrm{PQ}^{\bullet-}$ by $\mathrm{O}_{2}$ with the formation of $\mathrm{O}_{2}{ }^{\bullet-}$ and $\mathrm{PQ}$. Furthermore, $\mathrm{PQH}_{2}$ can be oxidized by $\mathrm{O}_{2}{ }^{\bullet-}$ with the formation of $\mathrm{PQ}^{\bullet-}$ that would again react with $\mathrm{O}_{2}$ to produce $\mathrm{O}_{2}^{\bullet-}$ and PQ (Figure 4) [128].

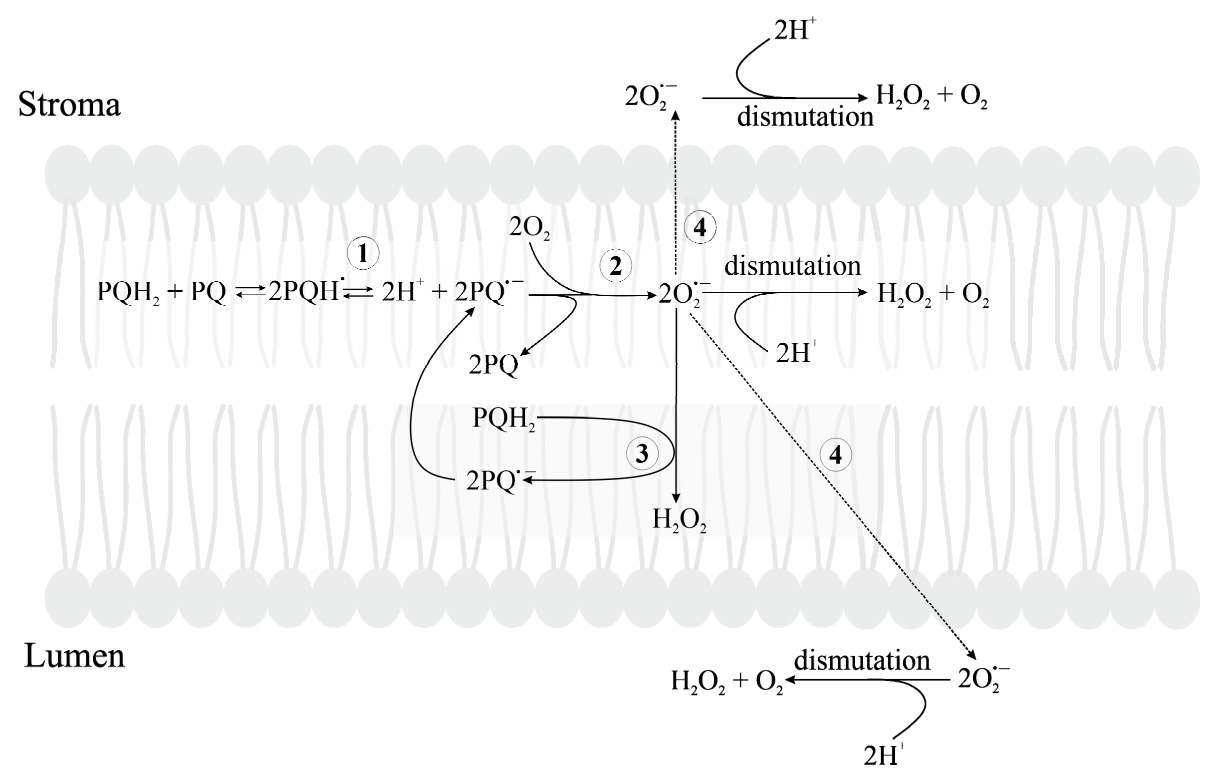

Figure 4. Autocatalytic oxidation of reduced plastoquinone $\left(\mathrm{PQH}_{2}\right)$ by $\mathrm{O}_{2}$ in the thylakoid membrane. 1 -formation of a plastosemiquinone radical $\left(\mathrm{PQH}^{\bullet}\right)$ by a dismutation reaction of $\mathrm{PQH}_{2}$ with $\mathrm{PQ}$; 2-reduction in $\mathrm{O}_{2}$ by a plastosemiquinone anion radical ( $\mathrm{PQ}^{\bullet-}$ ) with formation of superoxide anion radical $\left(\mathrm{O}_{2}{ }^{\bullet-}\right) ; 3$ - oxidation of $\mathrm{PQH}_{2}$ by $\mathrm{O}_{2}{ }^{\bullet-}$ with formation of hydrogen peroxide $\left(\mathrm{H}_{2} \mathrm{O}_{2}\right)$ and PQ; 4-diffusion of $\mathrm{O}_{2}{ }^{\bullet-}$ from thylakoid membrane to stroma and to lumen. In the autocatalytic oxidation of $\mathrm{PQH}_{2}$, the reaction of $\mathrm{O}_{2}{ }^{\bullet-}$ with $\mathrm{PQH}_{2}$ provides excess $\mathrm{PQ}^{\bullet-}$ that can be involved in the formation of $\mathrm{O}_{2}{ }^{\bullet-}$ and, in turn, accelerates the oxidation of $\mathrm{PQH}_{2}$ [128].

Thylakoid membranes have also been shown to accumulate $\mathrm{H}_{2} \mathrm{O}_{2}$ in the presence of cytochrome $c$ that reacts with $\mathrm{O}_{2}{ }^{\bullet-}$ and prevents the formation of $\mathrm{H}_{2} \mathrm{O}_{2}$ via superoxide dismutation (Reaction (31)) [284]. These data suggest that a considerable amount of $\mathrm{H}_{2} \mathrm{O}_{2}$ is generated inside the thylakoid membrane in the reaction of $\mathrm{O}_{2}{ }^{\bullet-}$ with $\mathrm{PQH}_{2}$ ([284], Figure 4), as earlier suggested by Khorobrykh and Ivanov [128]. These results contradict with the results of Asada et al. [124], where cytochrome $c$ completely inhibited $\mathrm{H}_{2} \mathrm{O}_{2}$ formation by thylakoids. However, in a later work of Takahashi and Asada [272], the formation of $\mathrm{H}_{2} \mathrm{O}_{2}$ in the presence of cytochrome $c$ was shown. It is possible that different light intensities caused the contradiction, as $\mathrm{H}_{2} \mathrm{O}_{2}$ formation appears to increase with light intensity [284].

The mechanism and efficiency of $\mathrm{O}_{2}$ reduction in the PQ pool are under debate. Autooxidation of $\mathrm{PQH}_{2}$ is one possible mechanism (Figure 4) but is it biologically significant? According to the redox potential, the reduction in $\mathrm{O}_{2}$ by both $\mathrm{PQ}^{\bullet-}$ and $\mathrm{PQ}^{2-}$ is thermodynamically favorable in aqueous solution since the redox potentials of $\mathrm{PQ} / \mathrm{PQ}^{\bullet-}$ and $\mathrm{PQ}^{\bullet-} / \mathrm{PQ}^{2-}$ are -165 and $-274 \mathrm{mV}$, respectively [299]. The deprotonation of $\mathrm{PQH}_{2}$ or $\mathrm{PQH}^{\bullet}$ is essential for $\mathrm{O}_{2}$ reduction. Since $\mathrm{PQ}^{2-}$ is mostly protonated under physiological $\mathrm{pH}, \mathrm{PQ}^{\bullet-}$ was considered the main form of reduced PQ that could be involved in $\mathrm{O}_{2}$ reduction in thylakoids. The reactions of semiquinones with $\mathrm{O}_{2}$ with formation of $\mathrm{O}_{2}{ }^{\bullet-}$ are equilibrium reactions where the quinone can be reduced by $\mathrm{O}_{2}{ }^{\bullet-}$ (Reaction (31)).

The equilibrium constant for the reaction of $\mathrm{O}_{2}$ with $\mathrm{PQ}^{\bullet-}$, as determined by the equation $(\mathrm{RT} / \mathrm{F}) \operatorname{lnK}=\mathrm{E}\left(\mathrm{O}_{2} / \mathrm{O}_{2}{ }^{\bullet-}\right)-\mathrm{E}\left(\mathrm{Q} / \mathrm{Q}^{\bullet-}\right)$, where $\mathrm{R}$ is the gas constant, $\mathrm{T}$ is temperature and $\mathrm{K}$ is the equilibrium constant, and $\mathrm{F}$ is the Faraday constant, is 1.56 if the redox potentials of $\mathrm{PQ} / \mathrm{PQ}^{\bullet-}$ 
and $\mathrm{O}_{2} / \mathrm{O}_{2}{ }^{\bullet-}$ are -165 and $-160 \mathrm{mV}$, respectively [61]. The forward and reverse second-order rate constants for the formation of $\mathrm{O}_{2}{ }^{\bullet-}$ by $\mathrm{PQ}^{\bullet-}$ (Reaction (31)) are $k_{\text {forward }} \sim 10^{8} \mathrm{M}^{-1} \mathrm{~s}^{-1}$ and $k_{\text {reverse }} \sim$ $7 \times 10^{7} \mathrm{M}^{-1} \mathrm{~s}^{-1}$ [61]. The equilibrium constant for Reaction (116) was estimated to be $10^{-9.2}$ [301], which shows that the formation of $\mathrm{PQH}^{\bullet}$ via Reaction (116) is negligible. Thus, the apparent rate of $\mathrm{O}_{2}{ }^{\bullet-}$ production in the $\mathrm{PQ}$ pool is determined by the rate of $\mathrm{PQ}^{\bullet-}$ appearance, rate of $\mathrm{O}_{2}{ }^{\bullet-}$ production via reaction of $\mathrm{O}_{2}$ with $\mathrm{PQ}^{\bullet-}$ (Reaction (31)) and the rate of $\mathrm{O}_{2}{ }^{\bullet-}$ removal from the equilibrium Reaction (31). In solvents with pure of $\mathrm{PQH}_{2}$ and $\mathrm{PQ}$, the apparent rate of $\mathrm{O}_{2}{ }^{\bullet-}$ production obviously results from the following reactions:

$$
\begin{gathered}
\mathrm{PQH}_{2}+\mathrm{PQ} \Delta 2 \mathrm{PQH}^{\bullet} \\
\mathrm{PQ}^{\bullet-}+\mathrm{H}^{+} \Delta \mathrm{PQH}^{\bullet} \\
\mathrm{Q}^{\bullet-}+\mathrm{O}_{2} \Delta \mathrm{Q}+\mathrm{O}_{2}^{\bullet-} \text { Reaction (31) } \\
\mathrm{PQH}_{2}+\mathrm{O}_{2}^{\bullet-} \rightarrow \mathrm{PQ}^{\bullet-}+\mathrm{H}_{2} \mathrm{O}_{2} \quad \text { Reaction (114) } \\
\mathrm{O}_{2}^{\bullet-}+\mathrm{O}_{2}^{\bullet-}+2 \mathrm{H}^{+} \rightarrow \mathrm{H}_{2} \mathrm{O}_{2}+\left(\mathrm{O}_{2} \text { or }{ }^{1} \mathrm{O}_{2}\right) \quad \text { Reaction (5) }
\end{gathered}
$$

In thylakoid membranes, $\mathrm{PQ}$ is reduced by PSII to $\mathrm{PQH}_{2}$ in the light. This lowers the concentration of $\mathrm{PQ}$, thereby preventing reaction (31) and leading to an increase in $\mathrm{PQH}_{2}$ oxidation by $\mathrm{O}_{2}{ }^{\bullet-}$.

In organic solvents, the redox potentials of both $\mathrm{PQ} / \mathrm{PQ}^{\bullet-}$ and $\mathrm{O}_{2} / \mathrm{O}_{2}{ }^{-{ }^{-}}$become more negative. The redox potentials of $\mathrm{PQ} / \mathrm{PQ}^{\bullet-}$ and $\mathrm{O}_{2} / \mathrm{O}_{2}{ }^{\bullet-}$ were estimated to be $-400[302,303]$ and $-600 \mathrm{mV}$ vs. NHE in DMF [54] and around $-640 \mathrm{mV}$ in acetonitrile [59,60], respectively. According to the redox potentials, the equilibrium constant is $10^{-7.8}$, and therefore a reaction of $\mathrm{PQ}^{\bullet-}$ with $\mathrm{O}_{2}$ is thermodynamically unfavorable in an aprotic medium. Thus, efficient $\mathrm{O}_{2}{ }^{\bullet-}$ production via Reaction (31) can be observed only in an aqueous solution or at the membrane-water interface, or in a protein pocket where the redox potentials of $\mathrm{O}_{2} / \mathrm{O}_{2}{ }^{\bullet-}$ and $\mathrm{PQ} / \mathrm{PQ}^{\bullet-}$ can be equal. The second-order rate constants for the autoxidation of $\mathrm{PQH}_{2}$ in different solvents, estimated from the initial rates, were found to range from $10^{-2}$ to $10^{-3} \mathrm{M}^{-1} \mathrm{~s}^{-1}$ for both aqueous and aprotic solvents [248,252]. However, fast $\mathrm{PQH}_{2}$ oxidation in organic solvent was observed after the addition of $\mathrm{KOH}$ [252]. This reaction likely results from the formation of $\mathrm{PQ}^{2-}$ with a very negative redox potential, $-1.1 \mathrm{~V}$ for $\mathrm{PQ} / \mathrm{PQ}^{2-}$ [301]. The rate constant of $\mathrm{PQH}_{2}$ oxidation associated with $\mathrm{O}_{2}$ reduction by the PQ pool in thylakoids was estimated to be $\sim 10^{3} \mathrm{M}^{-1} \mathrm{~s}^{-1}$ if the reaction occurs inside the thylakoid membrane [128], and a later work calculated this rate constant to be $1.21 \times 10^{-3} \mathrm{M} \mathrm{s}^{-1}$ while the rate of $\mathrm{PQH}_{2}$ autoxidation was $\sim 10^{-8} \mathrm{M} \mathrm{s}^{-1}$ [252]. These rates were calculated assuming that $\mathrm{PQH}_{2}$ oxidation by $\mathrm{O}_{2}$ is a second-order chemical reaction and the oxidation of $\mathrm{PQH}_{2}$ occurs in the volume of thylakoid membrane. The steady-state concentration of $\mathrm{PQ}^{\bullet-}$ inside the thylakoid membrane produced via reaction (116) can be estimated to be about $10^{-8} \mathrm{M}$. The following values were used in the calculations: amount of photoactive PQ, $14 \times 10^{-3} \mathrm{~mol} \mathrm{PQ}(\mathrm{mol} \mathrm{Chl})^{-1}$ [248]; volume of thylakoid membrane, $4.6 \times 10^{-6} \mathrm{~L}(\mathrm{mg} \mathrm{Chl})^{-1}$ [304]; molar mass of Chl, $894 \mathrm{~g} \mathrm{~mol}^{-1}$ [304]; the equilibrium constant for reaction (116) was taken as $10^{-10}$; and the ratio of $\mathrm{PQ}$ and $\mathrm{PQH}_{2}$ was taken as $1 / 9$. If $\mathrm{O}_{2}{ }^{-}$is very rapidly removed and therefore Reaction (31) can be considered an irreversible reaction with a second order rate constant of about $10^{8} \mathrm{M}^{-1} \mathrm{~s}^{-1}$, then the rate of $\mathrm{PQH}_{2}$ oxidation by $\mathrm{O}_{2}$ inside the thylakoid membrane can be estimated to be $2.4 \times 10^{-3} \mathrm{M} \mathrm{s}^{-1}$. This estimated rate is close to the rate of $\mathrm{PQH}_{2}$ oxidation by $\mathrm{O}_{2}$ inside the thylakoid membrane, calculated from the $\mathrm{O}_{2}$ consumption rate [252]. Thus, $\mathrm{O}_{2}$ reduction by the $\mathrm{PQ}$ pool via an autoxidation mechanism (Figure 4) occurs when $\mathrm{O}_{2}{ }^{\bullet-}$ is efficiently consumed and the second-order rate constant is about $10^{8} \mathrm{M}^{-1} \mathrm{~s}^{-1}$. The consumption of $\mathrm{O}_{2}{ }^{\bullet-}$ can occur via the reaction of $\mathrm{O}_{2}{ }^{\bullet-}$ with $\mathrm{PQH}_{2}$, Reaction (114). The second-order rate constant for the reaction of $\mathrm{O}_{2}{ }^{\bullet-}$ with $\mathrm{PQH}_{2}$ has recently been estimated to be $4 \times 10^{4} \mathrm{M}^{-1} \mathrm{~s}^{-1}$ [252]. The second-order rate constant for the oxidation of $\mathrm{PQH}_{2}$ by $\mathrm{O}_{2}$ in illuminated thylakoids is within $10^{2}-10^{3} \mathrm{M}^{-1} \mathrm{~s}^{-1}$. Thus, the autoxidation of $\mathrm{PQH}_{2}$ by $\mathrm{O}_{2}$ can explain $\mathrm{O}_{2}$ consumption in the light in the presence of an inhibitor of Cyt b6f only with some assumptions. In addition, the rate of $\mathrm{PQH}_{2}$ oxidation in thylakoids in the light is over 20 times as fast as the rate of oxidation of $\mathrm{PQH}_{2}$ in the dark 
after photoreduction [248], suggesting that light-dependent reaction(s) dominate in the $\mathrm{O}_{2}$-dependent oxidation of the PQ pool.

The PQ pool has also been found to scavenge ${ }^{1} \mathrm{O}_{2}$ in thylakoid membranes [305-307], with the second-order rate constant of the reaction of ${ }^{1} \mathrm{O}_{2}$ with $\mathrm{PQH}_{2}, 0.97 \times 10^{8} \mathrm{M}^{-1} \mathrm{~s}^{-1}$ in acetonitrile [50]. The reaction of ${ }^{1} \mathrm{O}_{2}$ with $\mathrm{PQH}_{2}$ in methanol was found to lead to the formation of $\mathrm{H}_{2} \mathrm{O}_{2}$ (Reaction (119)) [48]. It was suggested that the reaction of ${ }^{1} \mathrm{O}_{2}$ with $\mathrm{PQH}_{2}$ is initiated by the formation of ${ }^{1} \mathrm{O}_{2}$ in PSII and can also proceed inside the thylakoid membrane [48]. The formation of $\mathrm{H}_{2} \mathrm{O}_{2}$ via oxidation of $\mathrm{PQH}_{2}$ by ${ }^{1} \mathrm{O}_{2}$ may occur in two ways. In the first one, ${ }^{1} \mathrm{O}_{2}$ reacts with $\mathrm{PQH}_{2}$ to form an unstable hydroperoxide adduct of the quinone ring $\left(\mathrm{PQH}_{2}-\mathrm{OO}\right)$, which directly decomposes to form $\mathrm{H}_{2} \mathrm{O}_{2}$ and PQ (Reaction (119)). In the second way, the hydroperoxide adduct decomposes to form $\mathrm{HO}_{2}{ }^{\bullet}$ and $\mathrm{PQH}^{\bullet}$ (Reaction (120)). This indirect mechanism would be similar to that proposed for the oxidation of $\mathrm{AscH}_{2}$ by ${ }^{1} \mathrm{O}_{2}$ [47]. In the indirect mechanism, $\mathrm{H}_{2} \mathrm{O}_{2}$ is produced by the oxidation of $\mathrm{PQH}_{2}$ to $\mathrm{PQH}$ by $\mathrm{HO}_{2}{ }^{\bullet}$ (Reaction (121)).

$$
\begin{gathered}
{ }^{3} \mathrm{P} 680+\mathrm{O}_{2} \rightarrow \mathrm{P} 680+{ }^{1} \mathrm{O}_{2} \\
{ }^{1} \mathrm{O}_{2}+\mathrm{PQH}_{2} \rightarrow\left[\mathrm{PQH}_{2}-\mathrm{OO}\right] \rightarrow \mathrm{PQ}+\mathrm{H}_{2} \mathrm{O}_{2} \\
{ }^{1} \mathrm{O}_{2}+\mathrm{PQH}_{2} \rightarrow\left[\mathrm{PQH}_{2}-\mathrm{OO}\right] \rightarrow \mathrm{PQH}^{\bullet}+\mathrm{HO}_{2} \\
\mathrm{PQH}_{2}+\mathrm{HO}_{2} \bullet \rightarrow \mathrm{PQH}^{\bullet}+\mathrm{H}_{2} \mathrm{O}_{2}
\end{gathered}
$$

Thus, the PSI-independent $\mathrm{O}_{2}$ reduction in the PQ pool may depend on ${ }^{1} \mathrm{O}_{2}$ production in PSII, and this reaction can cause the formation of $\mathrm{H}_{2} \mathrm{O}_{2}$ inside the thylakoid membrane.

$\mathrm{O}_{2}$ reduction, associated with the PQ pool, also occurs without any inhibitors [264]. The ratio of the rate of $\mathrm{O}_{2}$ reduction in PSI and the rate of $\mathrm{O}_{2}$ reduction in the PQ pool, in the absence of any inhibitors, reaches 1:1 at a high light intensity [264]. However, the rate of $\mathrm{O}_{2}$ reduction by the PQ pool in the presence of DNP-INT is saturated at a low light intensity $[128,264,308]$. These data confirm that $\mathrm{O}_{2}$ reduction in a PQ pool in thylakoids without any inhibitors can occur parallel to $\mathrm{O}_{2}$ reduction in PSI. Interestingly, efficient $\mathrm{O}_{2}$ reduction by the PQ pool is observed at pH 5.0 in the absence of inhibitors, but not in the presence of DNP-INT $[128,264]$. The simplest explanation for differences in $\mathrm{O}_{2}$ reduction by the $\mathrm{PQ}$ pool in the absence and presence of DNP-INT, is to assume that the formation of $\mathrm{O}_{2}{ }^{\bullet-}$ occurs in PSI. $\mathrm{O}_{2}{ }^{\bullet-}$ can react with $\mathrm{PQH}_{2}$ to form $\mathrm{H}_{2} \mathrm{O}_{2}$ via Reaction (114) [264].

The autoxidation of $\mathrm{PQH}_{2}$ does not imply the participation of any enzymes. However, the oxidation of the PQ pool with PTOX is widely discussed [309]. PTOX is a non-heme diiron quinol oxidase that oxidizes $\mathrm{PQH}_{2}$ and reduces $\mathrm{O}_{2}$ to $\mathrm{H}_{2} \mathrm{O}$. PTOX is localized in the non-appressed regions of the thylakoid membrane [310]. It has been suggested that PTOX provides an alternative electron flow from the PQ pool to $\mathrm{O}_{2}$ to prevent photoinhibition of PSII [311]. However, in higher plants, PTOX-mediated electron flow to $\mathrm{O}_{2}$ is negligible [312] or its contribution is less than one percent of the total electron flow through PETC $[313,314]$. However, PTOX may depend on conditions, as high PTOX content and high PTOX activity were induced in the alpine species Ranunculus glacialis L. during growth in strong light [315]. The rate of PTOX-mediated electron flow is approximately $0.3 \mathrm{e}^{-} \mathrm{s}^{-1}$ $(\mathrm{P} 680)^{-1}$ [313]. This makes the rate of $\mathrm{PQH}_{2}$ oxidation equal to $0.15 \mathrm{PQH}_{2}(\mathrm{P} 680)^{-1} \mathrm{~s}^{-1}$, or $0.35 \mu \mathrm{mol}$ $\mathrm{PQH}_{2}(\mathrm{mg} \mathrm{Chl})^{-1} \mathrm{~h}^{-1}$, assuming that the ratio of PSII to Chl is 1:420. Thus, the rate of $\mathrm{PQH}_{2}$ oxidation can be estimated to be $8.68 \times 10^{-5} \mathrm{M} \mathrm{s}^{-1}$ inside the thylakoid membrane [252]. The second-order rate constant of PTOX-mediated oxidation of $\mathrm{PQH}_{2}$ inside the thylakoid membrane is $10.6 \mathrm{M}^{-1} \mathrm{~s}^{-1}$. In the light, the oxidation of $\mathrm{PQH}_{2}$ by $\mathrm{PTOX}$, associated with the reduction of $\mathrm{O}_{2}$ to $\mathrm{H}_{2} \mathrm{O}$, would not lead to consumption of $\mathrm{O}_{2}$ because of its matching stoichiometry with $\mathrm{O}_{2}$ production by PSII, Reactions (122) and (123).

$$
\begin{gathered}
2 \mathrm{PQH}_{2}+\mathrm{O}_{2} \rightarrow 2 \mathrm{PQ}+2 \mathrm{H}_{2} \mathrm{O} \\
\mathrm{PSII}+2 \mathrm{H}_{2} \mathrm{O}+2 \mathrm{PQ} \rightarrow 2 \mathrm{PQH}_{2}+\mathrm{O}_{2}
\end{gathered}
$$


PTOX-mediated electron flow to $\mathrm{O}_{2}$ is assumed to produce no ROS. However, isolated PTOX can oxidize decylPQH 2 with the formation of $\mathrm{O}_{2}{ }^{\bullet-}$ or $\mathrm{H}_{2} \mathrm{O}_{2}$ at $\mathrm{pH} 8.0$ or in substrate-limiting concentrations [316]. The efficiency of ROS production by PTOX was estimated to be around $17 \%$ of the total $\mathrm{O}_{2}$-reduction activity of PTOX [316]. The rate of PTOX-mediated $\mathrm{PQH}_{2}$ oxidation associated with the formation of $\mathrm{H}_{2} \mathrm{O}_{2}$ was estimated to be $1.47 \times 10^{-5} \mathrm{M} \mathrm{s}^{-1}$, with the second-order rate constant of $1.8 \mathrm{M}^{-1} \mathrm{~s}^{-1}$ inside the thylakoid membrane [252]. Thus, the estimated rate of PTOX-mediated $\mathrm{O}_{2}$ reduction is 100 times less than the rate of $\mathrm{O}_{2}$ reduction by the PQ pool in illuminated thylakoids. Furthermore, if $\mathrm{O}_{2}{ }^{\bullet-}$ is formed by $\mathrm{PTOX}, \mathrm{PQ}^{\bullet-}$ might also be formed.

$\mathrm{PQ}^{\bullet-}$ is also considered a source of $\mathrm{O}_{2}{ }^{\bullet-}$ production by Cyt b6f via the reaction of $\mathrm{O}_{2}$ with $\mathrm{PQ}^{\bullet-}$. It has been suggested that $\mathrm{PQ}^{\bullet-}$, generated via one-electron oxidation of $\mathrm{PQH}_{2}$ at the $\mathrm{Q}_{\mathrm{O}}$ site by the 2Fe-2S cluster of the high-potential, Rieske iron-sulfur protein of the Cyt b6f (Reaction (124)), can be oxidized by the conversion of $\mathrm{O}_{2}$ to $\mathrm{O}_{2}{ }^{\bullet-}$ [317].

$$
\mathrm{PQH}_{2}+2 \mathrm{Fe}-2 \mathrm{~S}_{\mathrm{ox}} \rightarrow \mathrm{PQ}^{\bullet-}+2 \mathrm{Fe}-2 \mathrm{~S}_{\text {red }}+2 \mathrm{H}^{+}
$$

Isolated Cyt b6f complexes have been shown to produce $\mathrm{H}_{2} \mathrm{O}_{2}$ when decylPQH $\mathrm{H}_{2}$ and $\mathrm{PC}$ were used as an electron donor and electron acceptor, respectively [317]. It was suggested that $\mathrm{H}_{2} \mathrm{O}_{2}$ appeared via $\mathrm{O}_{2}{ }^{\bullet-}$ dismutation. No detectable $\mathrm{O}_{2}{ }^{\bullet-}$ formation is observed in the presence of DBMIB, which has been shown to bind to an iron-sulfur binding site and at a position distal to the iron-sulfur binding site in Cyt b6f. This indicates that the mechanism of $\mathrm{H}_{2} \mathrm{O}_{2}$ production is related to the oxidation of $\mathrm{PQH}_{2}$ at the QO site of Cyt b6f. The production of $\mathrm{O}_{2}{ }^{\bullet-}$ in Cyt b6f was also shown with EPR spectroscopy [317]. $\mathrm{O}_{2}{ }^{\bullet-}$ can be formed via the interaction of $\mathrm{O}_{2}$ with $\mathrm{PQ}^{\bullet-}$ in the Qo pocket or/and with the interaction of $\mathrm{O}_{2}$ with the reduced form of $\mathrm{p}$-side heme $\mathrm{b}_{\mathrm{p}}$ [317]. The rate of $\mathrm{O}_{2}{ }^{\bullet-}$ production by the isolated Cyt b6f is 4.5 (Cyt b6f) $)^{-1} \mathrm{~s}^{-1}$. This gives a rate of $\mathrm{O}_{2}{ }^{\bullet-}$ production inside thylakoid membrane of about $2.6 \times 10^{-3} \mathrm{M} \mathrm{s}^{-1}$, assuming that the ratio of Cyt b6f and $\mathrm{Chl}$ is 1:420 and the volume of the thylakoid membrane is $4.6 \times 10^{-6} \mathrm{~L}(\mathrm{mg} \mathrm{Chl})^{-1}$ [304]. This rate is close to the rate of $\mathrm{O}_{2}{ }^{\bullet-}$ production by the PQ pool in the presence of DNP-INT. As DNP-INT blocks the oxidation of $\mathrm{PQH}_{2}$ at the $\mathrm{Q}_{\mathrm{O}}$ site, the oxidation of $\mathrm{PQH}_{2}$ in the $\mathrm{Q}_{\mathrm{O}}$ site cannot be responsible for $\mathrm{O}_{2}$ reduction in the $\mathrm{PQ}$ pool in the presence of DNP-INT. The formation of $\mathrm{PQ}^{\bullet-}$ at the Qi site of Cyt b6f appears to cause $\mathrm{O}_{2}$ reduction in the PQ pool in the presence of DNP-INT (S. Khorobrykh and E. Tyystjärvi, unpublished data). The possible means of the reduction in $\mathrm{O}_{2}$ in Cyt b6f are shown in Figure 5.

The formation of $\mathrm{HO}^{\bullet}$ has never been detected in the PQ pool, although it is supposed to happen. In the chloroplast stroma, $\mathrm{H}_{2} \mathrm{O}_{2}$ is efficiently scavenged, which would limit $\mathrm{HO}^{\bullet}$ formation. However, $\mathrm{H}_{2} \mathrm{O}_{2}$ formed inside membranes by the PQ pool is not efficiently scavenged, and may therefore react with $\mathrm{PQ}^{\bullet-}$ to form $\mathrm{HO}^{\bullet}$ via the Fenton mechanism (Reaction (125)).

$$
\mathrm{PQ}^{\bullet-}+\mathrm{H}_{2} \mathrm{O}_{2} \rightarrow \mathrm{PQ}+\mathrm{HO}^{\bullet}+\mathrm{OH}^{-}
$$


(A)

Formation of $\mathrm{O}_{2}^{-}$and $\mathrm{H}_{2} \mathrm{O}_{2}$ at $\mathrm{Q}_{\mathrm{o}}$ site of Cyt b6f

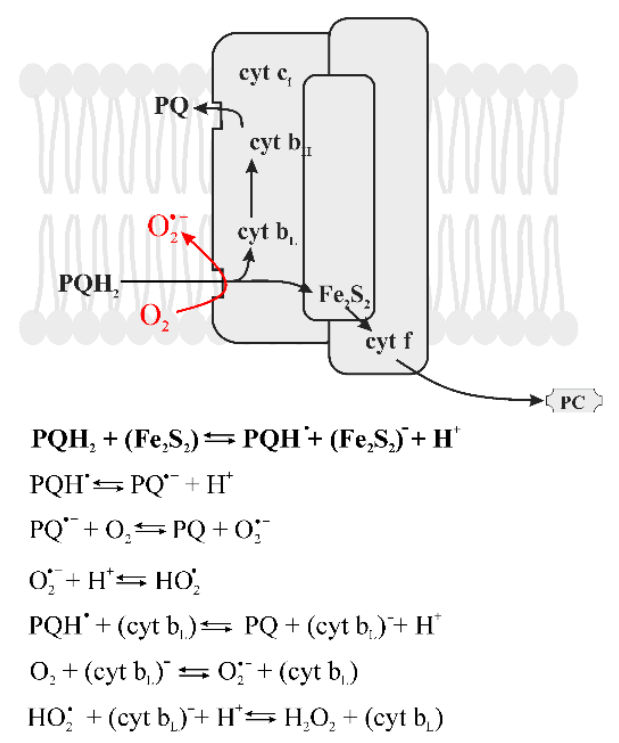

(B)

Formation of $\mathrm{O}_{2}^{-}$and $\mathrm{H}_{2} \mathrm{O}_{2}$ at $\mathrm{Q}_{1}$ site of Cyt b6f

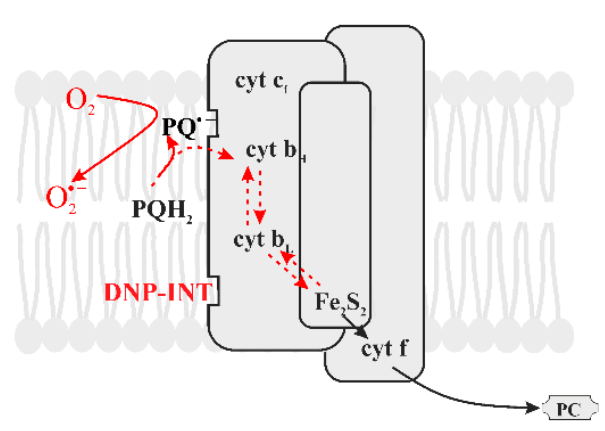

$\mathrm{PQH}_{2}+\left(\mathrm{cyt}_{\mathrm{H}}\right) \leftrightharpoons \mathrm{PQH}^{+}+\left(\mathrm{cyt} \mathrm{b}_{\mathrm{H}}\right)^{-}+\mathrm{H}^{+}$

$\mathrm{PQH}^{\circ} \leftrightharpoons \mathrm{PQ}^{-}+\mathrm{H}^{+}$

$\mathrm{PQ}^{--}+\mathrm{O}_{2} \leftrightharpoons \mathrm{PQ}+\mathrm{O}^{--}$

$\mathrm{O}_{2}^{--}+\mathrm{H}^{+} \leftrightharpoons \mathrm{HO}_{2}^{-}$

$\mathrm{HO}_{2}^{-}+\left(\mathrm{cyt} \mathrm{b}_{\mathrm{H}}\right)^{-}+\mathrm{H}^{+} \leftrightharpoons \mathrm{H}_{2} \mathrm{O}_{2}+\left(\right.$ cyt b $\left._{\mathrm{H}}\right)$

Figure 5. The proposed generation of $\mathrm{O}_{2}{ }^{\bullet-}$ in Cyt b6f. (A) In the $\mathrm{Q}$ o site of Cyt b6f, $\mathrm{PQH}^{\bullet}$ is generated (Table 2) by the $2 \mathrm{Fe}-2 \mathrm{~S}$ cluster of the high-potential Rieske iron-sulfur protein. $\mathrm{PQ}^{\bullet-}$ that has a long residence time within the $Q_{\mathrm{O}}$ pocket, and cytochrome $b_{\mathrm{L}}$ can also serve as a reductant for the generation of $\mathrm{O}_{2}{ }^{\bullet-}$ in Cyt b6f. In addition, $\mathrm{HO}_{2}{ }^{\bullet}$, can be reduced by cytochrome $b_{\mathrm{L}}$ to form $\mathrm{H}_{2} \mathrm{O}_{2}$ [317]. (B) The proposed generation of $\mathrm{O}_{2}{ }^{--}$in Cyt b6f in the presence of DNP-INT, an inhibitor of $\mathrm{PQH}_{2}$ oxidation by Cyt b6f. The oxidation of $\mathrm{PQH}_{2}$ does not occur in $\mathrm{Q}_{\mathrm{O}}$ site, formation of $\mathrm{PQH}^{\bullet}$ and its deprotonation can occur in the Qi site. $\mathrm{PQH}^{\bullet}$ can be oxidized in subsequent reactions with $\mathrm{O}_{2}$ or with hemes $b_{\mathrm{H}}$ or $b_{\mathrm{L}}$. $\mathrm{H}_{2} \mathrm{O}_{2}$ can be formed via the reaction of $\mathrm{O}_{2}{ }^{\bullet-}$ with $\mathrm{PQH}_{2}$ or via the reaction of $\mathrm{HO}_{2}{ }^{\bullet}$ with cytochrome $b_{\mathrm{H}}$ or cytochrome $b_{\mathrm{L}}$.

\section{Damage Caused by ROS in the Chloroplast}

\subsection{Damage to PSII}

PSII is the main producer of ${ }^{1} \mathrm{O}_{2}$ in the chloroplast and a minor producer of other ROS (see Section 3.2), and therefore it is of great interest whether PSII is damaged by ${ }^{1} \mathrm{O}_{2}$. In isolated PSII core complexes, electron transfer activity is lost and pigments are bleached only in the presence of $\mathrm{O}_{2}$, suggesting an effect of ROS [318]. Furthermore, PSII is sensitive to damage caused by externally applied ${ }^{1} \mathrm{O}_{2}$, as shown by a decrease in the quantum yield of PSII in lincomycin-treated tobacco leaves illuminated with the ${ }^{1} \mathrm{O}_{2}$ sensitizer Rose Bengal [189].

The above results indicate that PSII can be damaged by ${ }^{1} \mathrm{O}_{2}$ but do not prove that ${ }^{1} \mathrm{O}_{2}$ produced by PSII is the agent of damage in the photoinhibition of PSII (for reviews, see [319,320]). The photoinhibition of thylakoid membranes does not depend on $\mathrm{O}_{2}$ and has a similar action spectrum under aerobic and anaerobic conditions [321], and photoinhibition in lincomycin-treated spinach leaf disks is only slightly slower in $\mathrm{CO}_{2}$ doped $\mathrm{N}_{2}$ than in air [322]. The effects of both deuterium oxide and ROS scavengers (reviewed by [319]) are variable and may depend on the type of complex. Similarly, effects of intrinsic ${ }^{1} \mathrm{O}_{2}$ quenchers and scavengers vary, as overproduction of the xanthophyll zeaxanthin protects against photoinhibition in vivo in the green alga Chlamydomonas reinhardtii [323] and the carotenoid-rich mutant $\triangle$ SigCDE of the cyanobacterium Synechocystis sp. PCC 6803 show protection against the damaging reaction of photoinhibition [193], whereas the same reaction is not more rapid in $\alpha$-tocopherol-deficient mutants of Arabidopsis [324] and Synechocystis [325]. Further indirect evidence on the participation of ${ }^{1} \mathrm{O}_{2}$ in photoinhibition of PSII also varies, as the modification of the recombination reactions of PSII 
toward non- ${ }^{1} \mathrm{O}_{2}$-producing direction provides protection against photoinhibition [326], whereas the protection offered by NPQ is very limited [327], suggesting that the photoinhibition of PSII may not depend only on the excitation of $\mathrm{Chl}[320,328]$. The photoinhibition-tolerant green alga Chlorella ohadii exhibits a recombination reaction model that is expected to lead to low ${ }^{1} \mathrm{O}_{2}$ production [329].

Apart from their direct effect on PSII electron transfer activity, ROS have been shown to cause loss [318] and fragmentation [330-333] of the D1 protein in isolated PSII core complexes [330] and PSII membranes [333]. Both ${ }^{1} \mathrm{O}_{2}$ [330] and $\mathrm{H}_{2} \mathrm{O}_{2}$ [332] cause fragmentation of the D1 protein. Miyao [333] concluded, on the basis of the protective effects of ROS scavengers, that several ROS, including $\mathrm{O}_{2}{ }^{\bullet-}$, $\mathrm{H}_{2} \mathrm{O}_{2},{ }^{1} \mathrm{O}_{2}$ and $\mathrm{HO}^{\bullet}$, participate in protein damage in PSII. The connection of these results to what happens in vivo is unclear, as the proteases responsible for the degradation of the D1 protein in vivo (for review, see [334]) have not been shown to be present in isolated PSII preparations. Kale et al. [335] detected the formation of $\mathrm{O}_{2}{ }^{\bullet-}$ and $\mathrm{HO}^{\bullet}$ in illuminated PSII membranes. Furthermore, the oxidative modifications of several amino acid residues of the D1 and D2 proteins were found to be associated with the formation of the radicals. Interestingly, both radicals were formed by PSII membranes throughout the illumination period, suggesting that they could contribute to the $\mathrm{O}_{2}$-dependent part of photoinhibition of PSII.

\subsection{Damage to PSI}

PSI has long been known to become inhibited, at least in certain plants, at chilling temperatures [336], in a reaction that depends on electron transfer from PSII to PSI [337]. The damage targets the iron-sulfur centers of PSI, and the remaining inactive PSI still functions as an excitation energy quencher [338]. The dependence of the photoinhibition of PSI on electron transfer, and the ability of PSI to reduce $\mathrm{O}_{2}$ to $\mathrm{O}_{2}{ }^{\bullet-}$, strongly suggest that $\mathrm{O}_{2}{ }^{\bullet-}, \mathrm{H}_{2} \mathrm{O}_{2}$ or $\mathrm{HO}$ participate in the damage [339]. However, neither the identity of the inhibitory ROS nor the exact site and the mechanism of production are known. Damage to PSI can be specifically induced by the application of fluctuating light, either in the form of short (10-300 ms) strong flashes [340], or in the form of few-seconds-long, saturating but not very strong flashes fired on top of short-term exposure of the plant to weak, PSII-specific light [341].

\subsection{Oxidation of Membrane Lipids by ROS}

Unsaturated fatty acids of membrane lipids can become peroxidated in a reaction with ${ }^{1} \mathrm{O}_{2}$ (Reaction (20)) or $\mathrm{HO}^{\bullet}$ (reaction (77)). Peroxidation by ${ }^{1} \mathrm{O}_{2}$ dominates the non-enzymatic formation of lipid peroxides in leaves, whereas radical-induced peroxidation is more common in non-photosynthetic tissues [4].

Fatty acid peroxides, in turn, decompose either spontaneously or enzymatically to oxylipin carbonyls [342]. Tri-unsaturated fatty acids especially fragment to malondialdehyde that is highly reactive in its protonated dialdehyde form $(\mathrm{O}=\mathrm{CH}-\mathrm{CH} 2-\mathrm{CH}=\mathrm{O})$ [343]. Both malondealdehyde and acrolein, another highly reactive fragmentation product, are produced under non-stressed conditions but their concentrations increase during stress [344,345]. Lipid-peroxide-derived aldehydes and ketones like malondialdehyde function both as agents of damage and signaling molecules in Arabidopsis $[344,346]$. Due to their reactivity towards ROS, tri-unsaturated fatty acids may function as ROS sinks [347], and signaling by products of lipid oxidation may be essential for plant cells' ability to survive oxidative stress [346].

\subsection{Damage to Stromal Proteins}

The production of ROS in the chloroplast is expected to damage proteins of the compartment of origin. In thylakoid membranes, light-induced damage primarily targets the photosystems. In the stroma, several proteins are known to be targets of ROS damage. The inhibitory effects are often ascribed to the oxidation of cysteine residues. 
ROS have a strong inhibitory effect on translation in cyanobacteria [348]. The mechanism of the inhibition by $\mathrm{H}_{2} \mathrm{O}_{2}$ is the oxidation of cysteine residues and the subsequent formation of an intramolecular disulfide bond in translation elongation factor G [348], and the formation of a sulfenic acid and an intermolecular disulfide bond in elongation factor $\mathrm{Tu}[349,350]$. The inhibition of translational elongation exerts its effect on the activity of PSII by inhibiting or slowing down the turnover of the D1 protein [351]. Similar ROS effects are expected in chloroplasts.

The Calvin-Benson cycle is inhibited by $\mathrm{H}_{2} \mathrm{O}_{2}$ [352] with the ribulose-1,5-bisphosphate carboxylase oxygenase (rubisco) as the most important target of oxidation [353]. Analysis of the proteome of $\mathrm{H}_{2} \mathrm{O}_{2}$-treated chloroplasts revealed modified cysteine residues in both subunits of rubisco, Fd-dependent glutamate synthase, ferredoxin-NADP ${ }^{+}$oxidoreductase 1 (FNR1) and glyceraldehyde 3-phosphate dehydrogenase subunit $\mathrm{B}$, and a similar analysis after methyl viologen treatment revealed oxidative changes in 24 chloroplast proteins and modified cysteines in rubisco large subunit, FNR1, myrosinase and $\mathrm{NAD}(\mathrm{P})$-binding Rossman-fold-containing protein [353]. The authors suggested that, due to its large amount, rubisco functions as a redox buffer in the chloroplast.

\subsection{Damage to Chloroplast DNA}

ROS are known to react with DNA [2], and chloroplast DNA is not an exception. A comparison of the integrity of DNA of the chloroplasts of mesophyll and bundle sheath cells of maize, a C4 plant, offers insight into ROS damage within the chloroplasts [354]. In C4 plants, mesophyll cells carry out the photosynthetic electron transfer reactions that produce NADPH and ATP, but also ROS, whereas the bundle sheath chloroplasts are almost devoid of PSII that produces $\mathrm{O}_{2}$. A drastically larger amount of DNA damage, analyzed with a long-sequence-specific variant of polymerase chain reaction, was found in the chloroplast DNA of light-grown maize plants in mesophyll cells than in bundle sheath cells [354]. Interestingly, mitochondrial DNA showed a similar difference between mesophyll and bundle sheath mitochondria. Doping soil with $\mathrm{Cr}(\mathrm{VI})$ that causes ROS production in leaves also caused damage, visualized by staining with 4',6-diamidino-2- phenylindole, in the chloroplast DNA [355].

\section{Detoxification of ROS in Plant Chloroplasts}

\subsection{Detoxification of $\mathrm{O}_{2}{ }^{\bullet-}$ and $\mathrm{H}_{2} \mathrm{O}_{2}$}

Plants have evolved a multitude of enzymatic and non-enzymatic ROS-scavenging and quenching mechanisms. ROS-mediated signaling and ROS detoxification are coupled, as signaling is generally initiated by the oxidation of target molecules, that therefore also act as antioxidants (see reviews $[10,356,357])$. Here, we discuss the main scavenging mechanisms and antioxidant molecules controlling ROS in the chloroplasts, with emphasis on ROS detoxification in the thylakoid membrane, or stromal-scavenging mechanisms in its immediate vicinity.

$\mathrm{O}_{2}{ }^{\bullet-}$, produced in chloroplasts, is scavenged efficiently by copper/zinc SODs residing on the stromal face of the thylakoid membrane [12,358]. The dismutation reaction, catalyzed by CuZnSODs, is described in Reactions (5), (44) and (45). While SOD is the main catalyst, the dismutation reaction can also be catalyzed by redox reactive metals such as manganese [359,360], or it can occur non-catalytically [68]. $\mathrm{O}_{2}{ }^{\bullet-}$ can also oxidize two highly important chloroplast antioxidants, $\mathrm{AscH}_{2}$ [62,64] (Reaction (34)) and GSH [66,67] (Reaction (37)).

$\mathrm{H}_{2} \mathrm{O}_{2}$ is reduced by $\mathrm{AscH}_{2}$ in a reaction catalyzed by APXs (Reactions (62)-(64)) [93]. The net reaction of $\mathrm{H}_{2} \mathrm{O}_{2}$ scavenging by $\mathrm{AscH}_{2}$ can be summarized as (Reaction (126)).

$$
\mathrm{H}_{2} \mathrm{O}_{2}+2 \mathrm{AscH}_{2} \rightarrow 2 \mathrm{H}_{2} \mathrm{O}+2 \mathrm{MDA}+2 \mathrm{H}^{+}
$$

The reaction produces water and MDA. Different APX isoenzymes are found in different chloroplast compartments. Stromal APXs and thylakoid APXs have specific roles in, e.g., plant development, but exhibit functional redundancy in ROS detoxification in mature leaves [361-363]. The rest of the 
ascorbate-glutathione cycle regenerates $\mathrm{AscH}_{2}[12,364]$. The first step is the reduction of MDA to $\mathrm{AscH}_{2}$ by $\mathrm{Fd}_{\text {red }}$ (Reaction (127)),

$$
\mathrm{MDA}+\mathrm{Fd}_{\mathrm{red}}+2 \mathrm{H}^{+} \rightarrow \mathrm{AscH}_{2}+\mathrm{Fd}
$$

or by NADPH in a reaction catalyzed by MDA reductase (Reaction (128)).

$$
2 \mathrm{MDA}+\mathrm{NADPH}+3 \mathrm{H}^{+} \rightarrow 2 \mathrm{AscH}_{2}+\mathrm{NADP}^{+}
$$

The complete description of the catalytic cycle of reduction of MDA to $\mathrm{AscH}_{2}$ is described in [12]. The MDA molecules that are not immediately reduced dismutate non-catalytically, forming $\mathrm{AscH}_{2}$ and DHA (Reaction (113)).

GSH donates electrons to DHA either non-catalytically or through catalytic oxidation mediated by DHA reductase, forming $\mathrm{AscH}_{2}$ and glutathione disulfide (GSSG) (Reaction (129)).

$$
\mathrm{DHA}+2 \mathrm{GSH} \rightarrow \mathrm{AscH}_{2}+\mathrm{GSSG}
$$

NADPH, formed by the PETC, is then used by glutathione reductase to reduce GSSG back to GSH (Reaction (130))

$$
\mathrm{GSSG}+\mathrm{NADPH}+\mathrm{H}^{+} \rightarrow \mathrm{NADP}^{+}+2 \mathrm{GSH},
$$

thereby completing the ascorbate-glutathione cycle. The functions of APXs in plants have been reviewed by [365]. Because the electrons utilized in the reduction of $\mathrm{O}_{2}$ to $\mathrm{O}_{2}{ }^{\bullet-}$ by PSI originate from water molecules broken down by PSII, and the end product of the production and scavenging of $\mathrm{H}_{2} \mathrm{O}_{2}$ is water, the whole scavenging system is often referred to as the water-water cycle [12].

PRXs, particularly two-cysteine peroxiredoxins (2-Cys PRX), have been shown to function in conjunction with thylakoid APXs in downplaying $\mathrm{H}_{2} \mathrm{O}_{2}$ accumulation during conditions causing oxidative stress in plants [366-368]. 2-Cys PRXs facilitate a peroxidative reduction of $\mathrm{H}_{2} \mathrm{O}_{2}$, utilizing electrons from NADPH in a reaction catalyzed by thioredoxin reductase $\mathrm{C}$ or, less efficiently, from reduced TRXs [366-368]. The catalytic cycle of peroxide detoxification by 2-Cys PRXs and their subsequent regeneration is described in detail in [369]. NADPH is produced both in the light, by PETC, and in the dark, by the oxidative pentose phosphate pathway [370], whereas TRXs are recycled to their reduced form by Fd produced in the light by PSI; the reduction in TRXs is catalyzed by thioredoxin reductases [371]. 2-Cys PRXs are not the only enzymes that can facilitate TRX-dependent $\mathrm{H}_{2} \mathrm{O}_{2}$ detoxification, as glutathione peroxidases also utilize TRXs as substrates instead of reduced glutathiones in plant chloroplasts, and can likely initiate a similar cycle to 2-Cys PRXs [372-375]. Many other components have been suggested to take part in the recycling of the PRX/glutathione peroxidases-initiated $\mathrm{H}_{2} \mathrm{O}_{2}$ detoxification cycle, such as glutaredoxin, cyclophilins and $\mathrm{AscH}_{2}$ [369].

\subsection{Detoxification of ${ }^{1} \mathrm{O}_{2}$}

Carotenoids and tocopherols are the main antioxidants against ${ }^{1} \mathrm{O}_{2}$ in chloroplasts [43]. Carotenoids function in the NPQ of singlet excited $\mathrm{Chl}$ (reviewed in $[376,377]$ ), quench ${ }^{3} \mathrm{Chl}$ and quench and scavenge ${ }^{1} \mathrm{O}_{2}$. Each LHCII subunit contains two luteins, a neoxanthin and a violaxanthin/zeaxanthin [378]. All eight $\mathrm{Chl} a$ molecules of an LHCII subunit are positioned within close proximity to either of the two luteins or neoxanthin, which facilitates efficient ${ }^{3} \mathrm{Chl}$-quenching especially by lutein, and lowers the probability of ${ }^{3} \mathrm{Chl}$ interaction with $\mathrm{O}_{2}$, quenching $95 \%$ of ${ }^{3} \mathrm{Chl}$ in LHCII [43,369-381]. Violaxanthin and zeaxanthin are not likely to be involved in ${ }^{3} \mathrm{Chl}$ quenching in LHCII, as they are bound far from the Chl molecules [382,383]. However, zeaxanthin can quench ${ }^{3}$ Chls in the monomeric Lhcb antenna subunits of PSII (Lhcb4-6) and in the dimeric Lhca subunits of PSI antennae [384]. In LHCII, zeaxanthin is specifically involved in NPQ. In high light, zeaxanthin is produced by violaxanthin de-epoxidase from violaxanthin through the intermediate antheraxanthin, 
and the newly formed zeaxanthin replaces violaxanthin in LHCII. A switch back to moderate light or darkness induces the epoxidation of zeaxanthin back to violaxanthin and the subsequent replacement of zeaxanthin with violaxanthin in LHCII [385].

The PSII core, consisting of the proximal antennae CP43 and CP47, the Mn-cluster and the RC (D1/D2/Cyt b559) [386,387], binds $11 \beta$-carotenes, two of which are located in the RC [386]. The distance between these two $\beta$-carotenes and the RC Chl P680 is too long to allow the participation of the $\beta$-carotenes in quenching of ${ }^{3} \mathrm{P} 680[170,191,386,388]$. However, there are indications that $\beta$-carotenes in other parts of the isolated PSII core are likely to quench ${ }^{3} \mathrm{Chls}$ [386].

The detoxification of ${ }^{1} \mathrm{O}_{2}$ itself [192] by carotenoids occurs mainly through physical quenching via electronic energy transfer mechanism (Reaction (17), where $\mathrm{A}$ is a carotenoid). The resulting triplet state of the carotenoid $\left({ }^{3} \mathrm{Car}\right)$ dissipates its excitation energy via a nonradiative transition to its ground state $[23,41,43,389]$. Carotenoids can also take part in the chemical scavenging of ${ }^{1} \mathrm{O}_{2}[43,390]$. Oxidation products of $\beta$-carotene found in plants in high light suggest that ${ }^{1} \mathrm{O}_{2}$ can oxidize the $\beta$-carotenes of PSII reaction centre [301,390]. $\beta$-cyclocitral $(\beta-C C)$, a volatile product of oxidation of $\beta$-carotene by ${ }^{1} \mathrm{O}_{2}$, has been shown to be involved in cell signaling [391] (see Section 6.1). In LHCII, ${ }^{1} \mathrm{O}_{2}$ produced by the interaction between $\mathrm{O}_{2}$ and the residual ${ }^{3} \mathrm{Chl}$ that is not quenched by carotenoids, is rapidly inactivated, due to the abundance of carotenoids in LHCII and free carotenoids such as zeaxanthin in the surrounding lipid matrix [388,392].

Other antioxidants in the thylakoid membrane are not bound to LHCs or, in stroma, offer an even greater capacity for the physical or chemical quenching of ${ }^{1} \mathrm{O}_{2}$. Tocopherols, or specifically $\alpha$-tocopherol, are considered as important antioxidants against ${ }^{1} \mathrm{O}_{2}$ [393]. The rate constants of the physical quenching of ${ }^{1} \mathrm{O}_{2}$ by tocopherols in organic solvents are significantly higher than those of chemical scavenging [389], suggesting that, similarly to carotenoids, the main quenching mechanism by $\alpha$-tocopherol is physical quenching (Reaction (17)) [43]. However, the oxidation of $\alpha$-tocopherol by ${ }^{1} \mathrm{O}_{2}$ produces 8-hydroperoxy-tocopherone that can be re-reduced to $\alpha$-tocopherol by $\mathrm{AscH}_{2}[394,395]$, which lends the recyclability of the stromal ascorbate-glutathione cycle to ${ }^{1} \mathrm{O}_{2}$ detoxification of the lipid phase. $\mathrm{AscH}_{2}$ also has the capacity to scavenge ${ }^{1} \mathrm{O}_{2}$ (reaction 24) that reaches the stroma [47]. Chloroplasts contain flavonoids in the envelope membrane, and they have the potential to quench ${ }^{1} \mathrm{O}_{2}$ both physically and chemically [396,397]. Even though the relatively remote location from the most prominent ${ }^{1} \mathrm{O}_{2}$ production sites does put their role as ${ }^{1} \mathrm{O}_{2}$ antioxidants in question, flavonoids have been shown to be involved in lowering the amount of ${ }^{1} \mathrm{O}_{2}$ in high light in vivo [397]. Other potential ${ }^{1} \mathrm{O}_{2}$ antioxidants include polyunsaturated fatty acids [4], $\mathrm{PQH}_{2}[48,305-307,398]$ and isoprene $[399,400]$.

\section{ROS Produced by Plant Chloroplasts Function as Signaling Molecules}

ROS are known to participate in retrograde signaling, acclimation to biotic or abiotic stresses, programmed cell death (PCD) and many other processes (for recent reviews, see [9-11,401-407]). Here, we aim to briefly summarize what is known (and what is not) about how chloroplast-derived ROS are sensed and how the signaling cascades are initiated. Signaling by ROS produced by enzymes like NADPH-oxidase (reviewed in [408]) will not be discussed here.

\subsection{Signaling by ${ }^{1} \mathrm{O}_{2}$}

The lifetime of ${ }^{1} \mathrm{O}_{2}$ in plant cells has not been measured, but is generally assumed to be too short (for review, see [23]; Section 2.1.4) to enable diffusion out of chloroplasts and, consequently, ${ }^{1} \mathrm{O}_{2}$ itself is unlikely to function as a messenger molecule. Instead, the accumulation of $\beta$-CC (a reaction product of $\beta$-carotene and ${ }^{1} \mathrm{O}_{2}$ ) has been shown to induce gene expression, leading to stress (e.g., high light) acclimation $[391,409,410]$. In theory, $\beta$-CC could directly travel to the nucleus and activate ${ }^{1} \mathrm{O}_{2}$ responsive genes (for discussion, see [411]), however, direct evidence is lacking. Methylene Blue Sensitivity 1 protein might participate in transferring the signal from cytosol to the nucleus [412,413]. In addition, $\beta$-CC can be converted to water-soluble $\beta$-cyclocitric acid, which also could function as a signaling molecule [410]. Other oxidation products of ${ }^{1} \mathrm{O}_{2}$ might have signaling functions, too [346,414]. 
Another ${ }^{1} \mathrm{O}_{2}$-induced pathway involves the Executer1 (EX1) (and possibly Executer2) proteins [415,416]. The oxidation of a tryptophan residue of EX1, presumably by ${ }^{1} \mathrm{O}_{2}$ [417], leads to the degradation of EX1 by FtsH, a protease that is also important to the repair cycle of PSII [418]. Afterwards, a signaling cascade leading to PCD is activated [419]. EX1 is not simply a repressor of the PCD pathway [407], however, it is not understood how the degradation of EX1 leads to the induction of PCD. In addition to cell death, EX1 is important in systemic acquired acclimation [420].

The $\beta$-CC and EX1 pathways are thought to operate independently [391]. A possible explanation of the need for two pathways is that small amounts of ${ }^{1} \mathrm{O}_{2}$ lead to acclimation responses while larger amounts initiate PCD (and still higher amounts cause damage and unregulated cell death [403]). Accordingly, under severe stress, the $\beta$-CC pathway, through Oxidative Signal-Inducible 1 kinase, may also lead to PCD, but even this route is EX1-independent [421,422]. Most $\beta$-CC is produced from the $\beta$-carotene located in the RC of PSII [390,423], and therefore in the grana core [424], whereas EX1 is located in grana margins [425]. As ${ }^{1} \mathrm{O}_{2}$ is not expected to diffuse far, the site of production rather than the amount may determine which signaling pathway is activated.

Why do plants need to react differently to ${ }^{1} \mathrm{O}_{2}$ produced in different sites? PSII repair occurs mainly in grana margins (for a review, see [426]), and it has been speculated that EX1 would activate PCD if PSII repair is impaired, possibly under adverse environmental conditions when loose Chls might produce ${ }^{1} \mathrm{O}_{2}$ [425]. Chl turnover was shown to associate with the repair of PSII [427], implying ${ }^{1} \mathrm{O}_{2}$ generation, even though $\mathrm{Chl}$ synthesis and degradation are tightly regulated and loose Chls are thought to be bound to specific proteins that prevent ${ }^{1} \mathrm{O}_{2}$ production [428]. During a low light to high light transition, the FtsH-protease may get transiently inactivated (possibly indirectly by $\mathrm{H}_{2} \mathrm{O}_{2}$; [429]), thus preventing activation of the EX1-induced PCD. This is in agreement with the view that the EX1 pathway does not respond to high light stress, but it is the $\beta$-CC pathway that initiates high light acclimation. Alternatively, the EX1 pathway might be important in plant defense against pathogens $[402,430] .{ }^{1} \mathrm{O}_{2}$ produced by $\mathrm{Chl}$ catabolites has been proposed to be involved in the hypersensitive response [431], and similarly to the $f l u$-mutant [115], ${ }^{1} \mathrm{O}_{2}$ produced by $\mathrm{Chl}$ catabolites has been suggested to initiate the EX1 pathway also in the wild type [432]. Interestingly, NADPH-protochlorophyllide oxidoreductases were shown to associate with EX1 and FtsH [425], though the interactions may be weak or transient, as they are not always observed [433]. PSII is a target of many pathogens [434] and a non-functional PSII repair cycle might also be involved in plant immunity [435]. However, the physiological role of the EX1 pathway is still unclear.

\subsection{Signaling by $\mathrm{H}_{2} \mathrm{O}_{2}$}

In contrast to ${ }^{1} \mathrm{O}_{2}$, the long lifetime of $\mathrm{H}_{2} \mathrm{O}_{2}$ enables its function as a messenger molecule. Exposito-Rodriguez et al. [436] observed that photosynthesis-derived $\mathrm{H}_{2} \mathrm{O}_{2}$ rapidly accumulated in the nuclei, and the addition of cytosolic $\mathrm{H}_{2} \mathrm{O}_{2}$ scavengers did not prevent this. The authors proposed that $\mathrm{H}_{2} \mathrm{O}_{2}$ originated from chloroplasts closely associated with the nucleus. The diffusion of $\mathrm{H}_{2} \mathrm{O}_{2}$ through membranes is not extremely rapid [95], but the transport may be facilitated by (specialized?) aquaporins [95,437,438]. The formation of stromules has been observed under stress [439], and they have been suggested to allow for direct contact between chloroplasts and the nucleus [440]. Another hurdle that chloroplast-originated $\mathrm{H}_{2} \mathrm{O}_{2}$ needs to overcome is that the powerful antioxidant systems of stroma (see Section 5.1) are believed to efficiently scavenge $\mathrm{H}_{2} \mathrm{O}_{2}$. Accordingly, it has been proposed that $\mathrm{H}_{2} \mathrm{O}_{2}$ produced inside the thylakoid membranes (see Section 3.2) might have a great importance in signaling [441]. On the contrary, a meta-analysis of 79 transcriptomic studies concluded that ROS responses are determined by timing rather than the site of origin [442]. Therefore, $\mathrm{H}_{2} \mathrm{O}_{2}$ may participate in multiple pathways, some of which are sensitive to the site of $\mathrm{H}_{2} \mathrm{O}_{2}$ production [443].

$\mathrm{H}_{2} \mathrm{O}_{2}$ is involved in many signaling pathways. For example, photosynthesis-derived ROS, probably $\mathrm{H}_{2} \mathrm{O}_{2}$, may induce enzymatic $\mathrm{O}_{2}{ }^{\bullet-}$ production by cytosolic NADPH-oxidases 408]. In addition, a reduced $P Q$ pool was proposed to cause stomatal closure via $\mathrm{H}_{2} \mathrm{O}_{2}$ accumulation [444]. 
Borisova-Mubarakshina et al. [445] showed evidence that $\mathrm{H}_{2} \mathrm{O}_{2}$ regulates PSII antenna size in barley during long-term acclimation to high light.

It is not clear what senses $\mathrm{H}_{2} \mathrm{O}_{2}$ in plant cells. SAL1 (an inositol polyphosphate 1-phosphatase) degrades phosphoadenosine phosphate (PAP) in chloroplasts. The oxidation of cysteine residues of SAL1, e.g., under high light, probably by $\mathrm{H}_{2} \mathrm{O}_{2}$, leads to the inactivation of SAL1 and accumulation of PAP [446]. PAP can be transported into the nucleus and activate genes protecting plants from oxidative stress $[447,448]$. In addition, it has been proposed that a glutathione peroxidase [449], heat shock transcription factors [450], APX [362] and protein phosphatases (reviewed in [451]) might function as $\mathrm{H}_{2} \mathrm{O}_{2}$ sensors.

In general, genes responding to ${ }^{1} \mathrm{O}_{2}$ were found to differ from those known to be regulated by $\mathrm{H}_{2} \mathrm{O}_{2}$ [391]. The available data suggest that $\mathrm{H}_{2} \mathrm{O}_{2}$ actually antagonizes EX1-mediated ${ }^{1} \mathrm{O}_{2}$ signaling [452,453]. On the other hand, $\mathrm{H}_{2} \mathrm{O}_{2}$ and the $\beta$-CC-mediated ${ }^{1} \mathrm{O}_{2}$ signaling pathways may converge at Oxidative Signal-Inducible 1 kinase [407,454]. $\beta$-CC also down-regulates SAL1 and up-regulates genes generating PAP [391,423], supporting the view that both $\mathrm{H}_{2} \mathrm{O}_{2}$ - and $\beta$-CC-signaling pathways induce stress acclimation.

\subsection{Signaling by $\mathrm{O}_{2}^{\bullet-}$}

In plant cells, SOD rapidly converts $\mathrm{O}_{2}{ }^{\bullet-}$ to $\mathrm{H}_{2} \mathrm{O}_{2}$. The reactivity of $\mathrm{O}_{2}{ }^{\bullet-}$ may also limit its specificity in signaling. However, the literature suggests that a set of genes is specifically induced by $\mathrm{O}_{2}{ }^{\bullet-}$ [455-457]. For example, Zinc-Finger Protein 12 was shown to be induced more strongly by $\mathrm{O}_{2}{ }^{\bullet-}$ than by $\mathrm{H}_{2} \mathrm{O}_{2}$ [458].

Author Contributions: Conceptualization, S.K., E.T., V.H. and H.M.; writing-original draft preparation, S.K., V.H., H.M. and E.T.; writing-review and editing, E.T., S.K., H.M. and V.H.; visualization, S.K.; supervision, E.T.; project administration, E.T.; funding acquisition, E.T. All authors have read and agreed to the published version of the manuscript.

Funding: This study was supported by the Academy of Finland (grant 307335, to ET), by Vilho, Yriö and Kalle Väisälä Foundation (to HM), University of Turku Graduate School and Finnish Cultural Foundation (to VH).

Conflicts of Interest: The authors declare no conflict of interest. The funders had no role in the design of the study; in the collection, analyses, or interpretation of data; in the writing of the manuscript, or in the decision to publish the results.

\section{Abbreviations}

\begin{tabular}{|c|c|}
\hline$\beta-C C$ & $\beta$-cyclocitral \\
\hline${ }^{1} \mathrm{Chl},{ }^{1} \mathrm{Chl}^{*}$ and ${ }^{3} \mathrm{Chl}$ & respectively, singlet state, singlet excited state and triplet excited state of chlorophyll \\
\hline${ }^{1} \mathrm{O}_{2}$ & singlet oxygen $\left({ }^{1} \Delta \mathrm{gO}_{2}\right)$ \\
\hline 2-Cys PRX & two-cysteine peroxiredoxin \\
\hline A & acceptor \\
\hline $\mathrm{A}_{1}$ & phylloquinone of PSI \\
\hline APX & ascorbate peroxidase \\
\hline $\mathrm{AscH}_{2}$ & ascorbate, ascorbic acid \\
\hline Car and ${ }^{3}$ Car & respectively, singlet and triplet state of carotenoid \\
\hline CAT & catalase \\
\hline Chl and $\mathrm{Chl}^{*}$ & respectively, chlorophyll and excited chlorophyll \\
\hline Chl $a$ & chlorophyll $a$ \\
\hline cyt & cytochrome \\
\hline cyt b559 & cytochrome b559 \\
\hline Cyt b6f & cytochrome b6/f complex \\
\hline DBMIB & 2,5-dibromo-6-isopropyl-3-methyl-1,4-benzoquinone \\
\hline DCMU & 3-(3,4-di-chlorophenyl)-1,1-dimethyl urea \\
\hline DHA & dehydroascorbate; DMF, dimethylformamide \\
\hline DNP-INT & 2-(2,4-dinitrophenoxy)-3-iodo-4-methyl-1-(1-methylethyl)-5-nitro-benzene \\
\hline$E m$ & midpoint redox potential \\
\hline$E_{0}^{\prime}$ & standard redox potential \\
\hline EPR & electron paramagnetic resonance \\
\hline EX1 & Executer1 \\
\hline $\mathrm{Fd}, \mathrm{Fd}_{\mathrm{ox}}$ and $\mathrm{Fd}_{\mathrm{red}}$ & ferredoxin, and oxidized and reduced ferredoxin, respectively \\
\hline FL & flavin \\
\hline $\mathrm{FL}^{\bullet-}$ & anion form of flavin semiquinone \\
\hline
\end{tabular}




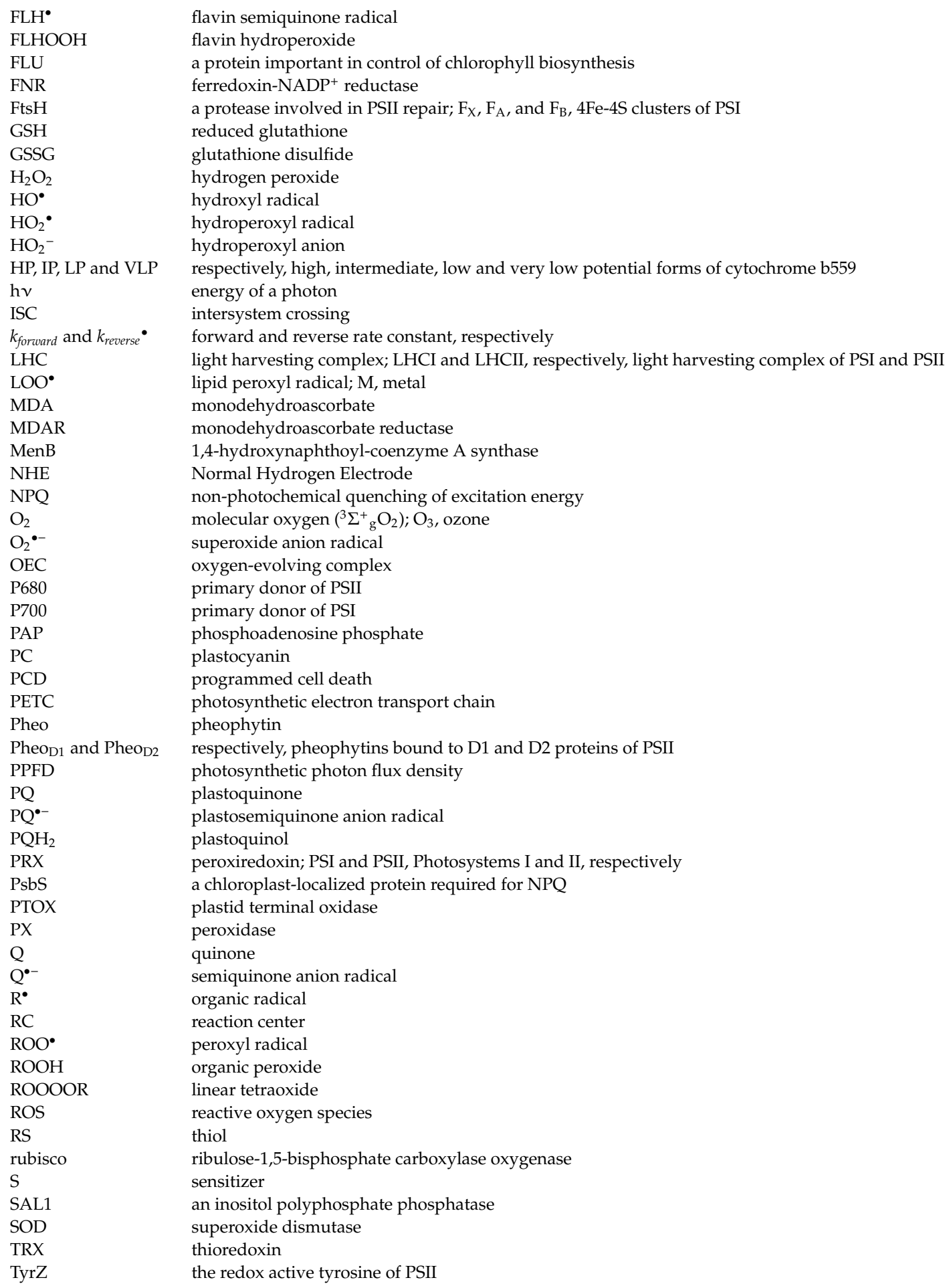

\section{References}

1. Steiger, H.M.; Beck, E.; Beck, R. Oxygen concentration in isolated chloroplasts during photosynthesis. Plant Physiol. 1977, 60, 903-906. [CrossRef]

2. Halliwell, B.; Gutteridge, J.M.C. Free Radicals in Biology and Medicine, 5th ed.; Oxford University Press: New York, NY, USA, 2015.

3. Tyystjärvi, E. Phototoxicity. In Plant Cell Death Processes; Noodén, L.D., Ed.; Academic Press: San Diego, CA, USA, 2004; pp. 271-283. 
4. Triantaphylidès, C.; Krischke, M.; Hoeberichts, F.A.; Ksas, B.; Gresser, G.; Havaux, M.; Van Breusegem, F.; Mueller, M.J. Singlet oxygen is the major reactive oxygen species involved in photooxidative damage to plants. Plant Physiol. 2008, 148, 960-968. [CrossRef]

5. Asada, K. Production and scavenging of reactive oxygen species in chloroplasts and their functions. Plant Physiol. 2006, 141, 391-396. [CrossRef]

6. Miyake, C.; Yonekura, K.; Kobayashi, Y.; Yokota, A. Cyclic electron flow within PSII functions in intact chloroplasts from spinach leaves. Plant Cell Physiol. 2002, 43, 951-957. [CrossRef]

7. Heber, U. Irrungen, Wirrungen? The Mehler reaction in relation to cyclic electron transport in $\mathrm{C}_{3}$ plants. Photosynth. Res. 2002, 73, 223-231. [CrossRef]

8. Peltier, G.; Tolleter, D.; Billon, E.; Cournac, L. Auxiliary electron transport pathways in chloroplasts of microalgae. Photosynth. Res. 2010, 106, 19-31. [CrossRef]

9. Noctor, G.; Reichheld, J.P.; Foyer, C.H. ROS-related redox regulation and signaling in plants. Semin. Cell Dev. Biol. 2018, 80, 3-12. [CrossRef] [PubMed]

10. Foyer, C.H. Reactive oxygen species, oxidative signaling and the regulation of photosynthesis. Environ. Exp. Bot. 2018, 154, 134-142. [CrossRef] [PubMed]

11. Foyer, C.H.; Noctor, G. Ascorbate and glutathione: The heart of the redox hub. Plant Physiol. 2011, 155, 2-18. [CrossRef] [PubMed]

12. Asada, K. The water-water cycle in chloroplasts: Scavenging of active oxygens and dissipation of excess photons. Annu. Rev. Plant Physiol. Plant Mol. Biol. 1999, 50, 601-639. [CrossRef] [PubMed]

13. Myake, C. Alternative electron flows (water-water cycle and cyclic electron flow around PSI) in photosynthesis: Molecular mechanisms and physiological functions. Plant Cell Physiol. 2010, 51, 1951-1963. [CrossRef] [PubMed]

14. Krinsky, N.I. Singlet oxygen in biological systems. Trends Biochem. Sci. 1977, 2, 35-38. [CrossRef]

15. Krasnovsky, A.A., Jr. Singlet oxygen and primary mechanisms of photodynamic therapy and photodynamic diseases. In Photodynamic Therapy at the Cellular Level; Uzdensky, A.B., Ed.; Research Signpost: Kerala, India, 2007; pp. 17-62.

16. Krasnovsky, A.A., Jr. Singlet molecular oxygen and primary mechanisms of photo-oxidative damage of chloroplasts. Studies based on detection of oxygen and pigment phosphorescence. Proc. R. Soc. Edinb. 1994, 102, 219-235. [CrossRef]

17. Schweitzer, C.; Schmidt, R. Physical mechanisms of generation and deactivation of singlet oxygen. Chem. Rev. 2003, 5, 1685-1757. [CrossRef] [PubMed]

18. You, Y. Chemical tools for the generation and detection of singlet oxygen. Org. Biomol. Chem. 2018, 16, 4044-4060. [CrossRef]

19. Haber, F.; Weiss, J. The catalytic decomposition of hydrogen peroxide by iron salts. Proc. R. Soc. Lond. A 1934, 147, 332-351.

20. Kellogg, E.W., III; Fridovich, I. Superoxide, hydrogen peroxide, and singlet oxygen in lipid peroxidation by a xanthine oxidase system. J. Biol. Chem. 1975, 250, 8812-8817.

21. Weinstein, J.; Bielski, B.H.J. Kinetics of the interaction of $\mathrm{HO}_{2}$ and $\mathrm{O}_{2}$ radicals with hydrogen peroxide; The Haber-Weiss reaction. J. Am. Chem. Soc. 1979, 101, 58-62. [CrossRef]

22. Melhuish, W.H.; Sutton, H.C. Study of the Haber-Weiss reaction using a sensitive method for detection of OH radicals. J. Chem. Soc. Chem. Commun. 1978, 22, 970-971. [CrossRef]

23. Mattila, H.; Khorobrykh, S.; Havurinne, V.; Tyystjärvi, E. Reactive oxygen species: Reactions and detection from photosynthetic tissues. J. Photochem. Photobiol. B Biol. 2015, 152, 176-214. [CrossRef]

24. MacManus-Spencer, L.A.; Edhlund, B.L.; McNeill, K. Singlet oxygen production in the reaction of superoxide with organic peroxides. J. Org. Chem. 2006, 71, 796-799. [CrossRef] [PubMed]

25. Mayeda, E.A.; Bard, A.J. The production of singlet oxygen in electrogenerated radical ion electron transfer reactions. J. Am. Chem. Soc. 1973, 95, 6223-6226. [CrossRef]

26. Takahama, U.; Nishimura, M. Formation of singlet molecular oxygen in illuminated chloroplasts. Effects on photoinactivation and lipid peroxidation. Plant Cell Physiol. 1975, 16, 737-748.

27. Khan, A.U.; Kasha, M. Singlet molecular oxygen in the Haber-Weiss reaction. Proc. Natl. Acad. Sci. USA 1994, 91, 12362-12367. [CrossRef] [PubMed]

28. Danen, W.C.; Arudi, R.L. Generation of singlet oxygen in the reaction of superoxide anion radical with diacyl peroxides. J. Am. Chem. Soc. 1978, 100, 3944-3945. [CrossRef] 
29. Russell, G.A. Deuterium-isotope effects in the autoxidation of aralkylhydrocarbons-mechanism of the interaction of peroxy radicals. J. Am. Chem. Soc. 1957, 79, 3871-3877. [CrossRef]

30. Mendenhall, G.D.; Sheng, X.C.; Wilson, T. Yields of excited carbonyl species from alkoxyl and from alkylperoxyl radical dismutations. J. Am. Chem. Soc. 1991, 113, 8976-8977. [CrossRef]

31. Niu, Q.J.; Mendenhall, G.D. Yields of singlet molecular oxygen from peroxyl radical termination. J. Am. Chem. Soc. 1992, 114, 165-172. [CrossRef]

32. Miyamoto, S.; Martinez, G.R.; Medeiros, M.H.; Di Mascio, P. Singlet molecular oxygen generated by biological hydroperoxides. J. Photochem. Photobiol. B. 2014, 139, 24-33. [CrossRef]

33. Kanofsky, J.R. Singlet oxygen production from the reactions of alkylperoxy radicals. Evidence from 1268-nm chemiluminescence. J. Org. Chem. 1986, 51, 3386-3388. [CrossRef]

34. Khan, A.U. The discovery of the chemical evolution of singlet oxygen. Some current chemical, photochemical, and biological applications. Int. J. Quantum Chem. 1991, 39, 251-267. [CrossRef]

35. Adam, W.; Kazakov, D.V.; Kazakov, V.P. Singlet-oxygen chemiluminescence in peroxide reactions. Chem. Rev. 2005, 105, 3371-3387. [CrossRef] [PubMed]

36. Aubry, J.M.; Cazin, B. Chemical sources of singlet oxygen. 2. Quantitative generation of singlet oxygen from hydrogen peroxide disproportionation catalyzed by molybdate ions. Inorg. Chem. 1988, 27, 2013-2014. [CrossRef]

37. Khan, A.U. Singlet molecular oxygen spectroscopy: Chemical and photosensitized. In Singlet $\mathrm{O}_{2}$; Frimer, A.A., Ed.; CRC Press: Boca Raton, FL, USA, 1985; pp. 39-79.

38. Ogilby, P.R.; Foote, C.S. Chemistry of singlet oxygen. 42. Effect of solvent, solvent isotopic substitution and temperature on the lifetime of singlet molecular oxygen $\left({ }^{1} \Delta \mathrm{gO}_{2}\right)$. J. Am. Chem. Soc. 1983, 105, 3423-3430. [CrossRef]

39. Arellano, J.B.; Yousef, Y.A.; Melø, T.B.; Mohamad, S.B.; Cogdell, R.J.; Naqvi, K.R. Formation and geminate quenching of singlet oxygen in purple bacterial reaction center. J. Photochem. Photobiol. B Biol. 2007, 87, 105-112. [CrossRef]

40. Bregnhøj, M.; Westberg, M.; Jensen, F.; Ogilby, P.R. Solvent-dependent singlet oxygen lifetimes: Temperature effects implicate tunneling and charge-transfer interactions. Phys. Chem. Chem. Phys. 2016, 18, 22946-22961. [CrossRef]

41. Conn, P.F.; Schalch, W.; Truscott, T.G. The singlet oxygen and carotenoid interaction. J. Photochem. Photobiol. B Biol. 1991, 11, 41-47. [CrossRef]

42. Koppenol, W.H. Reactions involving singlet oxygen and the superoxide anion. Nature 1976, 262, $420-421$. [CrossRef]

43. Triantaphylidès, C.; Havaux, M. Singlet oxygen in plants: Production, detoxification and signaling. Trends Plant. Sci. 2009, 14, 219-228. [CrossRef]

44. Davies, M.J. Reactive species formed on proteins exposed to singlet oxygen. Photochem. Photobiol. Sci. 2004, 3, 17-25. [CrossRef]

45. Jiang, G.; Chen, J.; Huang, J.S.; Che, C.M. Highly efficient oxidation of amines to imines by singlet oxygen and its application in Ugi-type reactions. Org. Lett. 2009, 11, 4568-4571. [CrossRef] [PubMed]

46. Li, C.; Hoffman, M.Z. Oxidation of phenol by singlet oxygen photosensitized by the Tris(2,2'-bipyridine)ruthenium(II) ion. J. Phys. Chem. A 2000, 104, 5998-6002. [CrossRef]

47. Kramarenko, G.G.; Hummel, S.G.; Martin, S.M.; Buettner, G.R. Ascorbate reacts with singlet oxygen to produce hydrogen peroxide. Photochem. Photobiol. 2006, 82, 1634-1637. [CrossRef]

48. Khorobrykh, S.A.; Karonen, M.; Tyystjärvi, E. Experimental evidence suggesting that $\mathrm{H}_{2} \mathrm{O}_{2}$ is produced within the thylakoid membrane in a reaction between plastoquinol and singlet oxygen. FEBS Lett. 2015, 589, 779-786. [CrossRef] [PubMed]

49. Bisby, R.H.; Morgan, C.G.; Hamblett, I.; Gormahn, A.A. Quenching of singlet oxygen by trolox C, ascorbate and amino acids: Effects of $\mathrm{pH}$ and temperature. J. Chem. Phys. A 1999, 103, 7454-7459. [CrossRef]

50. Gruszka, J.; Pawlak, A.; Kruk, J. Tocochromanols, plastoquinol, and other biological prenyllipids as singlet oxygen quenchers-determination of singlet oxygen quenching rate constants and oxidation products. Free Radic. Biol. Med. 2008, 45, 920-928. [CrossRef] [PubMed]

51. Krasnovsky, A.A., Jr. Singlet molecular oxygen in photobiochemical systems: IR phosphorescence studies. Membr. Cell Biol. 1998, 12, 665-690. 
52. Skovsen, E.; Snyder, J.W.; Lambert, J.D.; Ogilby, P.R. Lifetime and diffusion of singlet oxygen in a cell. J. Phys. Chem. B 2005, 109, 8570-8573. [CrossRef]

53. Sawyer, D.T.; Gibian, M.J. The chemistry of superoxide ion. Tetrahedron 1979, 35, 1471-1481. [CrossRef]

54. Afanas'ev, I.B. Superoxide Ion: Chemistry and Biological Implications; CRC Press: Boca Raton, FL, USA, 1989; p. 296.

55. Frimer, A.A. Superoxide chemistry in non-aqueous media. In Oxygen Radicals in Biology and Medicine. Basic Life Sciences; Simic, M.G., Taylor, K.A., Ward, J.F., von Sonntag, C., Eds.; Springer: Boston, MA, USA, 1988; Volume 49, pp. 29-38.

56. Todres, Z.V. Ion-Radical Organic Chemistry: Principles and Applications, 2nd ed.; CRC Press: Boca Raton, FL, USA, 2008; p. 496.

57. Koppenol, W.H. Solvation of the superoxide anion. In Oxy Radicals and Their Scavenger System; Gohen, G., Greenwald, R.A., Eds.; Elsevier Biomedical: New York, NY, USA, 1983; pp. 274-277.

58. Armstrong, D.A.; Huie, R.E.; Koppenol, W.H.; Lymar, S.V.; Merenyi, G.; Neta, P.; Ruscic, B.; Stanbury, D.M.; Steenken, S.; Wardman, P. Standard electrode potentials involving radicals in aqueous solution: Inorganic radicals (IUPAC Technical Report). Pure Appl. Chem. 2015, 87, 1139-1150. [CrossRef]

59. Sawyer, D.T.; Roberts, J.L., Jr. Hydroxide ion: An effective one-electron reducing agent? Acc. Chem. Res. 1988, 21, 469-476. [CrossRef]

60. Peover, M.E.; White, B.S. Electrolytic reduction of oxygen in aprotic solvents: The superoxide ion. Electrochim. Acta 1966, 11, 1061-1067. [CrossRef]

61. Song, Y.; Buettner, G.R. Thermodynamic and kinetic considerations for the reaction of semiquinone radicals to form superoxide and hydrogen peroxide. Free Radic. Biol. Med. 2010, 49, 919-962. [CrossRef] [PubMed]

62. Gotoh, N.; Niki, E. Rates of interactions of superoxide with vitamin E, vitamin C and related compounds as measured by chemiluminescence. Biochim. Biophys. Acta 1992, 1115, 201-207. [CrossRef]

63. Cabelli, D.E.; Bielski, B.H.J. Kinetics and mechanism for the oxidation of ascorbic acid/ascorbate by $\mathrm{HO}_{2} / \mathrm{O}_{2}{ }^{-}$ (hydroperoxyl/superoxide) radicals. A pulse radiolysis and stopped-flow photolysis study. J. Phys. Chem. 1983, 87, 1809-1812. [CrossRef]

64. Afanas'ev, I.B.; Grabovetskii, V.V.; Kuprianova, N.S. Kinetics and mechanism of the reactions of superoxide ion in solution. Part 5. Kinetics and mechanism of the interaction of superoxide ion with vitamin $\mathrm{E}$ and ascorbic acid. J. Chem. Soc. Perkin Trans. 1987, 2, 281-285. [CrossRef]

65. Wefers, H.; Sies, H. Oxidation of glutathione by the superoxide radical to the disulfide and the sulfonate yielding singlet oxygen. Eur. J. Biochem. 1983, 137, 29-36. [CrossRef]

66. Winterbourn, C.C.; Metodiewa, D. The reaction of superoxide with reduced glutathione. Arch. Biochem. Biophys. 1994, 314, 284-290. [CrossRef]

67. Winterbourn, C.C.; Metodiewa, D. Reactivity of biologically important thiol compounds with superoxide and hydrogen peroxide. Free Radic. Biol. Med. 1999, 27, 322-328. [CrossRef]

68. Bielski, B.H.J.; Cabelli, D.E.; Arudi, R.L.; Ross, A.B. Reactivity of $\mathrm{HO}_{2} / \mathrm{O}_{2}{ }^{-}$radicals in aqueous solution. J. Phys. Chem. Ref. Data 1985, 14, 1041-1100. [CrossRef]

69. Frimer, A.A. The organic chemistry of superoxide anion radical. In The Chemistry of Functional Groups: Peroxides; Patai, S., Ed.; Wiley: Chichester, UK, 1983; pp. 429-461.

70. Kobayashi, S.; Tezuka, T.; Ando, W. Nucleophilic and electron transfer oxidations of troponoid compounds by superoxide ion. J. Chem. Soc. Chem. Commun. 1979, 11, 508-510. [CrossRef]

71. Shibata, K.; Saito, Y.; Urano, K.; Matsui, M. Reaction of Schiff bases with superoxide ion in acetonitrile. Bull. Chem. Soc. Jpn. 1986, 59, 3323-3325. [CrossRef]

72. Pospíšil, P. Production of reactive oxygen species by photosystem II. Biochim. Biophys. Acta 2009, 1787, 1151-1160. [CrossRef] [PubMed]

73. Korshunov, S.; Imlay, J.A. Detection and quantification of superoxide formed within the periplasm of Escherichia coli. J. Bacteriol. 2006, 188, 6326-6334. [CrossRef] [PubMed]

74. Winterbourn, C.C. The biological chemistry of hydrogen peroxide. Methods Enzymol. 2013, 528, 3-25.

75. Campos-Martin, J.M.; Blanco-Brieva, G.; Fierro, J.L.G. Hydrogen Peroxide Synthesis: An Outlook beyond the Anthraquinone Process. Angew. Chem. Int. Ed. 2006, 45, 6962-6984. [CrossRef]

76. Flaherty, D.W. Direct Synthesis of $\mathrm{H}_{2} \mathrm{O}_{2}$ from $\mathrm{H}_{2}$ and $\mathrm{O}_{2}$ on Pd Catalysts: Current Understanding, Outstanding Questions, and Research Needs. ACS Catal. 2018, 82, 1520-1527. [CrossRef] 
77. Melis, A.; Zhang, L.; Forestier, M.; Ghirardi, M.L.; Seibert, M. Sustained photobiological hydrogen gas production upon reversible inactivation of oxygen evolution in the green alga Chlamydomonas reinhardtii. Plant Physiol. 2000, 122, 127-136. [CrossRef]

78. Kosourov, S.; Jokel, M.; Aro, E.-M.; Allahverdiyeva, Y. A new approach for sustained and efficient $\mathrm{H}_{2}$ photoproduction by Chlamydomonas reinhardtii. Energy Environ. Sci. 2018, 11, 1431-1436. [CrossRef]

79. Claiborne, A.; Miller, H.; Parsonage, D.; Ross, R.P. Protein-sulfenic acid stabilization and function in enzyme catalysis and gene regulation. FASEB J. 1993, 7, 1483-1490. [CrossRef]

80. Salmeen, A.; Andersen, J.N.; Myers, M.P.; Meng, T.C.; Hinks, J.A.; Tonks, N.K.; Barford, D. Redox regulation of protein tyrosine phosphatase 1B involves a sulphenyl-amide intermediate. Nature 2003, 423, 769-773. [CrossRef] [PubMed]

81. Stone, J.R. An assessment of proposed mechanisms for sensing hydrogen peroxide in mammalian systems. Arch. Biochem. Biophys. 2004, 422, 119-124. [CrossRef] [PubMed]

82. Vasquez-Vivar, J.; Denicola, A.; Radi, R.; Augusto, O. Peroxynitrite-mediated decarboxylation of pyruvate to both carbon dioxide and carbon dioxide radical anion. Chem. Res. Toxicol. 1997, 10, 786-794. [CrossRef] [PubMed]

83. Bakhmutova-Albert, E.V.; Yao, H.; Denevan, D.E.; Richardson, D.E. Kinetics and mechanism of peroxymonocarbonate formation. Inorg. Chem. 2010, 49, 11287-11296. [CrossRef] [PubMed]

84. Mizuta, Y.; Masumizu, T.; Kohno, M.; Mori, A.; Packer, L. Kinetic analysis of the Fenton reaction by ESR-spin trapping. Biochem. Mol. Biol. Int. 1997, 43, 1107-1120. [CrossRef]

85. Masarwa, M.; Cohen, H.; Meyerstein, D.; Hickman, D.L.; Bakac, A.; Espenson, J.H. Reactions of low valent transition metal complexes with hydrogen peroxide. Are they "Fenton-like" or not? 1. The case of $\mathrm{Cu}^{+} \mathrm{aq}$ and $\mathrm{Cr}^{2+}$ aq. J. Am. Chem. Soc. 1988, 110, 4293-4297. [CrossRef]

86. Moffett, J.W.; Zika, R.G. Reaction kinetics of hydrogen peroxide with copper and iron in seawater. Environ. Sci. Technol. 1987, 21, 804-810. [CrossRef]

87. Salgado, P.; Melin, V.; Contreras, D.; Moreno, Y.; Mansilla, H.D. Fenton reaction driven by iron ligands. J. Chil. Chem. Soc. 2013, 58, 2096-2101. [CrossRef]

88. Winterbourn, C.C. Toxicity of iron and hydrogen peroxide: The Fenton reaction. Toxicol. Lett. 1995, 82/83, 969-974. [CrossRef]

89. Goldstein, S.; Meyerstein, D.; Czapski, G. The Fenton reagents. Free Radic. Biol. Med. 1993, 15, 435-445. [CrossRef]

90. Davies, M.J.; Hawkins, C.L.; Pattison, D.I.; Rees, M.D. Mammalian heme peroxidases: From molecular mechanisms to health implications. Antioxid. Redox Signal. 2008, 10, 1199-1234. [CrossRef] [PubMed]

91. Miayke, C.; Michihata, F.; Asada, K. Scavenging of hydrogen peroxide in prokaryotic and eukaryotic algae: Acquisition of ascorbate peroxidase during the evolution of cyanobacteria. Plant Cell Physiol. 1991, 32, $33-43$.

92. Asada, K. The water-water cycle as alternative photon and electron sinks. Philos. Trans. R. Soc. Lond. B Biol. Sci. 2000, 355, 1419-1431. [CrossRef]

93. Deyhimi, F.; Nami, F. Peroxidase-catalyzed electrochemical assay of hydrogen peroxide: A ping-pong mechanism. Int. J. Chem. Kinet. 2012, 44, 699-704. [CrossRef]

94. Antunes, F.; Cadenas, E. Estimation of $\mathrm{H}_{2} \mathrm{O}_{2}$ gradients across biomembranes. FEBS Lett. 2000, 475, 121-126. [CrossRef]

95. Bienert, G.P.; Møller, A.L.; Kristiansen, K.A.; Schulz, A.; Møller, I.M.; Schjoerring, J.K.; Jahn, T.P. Specific aquaporins facilitate the diffusion of hydrogen peroxide across membranes. J. Biol. Chem. 2007, 282, 1183-1192. [CrossRef]

96. Bienert, G.P.; Schjoerring, J.K.; Jahn, T.P. Membrane transport of hydrogen peroxide. Biochim. Biophys. Acta 2006, 1758, 994-1003. [CrossRef]

97. Weller, J.; Kizina, K.M.; Can, K.; Bao, G.; Müller, M. Response properties of the genetically encoded optical $\mathrm{H}_{2} \mathrm{O}_{2}$ sensor HyPer. Free Radic. Biol. Med. 2014, 76, 227-241. [CrossRef]

98. Costa, A.; Drago, I.; Behera, S.; Zottini, M.; Pizzo, P.; Schroeder, J.I.; Pozzan, T.; Lo Schiavo, F. $\mathrm{H}_{2} \mathrm{O}_{2}$ in plant peroxisomes: An In Vivo analysis uncovers a Ca2+- dependent scavenging system. Plant J. 2010, 62, 760-772. [CrossRef]

99. Buettner, G.R. The pecking order of free radicals and antioxidants: Lipid peroxidation, $\alpha$-tocopherol, and ascorbate. Arch. Biochem. Biophys. 1993, 300, 535-543. [CrossRef] 
100. Buxton, G.V.; Greenstock, C.L.; Helman, W.P.; Ross, A.B. Critical review of rate constants for reactions of hydrated electrons, hydrogen atoms and hydroxyl radicals $\left({ }^{\bullet} \mathrm{OH} /{ }^{\bullet} \mathrm{O}^{-}\right)$in aqueous solution. J. Phys. Chem. Ref. Data. 1988, 17, 513-886. [CrossRef]

101. Haag, W.R.; Yao, C.C.D. Rate constants for reaction of hydroxyl radicals with several drinking water contaminants. Environ. Sci. Technol. 1992, 26, 1005-1013. [CrossRef]

102. Gligorovski, S.; Strekowski, R.; Barbati, S.; Vione, D. Environmental implications of hydroxyl radicals $\left({ }^{\bullet} \mathrm{OH}\right)$. Chem. Rev. 2015, 115, 13051-13092. [CrossRef] [PubMed]

103. Herrmann, H. On the Photolysis of simple anions and neutral molecules as sources of $\mathrm{O}^{-} / \mathrm{OH}, \mathrm{SOx}-\mathrm{and} \mathrm{Cl}$ in Aqueous Solution. Phys. Chem. Chem. Phys. 2007, 9, 3935-3964. [CrossRef]

104. Kwon, B.G.; Kwon, J.-H. Measurement of the hydroxyl radical formation from $\mathrm{H}_{2} \mathrm{O}_{2}, \mathrm{NO}_{3}{ }^{-}$, and $\mathrm{Fe}(\mathrm{III})$ using a continuous flow Injection analysis. J. Ind. Eng. Chem. 2010, 16, 193-199. [CrossRef]

105. Peyton, G.R.; Glaze, W.H. Destruction of pollutants in water with ozone in combination with ultraviolet radiation. 3. Photolysis of aqueous ozone. Environ. Sci. Technol. 1988, 22, 761-767. [CrossRef]

106. Tripathi, G.N.R. Electron-transfer component in hydroxyl radical reactions observed by time resolved resonance Raman spectroscopy. J. Am. Chem. Soc. 1998, 120, 4161-4166. [CrossRef]

107. Fisher, S.C.; Schoonen, M.A.; Brownawell, B.J. Phenylalanine as a hydroxyl radical-specific probe in pyrite slurries. Geochem. Trans. 2012, 13, 3. [CrossRef]

108. Leeuwenburgh, C.; Hansen, P.; Shaish, A.; Holloszy, J.O.; Heinecke, J.W. Markers of protein oxidation by hydroxyl radical and reactive nitrogen species in tissues of aging rats. Am. J. Physiol. 1998, 274, 453-461. [CrossRef]

109. Koppenol, W.H.; Butler, J. Energetics of interconversion reactions of oxyradicals. Adv. Free Radic. Biol. Med. 1985, 1, 91-131. [CrossRef]

110. Pryor, W.A. Oxy-radicals and related species: Their formation, lifetimes, and reactions. Annu. Rev. Physiol. 1986, 48, 657-667. [CrossRef] [PubMed]

111. Codorniu-Hernández, E.; Kusalik, P.G. Mobility mechanism of hydroxyl radicals in aqueous solution via hydrogen transfer. J. Am. Chem. Soc. 2012, 134, 532-538. [CrossRef] [PubMed]

112. Peterhansel, C.; Horst, I.; Niessen, M.; Blume, C.; Kebeish, R.; Kürkcüoglu, S.; Kreuzaler, F. Photorespiration. Arab. Book 2010, 8, e0130. [CrossRef]

113. Noctor, G.; Veljovic-Jovanovic, S.; Driscoll, S.; Novitskaya, L.; Foyer, C.H. Drought and oxidative load in the leaves of C3 plants: A predominant role for photorespiration? Ann. Bot. 2002, 89, 841-850. [CrossRef] [PubMed]

114. Krieger-Liszkay, A. Singlet oxygen production in photosynthesis. J. Exp. Bot. 2005, 56, 337-346. [CrossRef] [PubMed]

115. op den Camp, R.G.L.; Przybyla, D.; Ochsenbein, C.; Laloi, C.; Kim, C.; Danon, A.; Wagner, D.; Hideg, E.; Göbel, C.; Feussner, I.; et al. Rapid induction of distinct stress responses after the release of singlet oxygen in Arabidopsis. Plant Cell 2003, 15, 2320-2332. [CrossRef]

116. Prasad, A.; Sedlářová, M.; Kale, R.S.; Pospíšil, P. Lipoxygenase in singlet oxygen generation as a response to wounding: In Vivo imaging in Arabidopsis thaliana. Sci. Rep. 2017, 7, 9831. [CrossRef]

117. Carrillo, N.; Ceccarelli, E.A. Open questions in ferredoxin-NADP+ reductase catalytic mechanism. Eur. J. Biochem. 2003, 270, 1900-1915. [CrossRef]

118. Zanetti, G.; Curti, B. Interactions between ferredoxin-NADP+ reductase and ferredoxin at different reduction levels of the two proteins. FEBS Lett. 1981, 129, 201-204. [CrossRef]

119. Pagani, S.; Vecchio, G.; Iametti, S.; Bianchi, R.; Bonomi, F. On the role of the 2Fe-2S cluster in the formation of the structure of spinach ferredoxin. Biochim. Biophys. Acta 1986, 870, 538-544. [CrossRef]

120. Cammack, R.; Rao, K.K.; Bargeron, C.P.; Hutson, K.G.; Andrew, P.W.; Rogers, L. Midpoint redox potentials of plant and algal ferredoxins. Biochem. J. 1977, 168, 205-209. [CrossRef]

121. Hosein, B.; Palmer, G. The kinetics and mechanism of oxidation of reduced spinach ferredoxin by molecular oxygen and its reduced products. Biochim. Biophys. Acta 1983, 723, 383-390. [CrossRef]

122. Allen, J.F. Oxygen reduction and optimum production of ATP in photosynthesis. Nature 1975, 256, 599-600. [CrossRef]

123. Furbank, R.; Badger, M. Oxygen exchange associated with electron transport and photophosphorilation in spinach thylakoids. Biochim. Biophys. Acta 1983, 723, 400-409. [CrossRef] 
124. Asada, K.; Kiso, K.; Yoshikawa, K. Univalent reduction of molecular oxygen by spinach chloroplasts on illumination. J. Biol. Chem. 1974, 249, 2175-2181.

125. Golbeck, J.H.; Radmer, R. Is the rate of oxygen uptake by reduced ferredoxin sufficient to account for photosystem I-mediated $\mathrm{O}_{2}$ reduction? In Advances in Photosynthesis Research; Sybesma, C., Ed.; Martinus Nijhoff/Dr W Junk Publishers: The Hague, The Netherlands, 1984; pp. 561-564.

126. Kozuleva, M.A.; Ivanov, B.N. Evaluation of the participation of ferredoxin in oxygen reduction in the photosynthetic electron transport chain of isolated pea thylakoids. Photosynth. Res. 2010, 105, 51-61. [CrossRef] [PubMed]

127. Allen, J.F.; Hall, D.O. The relationship of oxygen uptake to electron transport in photosystem I of isolated chloroplasts: The role of superoxide and ascorbate. Biochem. Biophys. Res. Commun. 1974, 58, 579-585. [CrossRef]

128. Khorobrykh, S.A.; Ivanov, B.N. Oxygen reduction in a plastoquinone pool of isolated pea thylakoids. Photosynth. Res. 2002, 71, 209-219. [CrossRef] [PubMed]

129. Allen, J.F. A two-step mechanism for photosynthetic reduction of oxygen by ferredoxin. Biochem. Biophys. Res. Commun. 1975, 66, 36-43. [CrossRef]

130. Gibson, Q.H.; Hastings, J.W. The oxidation of reduced flavin mononucleotide by molecular oxygen. Biochem. J. 1962, 83, 368-377. [CrossRef]

131. Kemal, C.; Chan, T.W.; Bruice, T.C. Reaction of ${ }^{3} \mathrm{O}_{2}$ with dihydroflavins. $1 . \mathrm{N}^{3,5}$-Dimethyl-1,5-dihydrolumiflavin and 1,5-dihydroisoalloxazines. J. Am. Chem. Soc. 1977, 99, 7272-7286. [CrossRef] [PubMed]

132. Kemal, C.; Bruice, T.C. The chemistry of an N5-methyl-1,5-dihydroflavin and its aminium cation radical. J. Am. Chem. Soc. 1976, 98, 3955-3964. [CrossRef] [PubMed]

133. Massey, V. Activation of molecular oxygen by flavins and flavoproteins. J. Biol. Chem. 1994, 269, $22459-22462$. [PubMed]

134. Massey, V. The reactivity of oxygen with flavoproteins. Int. Congr. Ser. 2002, 1233, 3-11. [CrossRef]

135. Massey, V. The chemical and biological versatility of riboflavin. Biochem. Soc. Trans. 2000, 28, $283-296$. [CrossRef] [PubMed]

136. Mayhew, S.G. The effects of $\mathrm{pH}$ and semiquinone formation on the oxidation-reduction potentials of flavin mononucleotide. A reappraisal. Eur. J. Biochem. 1999, 265, 698-702. [CrossRef]

137. Hille, R.; Nishino, T. Flavoprotein structure and mechanism. 4. Xanthine oxidase and xanthine dehydrogenase. FASEB J. 1995, 9, 995-1003. [CrossRef]

138. Wohlfahrt, G.; Trivić, S.; Zeremski, J.; Peričin, D.; Leskovac, V. The chemical mechanism of action of glucose oxidase from Aspergillus niger. Mol. Cell Biochem. 2004, 260, 69-83. [CrossRef]

139. Romero, E.; Gómez Castellanos, J.R.; Gadda, G.; Fraaije, M.W.; Mattevi, A. Same substrate, many reactions: Oxygen activation in flavoenzymes. Chem. Rev. 2018, 118, 1742-1769. [CrossRef]

140. Miyake, C.; Schreiber, U.; Hormann, H.; Sano, S.; Asada, K. The FAD-enzyme monodehydroascorbate radical reductase mediates photoproduction of superoxide radicals in spinach thylakoid membranes. Plant Cell Physiol. 1998, 39, 821-829. [CrossRef]

141. Sano, S.; Miyake, C.; Mikami, B.; Asada, K. Molecular characterization of monodehydroascorbate radical reductase from cucumber highly expressed in Eschericia coli. J. Biol. Chem. 1995, 270, 21354-21361. [CrossRef] [PubMed]

142. Kobayashi, K.; Tagawa, S.; Sano, S.; Asada, K. A direct demonstration of the catalytic action of monodehydroascorbate reductase by pulse radiolysis. J. Biol. Chem. 1995, 270, 27551-27554. [CrossRef] [PubMed]

143. Goetze, D.C.; Carpentier, R. Ferredoxin-NADP ${ }^{+}$reductase is the site of oxygen reduction in pseudocyclic electron transport. Can. J. Bot. 1994, 72, 256-260. [CrossRef]

144. Hossain, M.A.; Asada, K. Monodehydroascorbate reductase from cucumber is a flavin adenine dinucleotide enzyme. J. Biol. Chem. 1985, 260, 12920-12926.

145. Ptushenko, V.V.; Cherepanov, D.A.; Krishtalik, L.I.; Semenov, A.Y. Semi-continuum electrostatic calculations of redox potentials in photosystem I. Photosynth. Res. 2008, 97, 55-74. [CrossRef]

146. Osmond, C.B.; Grace, S.C. Perspectives on photoinhibition and photorespiration in the field: Quintessential inefficiencies of the light and dark reactions of photosynthesis? J. Exp. Bot. 1995, 48, 1351-1362. [CrossRef]

147. Badger, M.; Sharkey, T.D.; Von Caemmerer, S. The relationship between steady-state gas-exchange of bean leaves and the levels of carbon-reducing-cycle intermediates. Planta 1984, 160, 305-313. [CrossRef] 
148. Helman, Y.; Tchernov, D.; Reinhold, L.; Shibata, M.; Ogawa, T.; Schwarz, R.; Ohad, I.; Kakplan, A. Genes encoding A-type flavoproteins are essetial for photoreduction of $\mathrm{O}_{2}$ in cyanobacteria. Curr. Biol. 2003, 13, 230-235. [CrossRef]

149. Zhang, P.; Allahverdiyeva, Y.; Eisenhut, M.; Aro, E.-M. Flavodiiron proteins in oxygenic photosynthetic organisms: Photoprotection of Photosystem II by Flv2 and Flv4 in Synechocystis sp. PCC 6803. PLoS ONE 2009, 4, e5331. [CrossRef] [PubMed]

150. Santana-Sanchez, A.; Solymosi, D.; Mustila, M.; Bersanini, L.; Aro, E.-M.; Allahverdiyeva, Y. Flavodiiron proteins 1-to-4 function in versatile combinations in $\mathrm{O}_{2}$ photoreduction in cyanobacteria. eLife 2019, 8, e45766. [CrossRef]

151. Shimakawa, G.; Miyake, C. Oxidation of $P_{700}$ ensures robust photosynthesis. Front. Plant. Sci. 2018, 9, 1617. [CrossRef]

152. Asada, K. Radical production and scavenging in the chloroplasts. In Photosynthesis and the Environment; Baker, N.R., Ed.; Kluwer Academic Publisher: Dordrecht, The Netherlands, 1996; pp. 128-150.

153. Yruela, I. Transition metals in plant photosynthesis. Metallomics 2013, 5, 1090-1109. [CrossRef] [PubMed]

154. Waldo, G.S.; Wright, E.; Whang, Z.H.; Briat, J.F.; Theil, E.C.; Sayers, D.E. Formation of the ferritin iron mineral occurs in plastids. Plant Physiol. 1995, 109, 797-802. [CrossRef] [PubMed]

155. Theil, E.C. Iron, ferritin, and nutrition. Annu. Rev. Nutr. 2004, 24, 327-343. [CrossRef] [PubMed]

156. Thomas, C.E.; Morehouse, L.A.; Aust, S.D. Ferritin and superoxide-dependent lipid peroxidation. J. Biol. Chem. 1985, 260, 3275-3280. [PubMed]

157. Šnyrychová, I.; Pospíšil, P.; Nauša, J. Reaction pathways involved in the production ofhydroxyl radicals in thylakoid membrane: EPR spin-trapping study. Photochem. Photobiol. Sci. 2006, 5, 472-476. [CrossRef]

158. Jakob, B.; Heber, U. Photoproduction and detoxification of hydroxyl radicals in chloroplasts and leaves and relation to photoinactivation of photosystems I and II. Plant Cell Physiol. 1996, 37, 629-635. [CrossRef]

159. Santabarbara, S.; Agostini, G.; Casazza, A.P.; Syme, C.D.; Heathcote, P.; Böhles, F.; Evans, M.C.; Jennings, R.C.; Carbonera, D. Chlorophyll triplet states associated with photosystem I and photosystem II in thylakoids of the green alga Chlamydomonas reinhardtii. Biochim. Biophys. Acta 2007, 1767, 88-105. [CrossRef]

160. Pospíšil, P. Molecular mechanisms of production and scavenging of reactive oxygen species by photosystem II. Biochim. Biophys. Acta 2012, 1817, 218-231. [CrossRef]

161. Hoff, A.J.; Rademaker, H.; van Grondelle, R.; Duysens, L.N.M. On the magnetic field dependence of the yield of the triplet state in reaction centers of photosynthetic bacteria. Biochim. Biophys. Acta 1977, 460, 547-554. [CrossRef]

162. Sétif, P.; Brettel, K. Photosystem I photochemistry under highly reducing conditions: Study of the P700 triplet state formation from the secondary radical pair $\left(\mathrm{P} 700^{+}-\mathrm{A}^{-}{ }_{1}\right)$. Biochim. Biophys. Acta 1990, 1020, 232-238. [CrossRef]

163. Antal, T.K.; Kovalenko, I.B.; Rubin, A.B.; Tyystjärvi, E. Photosynthesis-related quantities for education and modeling. Photosynth. Res. 2013, 117, 1-30. [CrossRef] [PubMed]

164. Rinalducci, S.; Pedersen, J.Z.; Zolla, L. Formation of radicals from singlet oxygen produced during photoinhibition of isolated light-harvesting proteins of photosystem II. Biochim. Biophys. Acta 2004, 1608, 63-73. [CrossRef] [PubMed]

165. Zolla, L.; Rinalducci, S. Involvement of active oxygen species in degradation of light-harvesting proteins under light stresses. Biochemistry 2002, 41, 14391-14402. [CrossRef] [PubMed]

166. Santabarbara, S.; Cazzalini, I.; Rivadossi, A.; Garlaschi, F.M.; Zucchelli, G.; Jennings, R.C. Photoinhibition In Vivo and In Vitro involves weakly coupled chlorophyll-protein complexes. Photochem. Photobiol. 2002, 6, 613-618. [CrossRef]

167. Santabarbara, S.; Neverov, K.; Garlaschi, F.M.; Zucchelli, G.; Jennings, R.C. Involvement of uncoupled antenna chlorophylls in photoinhibition in thylakoids. FEBS Lett. 2001, 491, 109-113. [CrossRef]

168. Schmidt, K.; Fufezan, C.; Krieger-Liszkay, A.; Satoh, H.; Paulsen, H. Recombinant watersoluble chlorophyll protein from Brassica oleracea var. botrys binds various chlorophyll derivatives. Biochemistry 2003, 42, 7427-7433. [CrossRef]

169. Cardona, T.; Sedoud, A.; Cox, N.; Rutherford, A.W. Charge separation in Photosystem II: A comparative and evolutionary overview. Biochim. Biophys. Acta 2012, 1817, 26-43. [CrossRef] 
170. Durrant,J.R.; Giorgi, L.B.; Barber, J.; Klug, D.R.; Porter, G. Characterization of triplet-states in isolated photosystem II reaction centres-Oxygen quenching as a mechanism for photodamage. Biochim. Biophys. Acta 1990, 1017, 167-175.

171. Macpherson, A.N.; Telfer, A.; Truscott, T.G.; Barber, J. Direct detection of singlet oxygen from isolated photosystem II reaction centers. Biochim. Biophys. Acta 1993, 1143, 301-309. [CrossRef]

172. Krieger-Liszkay, A.; Fufezan, C.; Trebst, A. Singlet oxygen production in photosystem II and related protection mechanism. Photosynth. Res. 2008, 98, 551-564. [CrossRef] [PubMed]

173. Rappaport, F.; Lavergne, J. Thermoluminescence: Theory. Photosynth. Res. 2009, 101, 205-216. [CrossRef] [PubMed]

174. Pospíšil, P. Production of reactive oxygen species by photosystem II as a response to light and temperature stress. Front. Plant Sci. 2016, 7, 1950. [CrossRef] [PubMed]

175. Diner, B.A.; Schlodder, E.; Nixon, P.J.; Coleman, W.J.; Rappaport, F.; Lavergne, J.; Vermaas, W.F.J.; Chisholm, D.A. Site-directed mutations at D1-His198 and D2-His197 of photosystem II in Synechocystis PCC 6803: Sites of primary charge separation and cation and triplet stabilization. Biochemistry 2001, 40, 9265-9281. [CrossRef]

176. Noguchi, T.; Tomo, T.; Inoue, Y. Triplet formation on a monomeric chlorophyll in the photosystem II reaction center as studied by time-resolved infrared spectroscopy. Biochemistry 2001, 40, 2176-2185. [CrossRef]

177. Loll, B.; Kern, J.; Saenger, W.; Zouni, A.; Biesiadka, J. Towards complete cofactor arrangement in the $3.0 \AA$ resolution structure of photosystem II. Nature 2005, 438, 1040-1044. [CrossRef]

178. Telfer, A.; Barber, J. Role of carotenoid bound to the photosystem II reaction centre. In Photosynthesis: From Light to Biosphere; Mathis, P., Ed.; Kluwer: Dordrecht, The Netherlands, 1995; Volume 5, pp. 15-20.

179. Hideg, E.; Spetea, C.; Vass, I. Singlet oxygen production in thylakoid membranes during photoinhibition as detected by EPR spectroscopy. Photosynth. Res. 1994, 39, 191-199. [CrossRef]

180. Hideg, E.; Spetea, C.; Vass, I. Singlet oxygen and free radical production during acceptor- and donor-side-induced photoinhibition. Studies with spin trapping EPR spectroscopy. Biochim. Biophys. Acta 1994, 1186, 143-152. [CrossRef]

181. Hideg, E.; Vass, I. Singlet oxygen is not produced by photosystem I under photoinhibitory conditions. Photochem. Photobiol. 1995, 62, 949-952. [CrossRef]

182. Fischer, B.B.; Krieger-Liszkay, A.; Eggen, R.L. Photosensitizers neutral red (type I) and rose bengal (type II) cause light-dependent toxicity in Chlamydomonas reinhardtii and induce the Gpxh gene via increased singlet oxygen formation. Environ. Sci. Technol. 2004, 38, 6307-6313. [CrossRef]

183. Hakala-Yatkin, M.; Tyystjärvi, E. Inhibition of Photosystem II by the singlet oxygen sensor compounds TEMP and TEMPD. Biochim. Biophys. Acta 2011, 1807, 243-250. [CrossRef] [PubMed]

184. Hideg, E.; Déak, Z.; Hakala-Yatkin, M.; Karonen, M.; Rutherford, A.W.; Tyystjärvi, E.; Vass, I.; Krieger-Liszkay, A. Pure forms of the singlet oxygen sensors TEMP and TEMPD do not inhibit Photosystem II. Biochim. Biophys. Acta 2011, 1807, 1658-1661. [CrossRef] [PubMed]

185. Karonen, M.; Mattila, H.; Huang, P.; Mamedov, F.; Styring, S.; Tyystjärvi, E. A tandem mass spectrometric method for singlet oxygen measurement. Photochem. Photobiol. 2014, 90, 965-971. [CrossRef] [PubMed]

186. Fischer, B.B.; Eggen, R.I.; Trebst, A.; Krieger-Liszkay, A. The glutathione peroxidase homologous gene Gpxh in Chlamydomonas reinhardtii is upregulated by singlet oxygen produced in photosystem II. Planta 2006, 223, 583-590. [CrossRef] [PubMed]

187. Hideg, E.; Kálai, T.; Hideg, K.; Vass, I. Photoinhibition of photosynthesis in vivo results in singlet oxygen production detection via nitroxide-induced fluorescence quenching in broad bean leaves. Biochemistry 1998, 37, 11405-11411. [CrossRef]

188. Hideg, E.; Ogawa, K.; Kálai, T.; Hideg, K. Singlet oxygen imaging in Arabidopsis thaliana leaves under photoinhibition by excess photosynthetically active radiation. Physiol. Plant. 2001, 112, 10-14. [CrossRef]

189. Hideg, E.; Kós, P.B.; Vass, I. Photosystem II damage induced by chemically generated singlet oxygen in tobacco leaves. Physiol. Plant. 2007, 131, 33-40. [CrossRef]

190. Hideg, E. A comparative study of fluorescent singlet oxygen probes in plant leaves. Cent. Eur. J. Biol. 2008, 330, 273-284. [CrossRef]

191. Telfer, A.; Bishop, S.M.; Phillips, D.; Barber, J. Isolated photosynthetic reaction center of photosystem II as a sensitizer for the formation of singlet oxygen. Detection and quantum yield determination using a chemical trapping technique. J. Biol. Chem. 1994, 269, 13244-13253. 
192. Rehman, A.U.; Czer, K.; Sass, L.; Vass, I. Characterization of singlet oxygen production and its involvement in photodamage of Photosystem II in the cyanobacterium Synechocystis PCC 6803 by histidine-mediated chemical trapping. Biochim. Biophys. Acta 2013, 1827, 689-698. [CrossRef]

193. Hakkila, K.; Antal, T.; Rehman, A.U.; Kurkela, J.; Wada, H.; Vass, I.; Tyystjärvi, E.; Tyystjärvi, T. Oxidative stress and photoinhibition can be separated in the cyanobacterium Synechocystis sp. PCC 6803. Biochim. Biophys. Acta 2014, 1837, 217-225. [CrossRef] [PubMed]

194. Davis, G.A.; Kanazawa, A.; Schöttler, M.A.; Kohzuma, K.; Froelich, J.E.; Rutherford, A.W.; Satoh-Cruz, M.; Minhas, D.; Tietz, S.; Dhingra, A.; et al. Limitations to photosynthesis by proton motive force-induced photosystem II photodamage. eLife 2016, 5, e16921. [CrossRef] [PubMed]

195. Prasad, A.; Sdelářová, M.; Pospíšil, P. Singlet oxygen imaging using fluorescent probe Singlet Oxygen Sensor Green in photosynthetic organisms. Sci. Rep. 2018, 8, 13685. [CrossRef] [PubMed]

196. Telfer, A.; Dhami, S.; Bishop, S.M.; Phillips, D.; Barber, J. $\beta$-Carotene quenches singlet oxygen formed by isolated photosystem II reaction centers. Biochemistry 1994, 33, 14469-14474. [CrossRef]

197. Caffarri, S.; Tibiletti, T.; Jennings, R.C.; Santabarbara, S. A comparison between plant photosystem I and photosystem II architecture and functioning. Curr. Protein Pept. Sci. 2014, 15, 296-331. [CrossRef]

198. Barber, J.; Chapman, D.J.; Telfer, A. Characterisation of a PS II reaction centre isolated from the chloroplasts of Pisum sativum. FEBS Lett. 1987, 220, 67-73. [CrossRef]

199. Yin, L.; Fristedt, R.; Herdean, A.; Solymosi, K.; Bertrand, M.; Andersson, M.X.; Mamedov, F.; Vener, A.V.; Schoefs, B.; Spetea, C. Photosystem II function and dynamics in three widely used Arabidopsis thaliana accessions. PLoS ONE 2012, 7, e46206. [CrossRef]

200. Khorobrykh, S.A.; Khorobrykh, A.A.; Yanykin, D.V.; Ivanov, B.N.; Klimov, V.V.; Mano, J. Photoproduction of catalase-insensitive peroxides on the donor side of manganese-depleted photosystem II: Evidence with a specific fluorescent probe. Biochemistry 2011, 50, 10658-10665. [CrossRef]

201. Yadav, D.K.; Pospíšil, P. Evidence on the formation of singlet oxygen in the donor side photoinhibition of photosystem II: EPR spin-trapping study. PLoS ONE 2012, 7, e45883. [CrossRef]

202. Pathak, V.; Prasad, A.; Pospíšil, P. Formation of singlet oxygen by decomposition of protein hydroperoxide in photosystem II. PLoS ONE 2017, 12, e0181732. [CrossRef]

203. Shuvalov, V.A.; Nuijs, A.M.; van Gorkom, H.J.; Smit, H.W.J.; Duysens, L.N.M. Picosecond absorbance changes upon selective excitation of the primary electron donor P-700 in photosystem I. Biochim. Biophys. Acta 1986, 850, 319-323. [CrossRef]

204. Sétif, P.; Hervo, G.; Mathis, P. Flash-induced absorption changes in Photosystem I, Radical pair or triplet state formation? Biochim. Biophys. Acta 1981, 638, 257-267. [CrossRef]

205. Rutherford, A.W.; Osyczka, A.; Rappaport, F. Back-reactions, short-circuits, leaks and other energy wasteful reactions in biological electron transfer: Redox tuning to survive life in O(2). FEBS Lett. 2012, 586, 603-616. [CrossRef] [PubMed]

206. Cazzaniga, S.; Li, Z.; Niyogi, K.K.; Bassi, R.; Dall'Osto, L. The Arabidopsis szl1 mutant reveals a critical role of $\beta$-carotene in photosystem I photoprotection. Plant Physiol. 2012, 159, 1745-1758. [CrossRef]

207. Jung, J.; Kim, H.-S. The chromophores as endogenous sensitizers involved in the photogeneration of singlet oxygen in spinach thylakoids. Photochem. Photobiol. 1990, 52, 1003-1009. [CrossRef]

208. Mehler, A.H. Studies on reactivity of illuminated chloroplasts. Mechanism of the reduction of oxygen and other Hill reagents. Arch. Biochem. Biophys. 1951, 33, 65-77. [CrossRef]

209. Glidewell, S.M.; Raven, J.A. Measurement of simultaneous oxygen evolution and uptake in Hydrodictyon africanum. J. Exp. Bot. 1975, 26, 479-488. [CrossRef]

210. Patterson, C.O.P.; Myers, J. Photosynthetic production of hydrogen peroxide by Anacystis nidulans. Plant Physiol. 1973, 51, 104-109. [CrossRef]

211. Egneus, H.; Heber, U.; Matthiesen, U.; Kirk, M. Reduction of oxygen by the electron transport chain of chloroplasts during assimilation of carbon dioxide. Biochim. Biophys. Acta 1975, 408, 252-268. [CrossRef]

212. Radmer, R.; Kok, B. Photoreduction of $\mathrm{O}_{2}$ primes and replaces $\mathrm{CO}_{2}$ assimilation. Plant Physiol. 1976, 58, 336-340. [CrossRef]

213. Elstner, E.F. Oxygen activation and oxygen toxicity. Annu. Rev. Plant Physiol. 1982, 33, 73-96. [CrossRef]

214. Badger, M.R. Photosynthetic oxygen exchange. Annu. Rev. Plant Physiol. 1985, 36, 27-53. [CrossRef]

215. Robinson, J.M. Does $\mathrm{O}_{2}$ photoreduction occur within chloroplasts In Vivo? Physiol. Plant. 1988, 72, 666-680. [CrossRef] 
216. Asada, K. Production and action of active oxygen species in photosynthesis tissues. In Causes of Photooxidative Stress and Amelioration of Defense Systems in Plants; Foyer, C.H., Mullineaux, P.M., Eds.; CRC Press: Boca Raton, FL, USA, 1994; pp. 77-104.

217. Ananyev, G.M.; Renger, G.; Wacker, U.; Klimov, V. The photoproduction of superoxide radicals and the superoxide-dismutase activity of photosystem II. The possible involvement of cytochrome b559. Photosynth. Res. 1994, 41, 327-338. [CrossRef] [PubMed]

218. Nugent, J.H.A. Photoreducible high spin iron electron paramagnetic resonance signals in dark-adapted Photosystem II: Are they oxidised non-haem iron formed from interaction of oxygen with PSII electron acceptors? Biochim. Biophys. Acta 2001, 1504, 288-298. [CrossRef]

219. Ishikita, H.; Biesiadka, J.; Loll, B.; Saenger, W.; Knapp, E.W. Cationic state of accessory chlorophyll and electron transfer through pheophytin to plastoquinone in photosystem II. Angew. Chem. Int. Ed. 2006, 45, 1964-1965. [CrossRef]

220. Rutherford, A.W.; Mullet, J.E.; Crofts, A.R. Measurement of the midpoint potential of the pheophytin acceptor of photosystem II. FEBS Lett. 1981, 123, 235-237. [CrossRef]

221. Klimov, V.V.; Allakhverdiev, S.I.; Demeter, S.; Krasnovskii, A.A. Photoreduction of pheophytin in the photosystem 2 of chloroplasts with respect to the redox potential of the medium. Dokl. Akad. Nauk SSSR 1979, 249, 227-230.

222. Mamedov, M.D.; Kurashov, V.N.; Cherepanov, D.A.; Semenov, A.Y. Photosysem II: Where does the light-induced voltage come from? Front. Biosci. 2010, 15, 1007-1017. [CrossRef]

223. Kato, Y.; Sugiura, M.; Oda, A.; Watanabe, T. Spectroelectrochemical determination of the redox potential of pheophytin a, the primary electron acceptor in photosystem II. Proc. Natl. Acad. Sci. USA 2009, 106, 17365-17370. [CrossRef]

224. Crofts, A.R.; Wraight, C.A. The electrochemical domain of photosynthesis. Biochim. Biophys. Acta 1983, 726, 149-185. [CrossRef]

225. Allakhverdiev, S.I.; Tsuchiya, T.; Watabe, K.; Kojima, A.; Los, D.A.; Tomo, T.; Klimov, V.V.; Mimuro, M. Redox potentials of primary electron acceptor quinone molecule (QA)- and conserved energetics of photosystem II in cyanobacteria with chlorophyll a and chlorophyll d. Proc. Natl. Acad. Sci. USA 2011, 108, 8054-8058. [CrossRef] [PubMed]

226. Tyystjärvi, E.; Vass, I. Light emission as a probe of charge separation and recombination in the photosynthetic apparatus: Relation of prompt fluorescence to delayed light emission and thermoluminescence. In Chlorophyll a Fluorescence: A Signature of Photosynthesis; Papageorgiou, G.C., Ed.; Kluwer Academic Publishers: Dordrecht, The Netherlands, 2004; pp. 363-388.

227. Brinkert, K.; De Causmaecker, S.; Krieger-Liszkay, A.; Fantuzzi, A.; Rutherford, A.W. Bicarbonate-induced redox tuning in Photosystem II for regulation and protection. Proc. Natl. Acad. Sci. USA 2016, 113, 12144-12149. [CrossRef]

228. Renger, G.; Eckert, H.J.; Bergmann, A.; Bernarding, J.; Liu, B.; Napiwotzki, A.; Reifarth, F.; Eichler, H.J. Fluorescence and spectroscopic studies of exciton trapping and electron transfer in photosystem II of higher plants. Aust. J. Plant Physiol. 1995, 22, 167-181. [CrossRef]

229. de Wijn, R.; van Gorkom, H.J. Kinetics of electron transfer from $\mathrm{Q}_{\mathrm{A}}$ to $\mathrm{Q}_{\mathrm{B}}$ in photosystem II. Biochemistry 2001, 40, 11912-11922. [CrossRef]

230. Rich, P.R.; Moss, D.A. The reaction of quinones in higher plant photosynthesis. In The Light Reaction; Barber, J., Ed.; Elsevier: Amsterdam, The Netherlands, 1987; pp. 421-445.

231. Crofts, A.R.; Robinson, H.H.; Snozzi, M. Reactions of quinols at catalytic sites: A diffusionrole in H-transfer. In Advances in Photosynthesis Research; Sybesma, C., Ed.; M. Nijhoff/Dr. W. Junk Publisher: The Hague, The Netherlands, 1984; pp. 1461-1468.

232. Kato, M.; Zhang, J.Z.; Paul, N.; Reisner, E. Protein film photoelectrochemistry of the water oxidation enzyme photosystem II. Chem. Soc. Rev. 2014, 43, 6485-6497. [CrossRef]

233. Zhu, Z.; Gunner, M.R. Energetics of quinone-dependent electron and proton transfers in Rhodobacter sphaeroides photosynthetic reaction centers. Biochemistry 2005, 44, 82-96. [CrossRef]

234. Klimov, V.V.; Ananyev, G.M.; Zastrizhnaya, O.M.; Wydrzynski, T.; Renger, G. Photoproduction of hydrogen peroxide in Photosystem II membrane fragments: A comparison of four signals. Photosynth. Res. 1993, 38, 409-416. [CrossRef] 
235. Arato', A.; Bondarava, N.; Krieger-Liszkay, A. Production of reactive oxygen species in chloride- and calcium-depleted photosystem II and their involvement in photoinhibition. Biochim. Biophys. Acta 2004, 1608, 171-180. [CrossRef]

236. Cleland, R.E.; Grace, S.C. Voltammetric detection of superoxide production by photosystem II. FEBS Lett. 1999, 457, 348-352. [CrossRef]

237. Zulfugarov, I.S.; Tovuu, A.; Eu, Y.J.; Dogsom, B.; Poudyal, R.S.; Nath, K.; Hall, M.; Banerjee, M.; Yoon, U.C.; Moon, Y.H.; et al. Production of superoxide from Photosystem II in a rice (Oryza sativa L.) mutant lacking PsbS. BMC Plant Biol. 2014, 14, 242. [CrossRef] [PubMed]

238. Vass, I.; Gatzen, G.; Holzwarth, A.R. Picosecond time-resolved fluorescence studies on photoinhibition and double reduction of $\mathrm{Q}_{\mathrm{A}}$ in Photosystem II. Biochim. Biophys. Acta 1993, 1183, 388-396. [CrossRef]

239. Müh, F.; Zouni, A. Cytochrome b 559 in photosystem II. In Cytochrome Complexes: Evolution, Structures, Energy Transduction, and Signaling; Cramer, W.A., Kallas, T., Eds.; Springer: Dordrecht, The Netherlands, 2015; pp. 147-175.

240. Shuvalov, V.A. Composition and function of cytochrome b559 in reaction centers of Photosystem II of green plants. J. Bioenerg. Biomembr. 1994, 26, 619-626. [CrossRef] [PubMed]

241. Yamashita, T. Modification of oxygen evolving center by Tris-washing. Photosynth. Res. 1986, 10, $473-481$. [CrossRef] [PubMed]

242. Horton, P.; Croze, E. The relationship between activity of chloroplast Photosystem II and the midpoint oxidation-reduction potential of cytochrome b-559. Biochim. Biophys. Acta 1977, 462, 86-101. [CrossRef]

243. Berthold, D.A.; Babcock, G.T.; Yocum, C.F. A highly resolved, oxygen-evolving photosystem II preparation from spinach thylakoid membranes: EPR and electron-transport properties. FEBS Lett. 1981, 134, 231-234. [CrossRef]

244. Babcock, G.T.; Widger, W.R.; Cramer, W.A.; Oertling, W.A.; Metz, J.G. Axial ligands of chloroplast cytochrome b-559: Identification and requirement for a heme-cross-linked polypeptide structure. Biochemistry 1985, 24, 3638-3645. [CrossRef]

245. Pospíšil, P.; Šnyrychová, I.; Kruk, J.; Strzałka, K.; Nauš, J. Evidence that cytochrome $b_{559}$ is involved in superoxide production in Photosystem II: Effect of synthetic short-chain plastoquinones in a cytochrome $b_{559}$ tobacco mutant. Biochem. J. 2006, 397, 321-327. [CrossRef]

246. Whitmarsh, J.; Cramer, W.A. A pathway for the reduction of cytochrome b-559 by Photosystem II in chloroplasts. Biochim. Biophys. Acta 1978, 501, 83-93. [CrossRef]

247. Gounaris, K.; Chapman, D.J.; Barber, J. Reconstitution of plastoquinone in the D1/D2/cytochrome b-559 Photosystem II reaction centre complex. FEBS Lett. 1988, 240, 143-147. [CrossRef]

248. Kruk, J.; Strzałka, K. Dark reoxidation of the plastoquinone-pool is mediated by the low-potential form of cytochrome b-559 in spinach thylakoids. Photosynth. Res. 1999, 62, 273-279. [CrossRef]

249. Kruk, J.; Strzałka, K. Redox changes of cytochrome $b_{559}$ in the presence of plastoquinones. J. Biol. Chem. 2001, 276, 86-91. [CrossRef]

250. Yadav, D.K.; Prasad, A.; Kruk, J.; Pospíšil, P. Evidence for the involvement of loosely bound plastosemiquinones in superoxide anion radical production in photosystem II. PLoS ONE 2014, 9, e115466. [CrossRef]

251. Guskov, A.; Kern, J.; Gabdulkhakov, A.; Broser, M.; Zouni, A.; Saenger, W. Cyanobacterial Photosystem II at 2.9 Å resolution: Role of quinones, lipids, channels and chloride. Nat. Struct. Mol. Biol. 2009, 16, 334-342. [CrossRef]

252. Khorobrykh, S.; Tyystjärvi, E. Plastoquinol generates and scavenges reactive oxygen species in organic solvent: Potential relevance for thylakoids. Biochim. Biophys. Acta 2018, 1859, 1119-1131. [CrossRef]

253. Tiwari, A.; Pospíšil, P. Superoxide oxidase and reductase activity of cytochrome b559 in photosystem II. Biochim. Biophys. Acta 2009, 1787, 985-994. [CrossRef]

254. Fine, P.L.; Frasch, W.D. The oxygen-evolving complex requires chloride to prevent hydrogen-peroxide formation. Biochemistry 1992, 31, 12204-12210. [CrossRef]

255. Antal, T.K.; Sarvikas, P.; Tyystjärvi, E. Two-Electron Reactions $S_{2} Q_{B} \rightarrow S_{0} Q_{B}$ and $S_{3} Q_{B} \rightarrow S_{1} Q_{B}$ are involved in deactivation of higher $S$ states of the oxygen-evolving complex of photosystem II. Biophys. J. 2009, 96, 1-9. [CrossRef] 
256. Pospíšil, P.; Šnyrychová, I.; Nauš, J. Dark production of reactive oxygen species in photosystem II membrane particles at elevated temperature: EPR spin-trapping study. Biochim. Biophys. Acta 2007, 1767, 854-859. [CrossRef]

257. Yamashita, A.; Nijo, N.; Pospísil, P.; Morita, N.; Takenaka, D.; Aminaka, R.; Yamamoto, Y.; Yamamoto, Y. Quality control of photosystem II: Reactive oxygen species are responsible for the damage to photosystem II under moderate heat stress. J. Biol. Chem. 2008, 283, 28380-28391. [CrossRef]

258. Navari-Izzo, F.; Pinzino, C.; Quartacci, M.F.; Sgherri, C.L. Superoxide and hydroxyl radical generation, and superoxide dismutase in PSII membrane fragments from wheat. Free Radic. Res. 1999, 33, 3-9. [CrossRef]

259. Zhang, S.; Weng, J.; Pan, J.; Tu, T.; Yao, S.; Xu, C. Study on the photo-generation of superoxide radicals in Photosystem II with EPR spin trapping techniques. Photosynth. Res. 2003, 75, 41-48. [CrossRef]

260. Pospísil, P.; Arató, A.; Krieger-Liszkay, A.; Rutherford, A.W. Hydroxyl radical generation by photosystem II. Biochemistry 2004, 43, 6783-6792. [CrossRef]

261. Khorobrykh, S.A.; Khorobrykh, A.A.; Klimov, V.V.; Ivanov, B.N. Photoconsumption of oxygen in photosystem II preparations under impairment of the water-oxidizing complex. Biochemistry 2002, 67, 683-688.

262. Yanykin, D.V.; Khorobrykh, A.A.; Khorobrykh, S.A.; Klimov, V.V. Photoconsumption of molecular oxygen on both donor and acceptor sides of photosystem II in Mn-depleted subchloroplast membrane fragments. Biochim. Biophys. Acta 2010, 1797, 516-523. [CrossRef]

263. Asada, K.; Kiso, K. The photooxidation of epinephrine by spinach chloroplasts and its inhibition by superoxide dismutase: Evidence for the formation of superoxide radicals in chloroplasts. Agric. Biol. Chem. 1973, 37, 453-454. [CrossRef]

264. Khorobrykh, S.; Mubarakshina, M.; Ivanov, B. Photosystem I is not solely responsible for oxygen reduction in isolated thylakoids. Biochim. Biophys. Acta 2004, 1657, 164-167. [CrossRef]

265. Fork, D.C.; Heber, U.W. Studies on electron-transport reactions of photosynthesis in plastome mutants of Oenothera. Plant Physiol. 1968, 43, 606-612. [CrossRef]

266. Kruk, J.; Jemiola-Rzeminska, M.; Burda, K.; Schmid, G.; Strzalka, K. Scavenging of superoxide generated in photosystem I by plastoquinol and other prenyllipids in thylakoid membranes. Biochemistry 2003, 42, 8501-8505. [CrossRef]

267. Nelson, N.; Yocum, C.F. Structure and function of photosystems I and II. Annu. Rev. Plant Biol. 2006, 57, 521-565. [CrossRef]

268. Brettel, K. Electron transfer and arrangement of the redox cofactors in photosystem I. Biochim. Biophys. Acta 1997, 1318, 322-373. [CrossRef]

269. Brettel, K.; Leibl, W. Electron transfer in photosystem I. Biochim. Biophys. Acta 2001, 1507, 100-114. [CrossRef]

270. Kirchhoff, H.; Schöttler, M.A.; Maurer, J.; Weis, E. Plastocyanin redox kinetics in spinach chloroplasts: Evidence for disequilibrium in the high potential chain. Biochim. Biophys. Acta 2004, 1659, 63-72. [CrossRef] [PubMed]

271. Nakamura, A.; Suzawa, T.; Kato, Y.; Watanabe, T. Species dependence of the redox potential of the primary electron donor p700 in photosystem I of oxygenic photosynthetic organisms revealed by spectroelectrochemistry. Plant Cell Physiol. 2011, 52, 815-823. [CrossRef]

272. Takahashi, M.; Asada, K. Superoxide production in aprotic interior of chloroplast thylakoids. Arch. Biochem. Biophys. 1988, 267, 714-722. [CrossRef]

273. Kozuleva, M.A.; Ivanov, B.N. The mechanisms of oxygen reduction in the terminal reducing segment of the chloroplast photosynthetic electron transport chain. Plant Cell Physiol. 2016, 57, 1397-1404. [CrossRef]

274. Kozuleva, M.; Klenina, I.; Proskuryakov, I.; Kirilyuk, I.; Ivanov, B. Production of superoxide in chloroplast thylakoid membranes: ESR study with cyclic hydroxylamines of different lipophilicity. FEBS Lett. 2011, 585, 1067-1071. [CrossRef]

275. Kozuleva, M.A.; Petrova, A.A.; Mamedov, M.D.; Semenov, A.Y.; Ivanov, B.N. $\mathrm{O}_{2}$ reduction by photosystem I involves phylloquinone under steady-state illumination. FEBS Lett. 2014, 588, 4364-4368. [CrossRef]

276. Sauer, K.; Mathis, P.; Acker, S.; van Best, J.A. Electron acceptors associated with P-700 in Triton solubilized photosystem I particles from spinach chloroplasts. Biochim. Biophys. Acta 1978, 503, 120-134. [CrossRef]

277. Hiyama, T.; Ke, B. A further study of P430: A possible primary electron acceptor of photosystem I. Arch. Biochem. Biophys. 1971, 147, 99-108. [CrossRef]

278. Asada, K.; Nakano, Y. Affinity for oxygen in photoreduction of molecular oxygen and scavenging of hydrogen peroxide in chloroplasts. Photochem. Photobiol. 1978, 28, 917-920. [CrossRef] 
279. Takahashi, M.; Asada, K. Dependence of oxygen affinity for Mehler reaction on photochemical activity of chloroplast thylakoids. Plant Cell Physiol. 1982, 23, 1457-1461.

280. Semenov, A.Y.; Mamedov, M.D.; Chamorovsky, S.K. Photoelectric studies of the transmembrane charge transfer reactions in photosystem I pigment-protein complexes. FEBS Lett. 2003, 553, 223-228. [CrossRef]

281. Semenov, A.Y.; Vassiliev, I.R.; van der Est, A.; Mamedov, M.D.; Zybailov, B.; Shen, G.; Stehlik, D.; Diner, B.A.; Chitnis, P.R.; Golbeck, J.H. Recruitment of a foreign quinone into the A1 site of photosystem I. Altered kinetics of electron transfer in phylloquinone biosynthetic pathway mutants studied by time-resolved optical, EPR, and electrometric techniques. J. Biol. Chem. 2000, 275, 23429-23438. [CrossRef]

282. Ivanov, B.N.; Ignatova, L.K.; Ovchinnikova, V.I.; Khorobrykh, S.A. Photoreduction of acceptor generated in an ascorbate peroxidase reaction in pea thylakoids. Biochemistry 1997, 62, 1082-1088.

283. Miyake, C.; Asada, K. Ferredoxin-dependent photoreduction of the monodehydroascorbate radical in spinach thylakoids. Plant Cell Physiol. 1994, 35, 539-549. [CrossRef]

284. Mubarakshina, M.; Khorobrykh, S.; Ivanov, B. Oxygen reduction in chloroplast thylakoids results in production of hydrogen peroxide inside the membrane. Biochim. Biophys. Acta 2006, 1757, 1496-1503. [CrossRef]

285. Takag, D.; Takumi, S.; Hashiguchi, M.; Sejima, T.; Miyake, C. Superoxide and singlet oxygen produced within the thylakoid membranes both cause photosystem I photoinhibition. Plant Physiol. 2016, 171, 1626-1634. [CrossRef]

286. Curci, R.; Edwards, J.O. Activation of hydrogen peroxide by organic compounds. In Catalytic Oxidations with Hydrogen Peroxide as Oxidant. Catalysis by Metal Complexes; Strukul, G., Ed.; Springer: Dordrecht, The Netherlands, 1992; Volume 9, pp. 45-95.

287. Kruk, J.; Strzałka, K. Identification of plastoquinone-C in spinach and maple leaves by reverse-phase high-performance liquid chromatography. Phytochemistry 1998, 49, 2267-2271. [CrossRef]

288. Kruk, J.; Karpinski, S. An HPLC-based method of estimation of the total redox state of plastoquinone in chloroplasts, the size of the photochemically active plastoquinone-pool and its redox state in thylakoids of Arabidopsis. Biochim. Biophys. Acta 2006, 1757, 1669-1675. [CrossRef]

289. Kruk, J.; Karpinski, S. Redox state analysis of the plastoquinone-pool in Arabidopsis thaliana reveals unexpected changes under different light conditions. In Photosynthesis: Fundamental Aspects to Global Perspectives; van der Est, A., Bruce, D., Eds.; International Society of Photosynthesis Research: Montreal, QC, Canada, 2005; pp. 568-570.

290. Lichtenthaler, H.K. Localization and functional concentrations of lipoquinones in chloroplasts. In Progress in Photosynthesis Research; Metzner, H., Ed.; Laupp: Tübingen, Germany, 1969; Volume 1, pp. 304-314.

291. Lichtenthaler, H.K.; Prenzel, U.; Douce, R.; Joyard, J. Localization of prenylquinones in the envelope of spinach chloroplasts. Biochim. Biophys. Acta 1981, 641, 99-105. [CrossRef]

292. Lichtenthaler, H.K. Biosynthesis, accumulation and emission of carotenoids, $\alpha$-tocopherol, plastoquinone, and isoprene in leaves under high photosynthetic irradiance. Photosynth. Res. 2007, 92, 163-179. [CrossRef] [PubMed]

293. Block, M.A.; Douce, R.; Joyard, J.; Rolland, N. Chloroplast envelope membranes: A dynamic interface between plastids and the cytosol. Photosynth. Res. 2007, 92, 225-244. [CrossRef] [PubMed]

294. Austin, J.R., 2nd; Frost, E.; Vidi, P.A.; Kessler, F.; Staehelin, L.A. Plastoglobules are lipoprotein subcompartments of the chloroplast that are permanently coupled to thylakoid membranes and contain biosynthetic enzymes. Plant Cell 2006, 18, 1693-1703. [CrossRef] [PubMed]

295. McCauley, S.W.; Melis, A. Quantitation of plastoquinone photoreduction in spinach chloroplasts. Photosynth. Res. 1986, 8, 3-16. [CrossRef] [PubMed]

296. Graan, T.; Ort, D.R. Quantitation of the rapid electron donors to P700, the functional plastoquinone pool, and the ratio of the photosystems in spinach chloroplasts. J. Biol. Chem. 1984, 259, 14003-14010.

297. Joliot, P.; Lavergne, J.; Beal, D. Plastoquinone compartmentation in chloroplasts. I. Evidence for domains with different rates of photo-reduction. Biochim. Biophys. Acta 1992, 1101, 1-12. [CrossRef]

298. Chapman, D.J.; Barber, J. Analysis of plastoquinone-9 levels in appressed and non-appressed thylakoid membrane regions. Biochim. Biophys. Acta 1986, 850, 170-172. [CrossRef]

299. Rich, P.R.; Bendall, D.S. The kinetics and thermodynamics of the reduction of cytochrome $c$ by substituted p-benzoquinols in solution. Biochim. Biophys. Acta 1980, 592, 506-518. [CrossRef] 
300. Elstner, E.F.; Frommeyer, D. Production of hydrogen peroxide by Photosystem II of spinach chloroplast lamellae. FEBS Lett. 1978, 86, 143-147. [CrossRef]

301. Hauska, G.; Hurt, E.; Gabellini, N.; Lockau, W. Comparative aspects of quinol-cytochrome c/plastocyanin oxidoreductases. Biochim. Biophys. Acta 1983, 726, 97-133. [CrossRef]

302. Prince, R.C.; Dutton, P.L.; Bruce, J.M. Electrochemistry of ubiquinones: Menaquinones and plastoquinones in aprotic solvents. FEBS Lett. 1983, 160, 273-276. [CrossRef]

303. Wardman, P. Bioreductive activation of quinones: Redox properties and thiol reactivity. Free Radic. Res. Commun. 1990, 8, 219-229. [CrossRef] [PubMed]

304. Lawlor, D.W. Photosynthesis: Metabolism, Control and Physiology, 1st ed.; Longman Scientific \& Technica: Essex, UK, 1987; p. 262.

305. Kruk, J.; Trebst, A. Plastoquinol as a singlet oxygen scavenger in photosystem II. Biochim. Biophys. Acta 2008, 1777, 154-162. [CrossRef] [PubMed]

306. Yadav, D.K.; Kruk, J.; Sinha, R.K.; Pospíšil, P. Singlet oxygen scavenging activity of plastoquinol in photosystem II of higher plants: Electron paramagnetic resonance spin-trapping study. Biochim. Biophys. Acta 2010, 1797, 1807-1811. [CrossRef]

307. Nowicka, B.; Kruk, J. Plastoquinol is more active than $\alpha$-tocopherol in singlet oxygen scavenging during high light stress of Chlamydomonas reinhardtii. Biochim. Biophys. Acta 2012, 1817, 389-394. [CrossRef]

308. Vetoshkina, D.V.; Ivanov, B.N.; Khorobrykh, S.A.; Proskuryakov, I.I.; Borisova-Mubarakshina, M.M. Involvement of the chloroplast plastoquinone pool in the Mehler reaction. Physiol. Plant. 2017, 161, 45-55. [CrossRef]

309. Cournac, L.; Josse, E.-M.; Joet, T.; Rumeu, D.; Redding, K.; Kuntz, M.; Peltier, G. Flexibility in photosynthetic electron transport: A newly identified chloroplasts oxidase involved in chlororespiration. Philos. Trans. R. Soc. Lond. B Biol. Sci. 2000, 355, 1447-1454. [CrossRef]

310. Lennon, A.M.; Prommeenate, P.; Nixon, P.J. Location, expression and orientation of the putative chlororespiratory enzymes, Ndh and IMMUTANS, in higher-plant plastids. Planta 2003, 218, 254-260. [CrossRef]

311. McDonald, A.E.; Ivanov, A.G.; Bode, R.; Maxwell, D.P.; Rodermel, S.R.; Huner, N.P. Flexibility in photosynthetic electron transport: The physiological role of plastoquinol terminal oxidase (PTOX). Biochim. Biophys. Acta 2011, 1807, 954-967. [CrossRef]

312. Nixon, P.J.; Rich, P.R. Chlororespiratory pathways and their physiological significance. In The Structure and Function of Plastids. Advances in Photosynthesis and Respiration; Wise, R.R., Hoober, J.K., Eds.; Springer: Dordrecht, The Netherlands, 2006; Volume 23, pp. 237-251.

313. Trouillard, M.; Shahbazi, M.; Moyet, L.; Rappaport, F.; Joliot, P.; Kuntz, M.; Finazzi, G. Kinetic properties and physiological role of the plastoquinone terminal oxidase (PTOX) in a vascular plant. Biochim. Biophys. Acta 2012, 1817, 2140-2148. [CrossRef] [PubMed]

314. Krieger-Liszkay, A.; Feilke, K. The dual role of the plastid terminal oxidase PTOX: Between a protective and a pro-oxidant function. Front. Plant Sci. 2016, 6, 1147. [CrossRef] [PubMed]

315. Yu, Q.; Feilke, K.; Krieger-Liszkay, A.; Beyer, P. Functional and molecular characterization of plastid terminal oxidase from rice (Oryza sativa). Biochim. Biophys. Acta 2014, 1837, 1284-1292. [CrossRef] [PubMed]

316. Baniulis, D.; Hasan, S.S.; Stofleth, J.T.; Cramer, W.A. Mechanism of enhanced superoxide production in the cytochrome b6f complex of oxygenic photosynthesis. Biochemistry 2013, 52, 8975-8983. [CrossRef] [PubMed]

317. Sang, M.; Xie, J.; Qin, X.C.; Wang, W.D.; Chen, X.B.; Wang, K.B.; Zhang, J.P.; Li, L.B.; Kuang, T.Y. High-light induced superoxide radical formation in cytochrome $b_{6} \mathrm{f}$ complex from Bryopsis corticulans as detected by EPR spectroscopy. J. Photochem. Photobiol. B 2011, 102, 177-181. [CrossRef] [PubMed]

318. Mishra, N.P.; Francke, C.; van Gorkom, H.J.; Ghanotakis, D.F. Destructive role of singlet oxygen during aerobic illumination of the Photosystem II core complex. Biochim. Biophys. Acta 1994, 1186, 81-90. [CrossRef]

319. Tyystjärvi, E. Photoinhibition of Photosystem II. Int. Rev. Cell Mol. Biol. 2013, 300, 243-303.

320. Vass, I. Role of charge recombination processes in photodamage and photoprotection of the photosystem II complex. Physiol. Plant. 2011, 142, 6-16. [CrossRef]

321. Hakala, M.; Tuominen, I.; Keränen, M.; Tyystjärvi, T.; Tyystjärvi, E. Evidence for the role of the oxygen-evolving manganese complex in photoinhibition of Photosystem II. Biochim. Biophys. Acta 2005, 1706, 68-80. [CrossRef]

322. Fan, D.Y.; Ye, Z.P.; Wang, S.C.; Chow, W. Multiple roles of oxygen in the photoinactivation and dynamic repair of Photosystem II in spinach leaves. Photosynth. Res. 2016, 127, 307-319. [CrossRef] 
323. Jahns, P.; Depka, B.; Trebst, A. Xanthophyll cycle mutants from Chlamydomonas reinhardtii indicate a role for zeaxanthin in the D1 protein turnover. Plant Physiol. Biochem. 2000, 38, 371-376. [CrossRef]

324. Hakala-Yatkin, M.; Sarvikas, P.; Paturi, P.; Mäntysaari, M.; Mattila, H.; Tyystjärvi, T.; Nedbal, L.; Tyystjärvi, E. Magnetic field protects plants against high light by slowing down production of singlet oxygen. Physiol. Plant. 2011, 142, 26-34. [CrossRef] [PubMed]

325. Inoue, S.; Ejima, K.; Iwai, E.; Hayashi, H.; Appel, J.; Tyystjärvi, E.; Murata, N.; Nishiyama, Y. Protection by $\alpha$-tocopherol of the repair of photosystem II during photoinhibition in Synechocystis sp. PCC 6803. Biochim. Biophys. Acta 2011, 1807, 236-241. [CrossRef] [PubMed]

326. Fufezan, C.; Gross, C.M.; Sjödin, M.; Rutherford, A.W.; Krieger-Liszkay, A.; Kirilovsky, D. Influence of the redox potential of the primary quinone electron acceptor on photoinhibition of photosystem II. J. Biol. Chem. 2007, 282, 12492-12502. [CrossRef]

327. Sarvikas, P.; Hakala, M.; Pätsikkä, E.; Tyystjärvi, T.; Tyystjärvi, E. Action spectrum of photoinhibition in leaves of wild type and npq1-2 and npq4-1 mutants of Arabidopsis thaliana. Plant Cell Physiol. 2006, 47, 391-400. [CrossRef]

328. Ohnishi, N.; Allakhverdiev, S.I.; Takahashi, S.; Higashi, S.; Watanabe, M.; Nishiyama, Y.; Murata, N. Two-step mechanism of photodamage to photosystem II: Step I occurs at the oxygen-evolving complex and step 2 occurs at the photochemical reaction center. Biochemistry 2005, 44, 8494-8499. [CrossRef] [PubMed]

329. Treves, H.; Raanan, H.; Kedem, I.; Murik, O.; Keren, N.; Zer, H.; Berkowicz, S.M.; Giordano, M.; Norici, A.; Shotland, Y.; et al. The mechanisms whereby the green alga Chlorella ohadii, isolated from desert soil crust, exhibits unparalleled photodamage resistance. New Phytol. 2016, 210, 1229-1243. [CrossRef]

330. Mishra, N.P.; Ghanotakis, D.F. Exposure of Photosystem II complex to chemically generated singlet oxygen results in D1 fragments similar to the ones observed during aerobic photoinhibition. Biochim. Biophys. Acta 1994, 1187, 296-300. [CrossRef]

331. Okada, K.; Ikeuchi, M.; Yamamoto, N.; Ono, T.; Miyao, M. Selective and specific cleavage of the D1 and D2 proteins of Photosystem II by exposure to singlet oxygen: Factors responsible for the susceptibility to cleavage of the proteins. Biochim. Biophys. Acta 1996, 1274, 73-79. [CrossRef]

332. Miyao, M.; Ikeuchi, M.; Yamamoto, N.; Ono, T. Specific degradation of the D1 protein of photosystem II by treatment with hydrogen peroxide in darkness: Implications for the mechanism of degradation of the D1 protein under illumination. Biochemistry 1995, 34, 10019-10026. [CrossRef]

333. Miyao, M. Involvement of active oxygen species in degradation of the D1 protein under strong illumination in isolated subcomplexes of photosystem II. Biochemistry 1994, 33, 9722-9730. [CrossRef] [PubMed]

334. Nixon, P.J.; Michoux, F.; Yu, J.; Boehm, M.; Komenda, J. Recent advances in understanding the assembly and repair of photosystem II. Ann. Bot. 2010, 106, 1-16. [CrossRef] [PubMed]

335. Kale, R.; Hebert, A.E.; Frankel, L.K.; Sallans, L.; Bricker, T.M.; Pospíšil, P. Amino acid oxidation of the D1 and D2 proteins by oxygen radicals during photoinhibition of Photosystem II. Proc. Natl. Acad. Sci. USA 2017, 114, 2988-2993. [CrossRef] [PubMed]

336. Terashima, I.; Funayama, S.; Sonoike, K. The site of photoinhibition in leaves of Cucumis sativus L. at low temperatures is photosystem I, not photosystem II. Planta 1994, 193, 300-306. [CrossRef]

337. Sonoike, K. Degradation of psaB gene product, the reaction center subunit of photosystem I, is caused during photoinhibition of photosystem I: Possible involvement of active oxygen species. Plant Sci. 1996, 115, 157-164. [CrossRef]

338. Tiwari, A.; Mamedov, F.; Grieco, M.; Suorsa, M.; Jajoo, A.; Styring, S.; Tikkanen, M.; Aro, E.-M. Photodamage of iron-sulphur clusters in photosystem I induces non-photochemical energy dissipation. Nat. Plants 2016, 2, 16035. [CrossRef] [PubMed]

339. Sonoike, K. Photoinhibition of photosystem I. Physiol. Plant. 2011, 142, 56-64. [CrossRef]

340. Sejima, T.; Takagi, D.; Fukayama, H.; Makino, A.; Miyake, C. Repetitive short-pulse light mainly inactivates photosystem I in sunflower leaves. Plant Cell Physiol. 2014, 55, 1184-1193. [CrossRef]

341. Tikkanen, M.; Grebe, S. Switching off photoprotection of photosystem I-a novel tool for gradual PSI photoinhibition. Physiol. Plant. 2018, 162, 156-161. [CrossRef]

342. Blée, E. Phytooxylipins and plant defense reactions. Prog. Lipid Res. 1998, 37, 33-72. [CrossRef]

343. Farmer, E.E.; Davoine, C. Reactive electrofile species. Curr. Opin. Plant Biol. 2007, 10, 380-386. [CrossRef] 
344. Mêne-Saffraneé, L.; Davoine, C.; Stolz, S.; Majcherczyk, P.; Farmer, E.E. Genetic removal of tri-unsaturated fatty acids suppresses developmental and molecular phenotypes of an Arabidopsis tocopherol-deficient mutant. Whole-body mapping of malondialdehyde pools in a complex eukaryote. J. Biol. Chem. 2007, 49, 35749-35756. [CrossRef] [PubMed]

345. Mano, J.; Khorobrykh, S.; Matsui, K.; Iijima, Y.; Sakurai, N.; Suzuki, H.; Shibata, D. Acrolein is formed from trienoic fatty acids in chloroplast: A targeted metabolimics approach. Plant Biotechnol. 2014, 31, 535-543. [CrossRef]

346. Farmer, E.E.; Mueller, M.J. ROS-mediated lipid peroxidation and RES-activated signaling. Annu. Rev. Plant. Biol. 2013, 64, 429-450. [CrossRef] [PubMed]

347. Mêne-Saffraneé, L.; Dubugnon, L.; Chételat, A.; Stolz, S.; Gouhier-Darimont, C.; Farmer, E.E. Nonenzymatic oxidation of trienoic fatty acids contributes to reactive oxygen species management in Arabidopsis. J. Biol. Chem. 2009, 284, 1702-1708. [CrossRef]

348. Kojima, K.; Oshita, M.; Nanjo, Y.; Kasai, K.; Tozawa, Y.; Hayashi, H.; Nishiyama, Y. Oxidation of elongation factor G inhibits the synthesis of the D1 protein of photosystem II. Mol. Microbiol. 2007, 65, 936-947. [CrossRef]

349. Yutthanasirikul, R.; Nagano, T.; Jimbo, H.; Hihara, Y.; Kanamori, T.; Ueda, T.; Haruyama, T.; Konno, H.; Yoshida, K.; Hisabori, T.; et al. Oxidation of a cysteine residue in elongation factor EF-Tu reversibly inhibits translation in the cyanobacterium Synechocystis sp. PCC 6803. J. Biol. Chem. 2016, 291, 5860-5870. [CrossRef]

350. Jimbo, H.; Yutthanasirikul, R.; Nagano, T.; Hisabori, T.; Hiharo, Y.; Nishiyama, Y. Oxidation of translation factor EF-Tu inhibits the repair of photosystem II. Plant Physiol. 2018, 176, 2691-2699. [CrossRef]

351. Nishiyama, Y.; Allakhverdiev, S.I.; Yamamamoto, H.; Hayashi, H.; Murata, N. Singlet oxygen inhibits the repair of photosystem II by suppressing the translation elongation of the D1 protein in Synechocystis sp. PCC 6803. Biochemistry 2004, 43, 11321-11330. [CrossRef]

352. Kaiser, W. The effect of hydrogen peroxide on $\mathrm{CO}_{2}$ fixation of isolated intact chloroplasts. Biochim. Biophys. Acta 1976, 440, 476-482. [CrossRef]

353. Muthuramalingam, M.; Matros, A.; Scheibe, R.; Mock, H.-P.; Dietz, K.-J. The hydrogen peroxide-sensitive proteome of the chloroplast in vitro and in vivo. Front. Plant Sci. 2013, 4, 54. [CrossRef] [PubMed]

354. Kumar, R.; Oldenburg, D.J.; Bendich, A.J. Molecular integrity of chloroplast DNA and mitochondrial DNA in mesophyll and bundle sheath cells of maize. Planta 2015, 241, 1221-1230. [CrossRef] [PubMed]

355. Balasaraswathi, K.; Jayaveni, S.; Sridevi, J.; Sujatha, D.; Aaron, K.P.; Rose, C. Cr-induced cellular injury and necrosis in Glycine max L.: Biochemical mechanism of oxidative damage in chloroplast. Plant Physiol. Biochem. 2017, 118, 653-666. [CrossRef] [PubMed]

356. Noctor, G.; Foyer, C.H. Intracellular redox compartmentation and ROS-related communication in regulation and signaling. Plant Physiol. 2016, 171, 1581-1592. [CrossRef] [PubMed]

357. Foyer, C.H.; Ruban, A.V.; Noctor, G. Viewing oxidative stress through the lens of oxidative signalling rather than damage. Biochem. J. 2017, 474, 877-883. [CrossRef] [PubMed]

358. Ogawa, K.; Kanematsu, S.; Takabe, K.; Asada, K. Attachment of CuZn-superoxide dismutase to thylakoid membranes at the site of superoxide generation (PSI) in spinach chloroplasts: Detection by immuno-gold labeling after rapid freezing and substitution method. Plant Cell Physiol. 1995, 36, 565-573.

359. Gray, B.; Carmichael, A.J. Kinetics of superoxide scavenging by dismutase enzymes and manganese mimics determined by electron spin resonance. Biochem. J. 1992, 281, 795-802. [CrossRef]

360. Barnese, K.; Gralla, E.B.; Valentine, J.S.; Cabelli, D.E. Biologically relevant mechanism for catalytic superoxide removal by simple manganese compounds. Proc. Natl. Acad. Sci. USA 2012, 109, 6892-6897. [CrossRef]

361. Giacomelli, L.; Masi, A.; Ripoll, D.R.; Lee, M.J.; van Wijk, K.J. Arabidopsis thaliana deficient in two chloroplast ascorbate peroxidases shows accelerated light-induced necrosis when levels of cellular ascorbate are low. Plant Mol. Biol. 2007, 65, 627-644. [CrossRef]

362. Kangasjärvi, S.; Lepistö, A.; Hännikäinen, K.; Piippo, M.; Luomala, E.M.; Aro, E.M.; Rintamäki, E. Diverse roles for chloroplast stromal and thylakoid-bound ascorbate peroxidases in plant stress responses. Biochem. J. 2008, 412, 275-285. [CrossRef]

363. Maruta, T.; Tanouchi, A.; Tamoi, M.; Yabuta, Y.; Yoshimura, K.; Ishikawa, T.; Shigeoka, S. Arabidopsis chloroplastic ascorbate peroxidase isoenzymes play a dual role in photoprotection and gene regulation under photooxidative stress. Plant Cell Physiol. 2010, 51, 190-200. [CrossRef] [PubMed] 
364. Shigeoka, S.; Ishikawa, T.; Tamoi, M.; Miyagawa, Y.; Takeda, T.; Yabuta, Y.; Yoshimura, K. Regulation and function of ascorbate peroxidase isoenzymes. J. Exp. Bot. 2002, 53, 1305-1319. [CrossRef]

365. Pandey, P.; Singh, J.; Achary, V.M.M.; Reddy, M.K. Redox homeostasis via gene families of ascorbate-glutathione pathway. Front. Environ. Sci. 2015, 3, 25. [CrossRef]

366. Awad, J.; Stotz, H.U.; Fekete, A.; Krischke, M.; Engert, C.; Havaux, M.; Berger, S.; Mueller, M.J. 2-Cysteine peroxiredoxins and thylakoid ascorbate peroxidase create a water-water cycle that is essential to protect the photosynthetic apparatus under high light stress conditions. Plant Physiol. 2015, 167, 1592-1603. [CrossRef] [PubMed]

367. Pérez-Ruiz, J.M.; Spínola, M.C.; Kirchsteiger, K.; Moreno, J.; Sahrawy, M.; Cejudo, F.J. Rice NTRC is a high-efficiency redox system for chloroplast protection against oxidative damage. Plant Cell 2006, 18, 2356-2368. [CrossRef]

368. Bernal-Bayard, P.; Ojeda, V.; Hervás, M.; Cejudo, F.J.; Navarro, J.A.; Velázquez-Campoy, A.; Pérez-Ruiz, J.M. Molecular recognition in the interaction of chloroplast 2-Cys peroxiredoxin with NADPH-thioredoxin reductase C (NTRC) and thioredoxin x. FEBS Lett. 2014, 588, 4342-4347. [CrossRef]

369. Pulido, P.; Spínola, M.C.; Kirchsteiger, K.; Guinea, M.; Pascual, M.B.; Sahrawy, M.; Sandalio, L.M.; Dietz, K.J.; González, M.; Cejudo, F.J. Functional analysis of the pathways for 2-Cys peroxiredoxin reduction in Arabidopsis thaliana chloroplasts. J. Exp. Bot. 2010, 61, 4043-4054. [CrossRef]

370. Dietz, K.J. Peroxiredoxins in plants and cyanobacteria. Antioxid. Redox Signal. 2011, 15, 1129-1159. [CrossRef]

371. Spínola, M.C.; Pérez-Ruiz, J.M.; Pulido, P.; Kirchsteiger, K.; Guinea, M.; González, M.; Cejudo, F.J. NTRC new ways of using NADPH in the chloroplast. Physiol. Plant. 2008, 133, 516-524. [CrossRef]

372. Crawford, N.A.; Droux, M.; Kosower, N.S.; Buchanan, B.B. Evidence for function of the ferredoxin/thioredoxin system in the reductive activation of target enzymes of isolated intact chloroplasts. Arch. Biochem. Biophys. 1989, 271, 223-239. [CrossRef]

373. Herbette, S.; Lenne, C.; Leblanc, N.; Julien, J.L.; Drevet, J.R.; Roeckel-Drevet, P. Two GPX-like proteins from Lycopersicon esculentum and Helianthus annuus are antioxidant enzymes with phospholipid hydroperoxide glutathione peroxidase and thioredoxin peroxidase activities. Eur. J. Biochem. 2002, 269, 2414-2420. [CrossRef] [PubMed]

374. Jung, B.G.; Lee, K.O.; Lee, S.S.; Chi, Y.H.; Jang, H.H.; Kang, S.S.; Lee, K.; Lim, D.; Yoon, S.C.; Yun, D.J.; et al. A Chinese cabbage cDNA with high sequence identity to phospholipid hydroperoxide glutathione peroxidases encodes a novel isoform of thioredoxin-dependent peroxidase. J. Biol. Chem. 2002, 277, 12572-12578. [CrossRef] [PubMed]

375. Chang, C.C.C.; Ślesak, I.; Jordá, L.; Sotnikov, A.; Melzer, M.; Miszalski, Z.; Mullineaux, P.M.; Parker, J.E.; Karpińska, B.; Karpiński, S. Arabidopsis chloroplastic glutathione peroxidases play a role in cross talk between photooxidative stress and immune responses. Plant Physiol. 2009, 150, 670-683. [CrossRef]

376. Ruban, A.V. Nonphotochemical chlorophyll fluorescence quenching: Mechanism and effectiveness in protecting plants from photodamage. Plant Phys. 2016, 170, 1903-1916. [CrossRef] [PubMed]

377. Malnoë, A. Photoinhibition or photoprotection of photosynthesis? Update on the (newly termed) sustained quenching component qH. Environ. Exp. Bot. 2018, 154, 123-133. [CrossRef]

378. Liu, Z.; Yan, H.; Wang, K.; Kuang, T.; Zhang, J.; Gui, L.; An, X.; Chang, W. Crystal structure of spinach major light-harvesting complex at 2.72 A resolution. Nature 2004, 428, 287-292. [CrossRef]

379. Peterman, E.J.; Dukker, F.M.; van Grondelle, R.; van Amerongen, H. Chlorophyll $a$ and carotenoid triplet states in light-harvesting complex II of higher plants. Biophys. J. 1995, 69, 2670-2678. [CrossRef]

380. Barzda, V.; Peterman, E.J.; van Grondelle, R.; van Amerongen, H. The influence of aggregation on triplet formation in light-harvesting chlorophyll a/b pigment-protein complex II of green plants. Biochemistry 1998, 37, 546-551. [CrossRef]

381. Mozzo, M.; Dall'Osto, L.; Hienerwadel, R.; Bassi, R.; Croce, R. Photoprotection in the antenna complexes of photosystem II: Role of individual xanthophylls in chlorophyll triplet quenching. J. Biol. Chem. 2008, 283, 6184-6192. [CrossRef]

382. Croce, R.; Remelli, R.; Varotto, C.; Breton, J.; Bassi, R. The neoxanthin binding site of the major light harvesting complex (LHCII) from higher plants. FEBS Lett. 1999, 456, 1-6. [CrossRef]

383. Caffarri, S.; Croce, R.; Breton, J.; Bassi, R. The major antenna complex of photosystem II has a xanthophyll binding site not involved in light harvesting. J. Biol. Chem. 2001, 276, 35924-35933. [CrossRef] [PubMed] 
384. Dall'Osto, L.; Holt, N.E.; Kaligotla, S.; Fuciman, M.; Cazzaniga, S.; Carbonera, D.; Frank, H.A.; Alric, J.; Bassi, R. Zeaxanthin protects plant photosynthesis by modulating chlorophyll triplet yield in specific light-harvesting antenna subunits. J. Biol. Chem. 2012, 287, 41820-41834. [CrossRef] [PubMed]

385. Niyogi, K.K.; Grossman, A.R.; Björkman, O. Arabidopsis mutants define a central role for the xanthophyll cycle in the regulation of photosynthetic energy conversion. Plant Cell 1998, 10, 1121-1134. [CrossRef] [PubMed]

386. Umena, Y.; Kawakami, K.; Shen, J.R.; Kamiya, N. Crystal structure of oxygen-evolving photosystem II at a resolution of $1.9 \AA$ A. Nature 2011, 473,55-60. [CrossRef]

387. Santabarbara, S.; Agostini, A.; Casazza, A.P.; Zucchelli, G.; Carbonera, D. Carotenoid triplet states in photosystem II: Coupling with low-energy states of the core complex. Biochim. Biophys. Acta 2015, 1847, 262-275. [CrossRef]

388. Fischer, B.B.; Hideg, É.; Krieger-Liszkay, A. Production, detection, and signaling of singlet oxygen in photosynthetic organisms. Antioxid. Redox Signal. 2013, 18, 2145-2162. [CrossRef]

389. Di Mascio, P.; Devasagayam, T.P.; Kaiser, S.; Sies, H. Carotenoids, tocopherols and thiols as biological singlet molecular oxygen quenchers. Biochem. Soc. Trans. 1990, 18, 1054-1056. [CrossRef]

390. Ramel, F.; Birtic, S.; Cuiné, S.; Triantaphylidès, C.; Ravanat, J.L.; Havaux, M. Chemical quenching of singlet oxygen by carotenoids in plants. Plant Physiol. 2012, 158, 1267-1278. [CrossRef]

391. Ramel, F.; Birtic, S.; Ginies, C.; Soubigou-Taconnat, L.; Triantaphylidès, C.; Havaux, M. Carotenoid oxidation products are stress signals that mediate gene responses to singlet oxygen in plants. Proc. Natl. Acad. Sci. USA 2012, 109, 5535-5540. [CrossRef]

392. Johnson, M.P.; Havaux, M.; Triantaphylidès, C.; Ksas, B.; Pascal, A.A.; Robert, B.; Davison, P.A.; Ruban, A.V.; Horton, P. Elevated zeaxanthin bound to oligomeric LHCII enhances the resistance of Arabidopsis to photooxidative stress by a lipid-protective, antioxidant mechanism. J. Biol. Chem. 2007, 282, 22605-22618. [CrossRef]

393. Foyer, C.H.; Trebst, A.; Noctor, G. Signaling and integration of defense functions of tocopherol, ascorbate and glutathione. In Photoprotection, Photoinhibition, Gene Regulation, and Environment. Advances in Photosynthesis and Respiration; Demmig-Adams, B., Adams, W.W., Mattoo, A.K., Eds.; Springer: Dordrecht, The Netherlands, 2008; Volume 21, pp. 241-268.

394. Neely, W.C.; Martin, J.M.; Barker, S.A. Products and relative reaction rates of the oxidation of tocopherols with singlet molecular oxygen. Photochem. Photobiol. 1988, 48, 423-428. [CrossRef] [PubMed]

395. Krieger-Liszkay, A.; Trebst, A. Tocopherol is the scavenger of singlet oxygen produced by the triplet states of chlorophyll in the PSII reaction centre. J. Exp. Bot. 2006, 57, 1677-1684. [CrossRef] [PubMed]

396. Nagai, S.; Ohara, K.; Mukai, K. Kinetic study of the quenching reaction of singlet oxygen by flavonoids in ethanol solution. J. Phys. Chem. B 2005, 109, 4234-4240. [CrossRef] [PubMed]

397. Agati, G.; Matteini, P.; Goti, A.; Tattini, M. Chloroplast-located flavonoids can scavenge singlet oxygen. New Phytol. 2007, 174, 77-89. [CrossRef] [PubMed]

398. Ferretti, U.; Ciura, J.; Ksas, B.; Rác, M.; Sedlářová, M.; Kruk, J.; Havaux, M.; Pospíšil, P. Chemical quenching of singlet oxygen by plastoquinols and their oxidation products in Arabidopsis. Plant J. 2018, 95, 848-861. [CrossRef]

399. Affek, H.P.; Yakir, D. Protection by isoprene against singlet oxygen in leaves. Plant Physiol. 2002, 129, $269-277$. [CrossRef]

400. Velikova, V.; Edreva, A.; Loreto, F. Endogenous isoprene protects Phragmites australis leaves against singlet oxygen. Physiol. Plant. 2004, 122, 219-225. [CrossRef]

401. Mignolet-Spruyt, L.; Xu, E.; Idänheimo, N.; Hoeberichts, F.; Mühlenbock, P.; Brosché, M.; Van Breusegem, F.; Kangasjärvi, J. Spreading the news: Subcellular and organellar reactive oxygen species production and signalling. J. Exp. Bot. 2016, 67, 3831-3844. [CrossRef]

402. Crawford, T.; Lehotai, N.; Strand, A. The role of retrograde signals during plant stress responses. J. Exp. Bot. 2018, 69, 2783-2795. [CrossRef]

403. Dogra, V.; Rochaix, J.D.; Kim, C. Singlet oxygen-triggered chloroplast-to-nucleus retrograde signalling pathways: An emerging perspective. Plant Cell Environ. 2018, 41, 1727-1738. [CrossRef]

404. Mullineaux, P.M.; Exposito-Rodriguez, M.; Laissue, P.P.; Smirnoff, N. ROS-dependent signalling pathways in plants and algae exposed to high light: Comparisons with other eukaryotes. Free Radic. Biol. Med. 2018, 122, 52-64. [CrossRef] [PubMed] 
405. Borisova-Mubarakshina, M.M.; Vetoshkina, D.V.; Ivanov, B.N. Antioxidant and signaling functions of the plastoquinone pool in higher plants. Physiol. Plant. 2019, 166, 181-198. [CrossRef] [PubMed]

406. Dietz, K.J.; Wesemann, C.; Wegener, M.; Seidel, T. Toward an integrated understanding of retrograde control of photosynthesis. Antioxid. Redox Signal. 2019, 30, 1186-1205. [CrossRef] [PubMed]

407. Wang, L.; Apel, K. Dose-dependent effects of ${ }^{1} \mathrm{O}_{2}$ in chloroplasts are determined by its timing and localization of production. J. Exp. Bot. 2019, 70, 29-40. [CrossRef] [PubMed]

408. Černý, M.; Habánová, H.; Berka, M.; Luklová, M.; Brzobohatý, B. Hydrogen peroxide: Its role in plant biology and crosstalk with signalling networks. Int. J. Mol. Sci. 2018, 19, 2812. [CrossRef] [PubMed]

409. Lv, F.; Zhou, J.; Zeng, L.; Xing, D. $\beta$-cyclocitral upregulates salicylic acid signalling to enhance excess light acclimation in Arabidopsis. J. Exp. Bot. 2015, 66, 4719-4732. [CrossRef]

410. D'Alessandro, S.; Mizokami, Y.; Légeret, B.; Havaux, M. The apocarotenoid $\beta$-cyclocitric acid elicits drought tolerance in plants. iScience 2019, 19, 461-473. [CrossRef]

411. Havaux, M. Small molecules: From structural diversity to signaling and regulatory roles. Carotenoid oxidation products as stress signals in plants. Plant J. 2013, 79, 597-606. [CrossRef]

412. Shao, N.; Duan, G.Y.; Bock, R. A mediator of singlet oxygen responses in Chlamydomonas reinhardtii and Arabidopsis identified by a luciferase-based genetic screen in algal cells. Plant Cell 2013, 25, 4209-4226. [CrossRef]

413. Shumbe, L.; D’alessandro, S.; Shao, N.; Chevalier, A.; Ksas, B.; Block, R.; Havaux, M. METHYLENE BLUE SENSITIVITY 1 (MBS1) is required for acclimation of Arabidopsis to singlet oxygen and acts downstream of $\beta$-cyclocitral. Plant Cell Environ. 2017, 40, 216-226. [CrossRef]

414. Shumbe, L.; Bott, R.; Havaux, M. Dihydroactinidiolide, a high light-induced $\beta$-carotene derivative that can regulate gene expression and photoacclimation in Arabidopsis. Mol. Plant 2014, 7, 1248-1251. [CrossRef] [PubMed]

415. Wagner, D.; Przybyla, D.; Op den Camp, R.; Kim, C.; Landgraf, F.; Lee, K.P.; Würsch, M.; Laloi, C.; Nater, M.; Hideg, E.; et al. The genetic basis of singlet oxygen-induced stress responses of Arabidopsis thaliana. Science 2004, 306, 1183-1185. [CrossRef] [PubMed]

416. Lee, K.P.; Kim, C.; Landgraf, F.; Apel, K. EXECUTER1- and EXECUTER2-dependent transfer of stress-related signals from the plastid to the nucleus of Arabidopsis thaliana. Proc. Natl. Acad. Sci. USA 2007, 104, 10270-10275. [CrossRef] [PubMed]

417. Dogra, V.; Li, M.; Singh, S.; Li, M.; Kim, C. Oxidative post-translational modification of EXECUTER1 is required for singlet oxygen sensing in plastids. Nat. Commun. 2019, 10, 2834. [CrossRef] [PubMed]

418. Dogra, V.; Duan, J.; Lee, K.P.; Lv, S.; Liu, R.; Kim, C. FtsH2-dependent proteolysis of EXECUTER1 is essential in mediating singlet oxygen-triggered retrograde signaling in Arabidopsis thaliana. Front. Plant Sci. 2017, 8, 1145. [CrossRef] [PubMed]

419. Danon, A.; Coll, N.S.; Apel, K. Cryptochrome-1-dependent execution of programmed cell death induced by singlet oxygen in Arabidopsis thaliana. Proc. Natl. Acad. Sci. USA 2006, 103, 17036-17041. [CrossRef]

420. Carmody, M.; Crisp, P.A.; d'Alessandro, S.; Ganguly, D.; Gordon, M.; Havaux, M.; Albrecht-Borth, V.; Pogson, B.J. Uncoupling high light responses from singlet oxygen retrograde signaling and spatial-temporal systemic acquired acclimation. Plant Physiol. 2016, 171, 1734-1749. [CrossRef]

421. Ramel, F.; Ksas, B.; Havaux, M. Jasmonate: A decision maker between cell death and acclimation in the response of plants to singlet oxygen. Plant Signal. Behav. 2013, 8, e26655. [CrossRef]

422. Shumbe, L.; Chevalier, A.; Legeret, B.; Taconnat, L.; Monnet, F.; Havaux, M. Singlet oxygen-induced cell death in Arabidopsis under high-light stress is controlled by OXI1 kinase. Plant Physiol. 2016, 170, 1757-1771. [CrossRef]

423. D'Alessandro, S.; Havaux, M. Sensing $\beta$-carotene oxidation in photosystem II to master plant stress tolerance. New Phytol. 2019, 223, 1776-1783. [CrossRef]

424. Armond, P.A.; Arntzen, C.J. Localization and characterization of photosystem II in grana and stroma lamellae. Plant Physiol. 1977, 59, 398-404. [CrossRef] [PubMed]

425. Wang, L.; Kim, C.; Xu, X.; Piskurewicz, U.; Dogra, V.; Singh, S.; Mahler, H.; Apel, K. Singlet oxygen- and EXECUTER1-mediated signaling is initiated in grana margins and depends on the protease FtsH2. Proc. Natl. Acad. Sci. USA 2016, 113, E3792-E3800. [CrossRef] [PubMed] 
426. Järvi, S.; Suorsa, M.; Aro, E.M. Photosystem II repair in plant chloroplasts-Regulation, assisting proteins and shared components with photosystem II biogenesis. Biochim. Biophys. Acta 2015, 1847, 900-909. [CrossRef] [PubMed]

427. Feierabend, J.; Dahne, S. Fate of the porphyrin cofactors during the light-dependent turnover of catalase and of the photosystem II reaction center protein D1 in mature rye leaves. Planta 1996, 198, 413-422. [CrossRef]

428. Hernandez-Prieto, M.A.; Tibiletti, T.; Abasova, L.; Kirilovsky, D.; Vass, I.; Funk, C. The small CAB-like proteins of the cyanobacterium Synechocystis sp. PCC 6803: Their involvement in chlorophyll biogenesis for Photosystem II. Biochim. Biophys. Acta 2011, 1807, 1143-1151. [CrossRef]

429. Zaltsman, A.; Feder, A.; Adam, Z. Developmental and light effects on the accumulation of FtsH protease in Arabidopsis chloroplasts: Implications for thylakoid formation and photosystem II maintenance. Plant J. 2005, 42, 609-617. [CrossRef]

430. Stael, S.; Kmiecik, P.; Willems, P.; Van Der Kelen, K.; Coll, N.S.; Teige, M.; Van Breusegem, F. Plant innate immunity-sunny side up? Trends Plant Sci. 2015, 20, 3-11. [CrossRef]

431. Mur, L.A.; Aubry, S.; Mondhe, M.; Kingston-Smith, A.; Gallagher, J.; Timms-Taravella, E.; James, C.; Papp, I.; Hörtensteiner, S.; Thomas, H.; et al. Accumulation of chlorophyll catabolites photosensitizes the hypersensitive response elicited by Pseudomonas syringae in Arabidopsis. New Phytol. 2010, 188, 161-174. [CrossRef]

432. Tarahi Tabrizi, S.; Sawicki, A.; Zhou, S.; Luo, M.; Willows, R.D. GUN4-Protoporphyrin IX is a singlet oxygen generator with consequences for plastid retrograde signaling. J. Biol. Chem. 2016, 291, 8978-8984. [CrossRef]

433. Kato, Y.; Hyodo, K.; Sakamoto, W. The photosystem II repair cycle requires FtsH turnover through the EngA GTPase. Plant Physiol. 2018, 178, 596-611. [CrossRef]

434. de Torres Zabala, M.; Littlejohn, G.; Jayaraman, S.; Studholme, D.; Bailey, T.; Lawson, T.; Tillich, M.; Licht, D.; Bölter, B.; Delfino, L.; et al. Chloroplasts play a central role in plant defence and are targeted by pathogen effectors. Nat. Plants 2015, 1, 15074. [CrossRef] [PubMed]

435. Järvi, S.; Isojärvi, J.; Kangasjärvi, S.; Salojärvi, J.; Mamedov, F.; Suorsa, M.; Aro, E.M. Photosystem II repair and plant immunity: Lessons learned from Arabidopsis mutant lacking the THYLAKOID LUMEN PROTEIN 18.3. Front. Plant Sci. 2016, 7, 405. [CrossRef] [PubMed]

436. Exposito-Rodriguez, M.; Laissue, P.P.; Yvon-Durocher, G.; Smirnoff, N.; Mullineaux, P.M. Photosynthesis dependent $\mathrm{H}_{2} \mathrm{O}_{2}$ transfer from chloroplasts to nuclei provides a high-light signalling mechanism. Nat. Commun. 2017, 8, 49. [CrossRef] [PubMed]

437. Mubarakshina-Borisova, M.M.; Kozuleva, M.A.; Rudenko, N.N.; Naydov, I.A.; Klenina, I.B.; Ivanov, B.N. Photosynthetic electron flow to oxygen and diffusion of hydrogen peroxide through the chloroplast envelope via aquaporins. Biochim. Biophys. Acta 2012, 1817, 1314-1321. [CrossRef] [PubMed]

438. Sadhukhan, A.; Kobayashi, Y.; Nakano, Y.; Iuchi, S.; Kobayashi, M.; Sahoo, L.; Koyama, H. Genomewide association study reveals that the aquaporin NIP1;1 contributes to variation in hydrogen peroxide sensitivity in Arabidopsis thaliana. Mol. Plant 2017, 10, 1082-1094. [CrossRef]

439. Brunkard, J.O.; Runkel, A.M.; Zambryski, P.C. Chloroplasts extend stromules independently and in response to internal redox signals. Proc. Natl. Acad. Sci. USA 2015, 112, 10044-10049. [CrossRef]

440. Caplan, J.L.; Kumar, A.S.; Park, E.; Padmanabhan, M.S.; Hoban, K.; Modla, S.; Czymmek, K.; Dinesh-Kumar, S.P. Chloroplast stromules function during innate immunity. Dev. Cell 2015, 34, 45-57. [CrossRef]

441. Ivanov, B.N.; Borisova-Mubarakshina, M.M.; Kozuleva, M.A. Formation mechanisms of superoxide radical and hydrogen peroxide in chloroplasts, and factors determining the signalling by hydrogen peroxide. Funct. Plant Biol. 2017, 45, 102-110. [CrossRef]

442. Willems, P.; Mhamdi, A.; Stael, S.; Storme, V.; Kerchev, P.; Noctor, G.; Gevaert, K.; Van Breusegem, F. The ROS wheel: Refining ROS transcriptional footprints. Plant Physiol. 2016, 171, 1720-1733. [CrossRef]

443. Sewelam, N.; Jaspert, N.; Van Der Kelen, K.; Tognetti, N.B.; Schmitz, J.; Frerigmann, H.; Stahl, E.; Zeier, J.; Van Breusegem, F.; Maurino, V.G. Spatial $\mathrm{H}_{2} \mathrm{O}_{2}$ signaling specificity: $\mathrm{H}_{2} \mathrm{O}_{2}$ from chloroplasts and peroxisomes modulates the plant transcriptome differentially. Mol. Plant 2014, 7, 1191-1210. [CrossRef]

444. Wang, W.H.; He, E.M.; Chen, J.; Guo, Y.; Chen, J.; Liu, X.; Zheng, H.L. The reduced state of the plastoquinone pool is required for chloroplast-mediated stomatal closure in response to calcium stimulation. Plant J. 2016, 86, 132-144. [CrossRef] [PubMed] 
445. Borisova-Mubarakshina, M.M.; Ivanov, B.N.; Vetoshkina, D.V.; Lubimov, V.Y.; Fedorchuk, T.P.; Naydov, I.A.; Kozuleva, M.A.; Rudenko, N.N.; Dall'Osto, L.; Cazzaniga, S.; et al. Long-term acclimatory response to exess excitation energy: Evidence for a role of hydrogen peroxide in the regulation of photosystem II antenna size. J. Exp. Bot. 2015, 66, 7151-7164. [CrossRef] [PubMed]

446. Chan, K.X.; Mabbitt, P.D.; Phua, S.Y.; Mueller, J.W.; Nisar, N.; Gigolashvili, T.; Stroeher, E.; Grassl, J.; Arlt, W.; Estavillo, G.M.; et al. Sensing and signaling of oxidative stress in chloroplasts by inactivation of the SAL1 phosphoadenosine phosphatase. Proc. Natl. Acad. Sci. USA 2016, 113, E4567-E4576. [CrossRef] [PubMed]

447. Estavillo, G.M.; Crisp, P.A.; Pornsiriwong, W.; Wirtz, M.; Collinge, D.; Carrie, C.; Giraud, E.; Whelan, J.; David, P.; Javot, H.; et al. Evidence for a SAL1-PAP chloroplast retrograde pathway that functions in drought and high light signaling in Arabidopsis. Plant Cell 2011, 23, 3992-4012. [CrossRef] [PubMed]

448. Gigolashvili, T.; Geier, M.; Ashykhmina, N.; Frerigmann, H.; Wulfert, S.; Krueger, S.; Mugford, S.G.; Kopriva, S.; Haferkamp, I.; Flügge, U.-I. The arabidopsis thylakoid ADP/ATP carrier TAAC has an additional role in supplying plastidic phosphoadenosine 5'-phosposulfate to the cytosol. Plant Cell 2012, 24, 4187-4204. [CrossRef] [PubMed]

449. Miao, Y.; Lv, D.; Wang, P.; Wang, X.C.; Chen, J.; Miao, C.; Song, C.P. An Arabidopsis glutathione peroxidase functions as both a redox transducer and a scavenger in abscisic acid and drought stress responses. Plant Cell 2006, 18, 2749-2766. [CrossRef]

450. Miller, G.; Mittler, R. Could heat shock transcription factors function as hydrogen peroxide sensors in plants? Ann. Bot. 2006, 98, 279-288. [CrossRef]

451. Bheri, M.; Pandey, G.K. Protein phosphatases meet reactive oxygen species in plant signaling networks. Environ. Exp. Bot. 2019, 161, 26-40. [CrossRef]

452. Laloi, C.; Stachowiak, M.; Pers-Kamczyc, E.; Warzych, E.; Murgia, I.; Apel, K. Cross-talk between singlet oxygen- and hydrogen peroxide-dependent signaling of stress responses in Arabidopsis thaliana. Proc. Natl. Acad. Sci. USA 2007, 104, 672-677. [CrossRef]

453. Šimková, K.; Moreau, F.; Pawlak, P.; Vriet, C.; Baruah, A.; Alexandre, C.; Hennig, L.; Apel, K.; Laloi, C. Integration of stress-related and reactive oxygen species-mediated signals by Topoisomerase VI in Arabidopsis thaliana. Proc. Natl. Acad. Sci. USA 2012, 109, 16360-16365. [CrossRef]

454. Rentel, M.C.; Lecourieux, D.; Ouaked, F.; Usher, S.L.; Petersen, L.; Okamoto, H.; Knight, H.; Peck, S.C.; Grierson, C.S.; Hirt, H.; et al. OXI1 kinase is necessary for oxidative burst-mediated signalling in Arabidopsis. Nature 2004, 427, 858-861. [CrossRef] [PubMed]

455. Gadjev, I.; Vanderauwera, S.; Gechev, T.S.; Laloi, C.; Minkov, I.N.; Shulaev, V.; Apel, K.; Inzé, D.; Mittler, R.; Van Breusegem, F. Transcriptomic footprints disclose specificity of reactive oxygen species signaling in Arabidopsis. Plant Physiol. 2006, 141, 436-445. [CrossRef]

456. Scarpeci, T.E.; Zanor, M.I.; Carrillo, N.; Mueller-Roeber, B.; Valle, E.M. Generation of superoxide anion in chloroplasts of Arabidopsis thaliana during active photosynthesis: A focus on rapidly induced genes. Plant Mol. Biol. 2008, 66, 361-378. [CrossRef] [PubMed]

457. Lee, D.J.; Choi, H.J.; Moon, M.E.; Chi, Y.T.; Ji, K.Y.; Choi, D. Superoxide serves as a putative signal molecule for plant cell division: Overexpression of CaRLK1 promotes the plant cell cycle via accumulation of $\mathrm{O}_{2}{ }^{-}$and decrease in $\mathrm{H}_{2} \mathrm{O}_{2}$. Physiol. Plant. 2017, 159, 228-243. [CrossRef] [PubMed]

458. Xu, J.; Tran, T.; Padilla Marcia, C.S.; Braun, D.M.; Goggin, F.L. Superoxide-responsive gene expression in Arabidopsis thaliana and Zea mays. Plant Physiol. Biochem. 2017, 117, 51-60. [CrossRef] [PubMed]

(C) 2020 by the authors. Licensee MDPI, Basel, Switzerland. This article is an open access article distributed under the terms and conditions of the Creative Commons Attribution (CC BY) license (http://creativecommons.org/licenses/by/4.0/). 